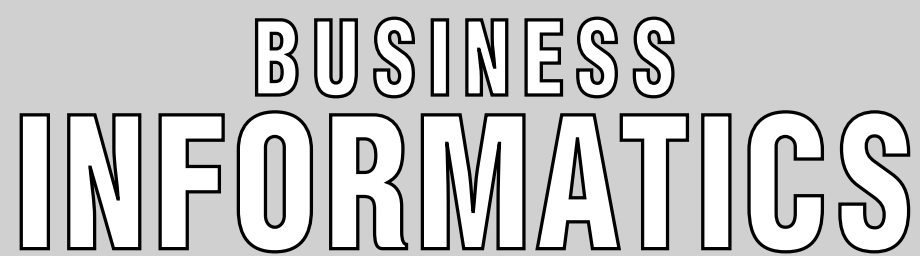

HSE SCIENTIFIC JOURNAL

\section{CONTENTS}

\section{Modeling of social and economic systems}

R.A. Karayev, R.N. Mikailova, I.I. Safarly,

N.Y. Sadikhova, X.F. Imamverdiyeva

Cognitive tools for dynamic analysis

of enterprise business strategies

N.F. Altukhova, E.V. Vasileva, M.V. Mirzoyan

Competence-based approach to managing staff

in public administration on the basis of ontologies

\section{G.A. Polynskaya, M.G. Mesropyan}

Detection of patterns and trends in patient behavior while using electronic applications and Internet resources for self-diagnosis.

\section{Information systems and technologies in business}

T.K. Bogdanova, D.Y. Neklyudov, O.M. Uvarova

Developing a new tariff plan of a telecommunications company taking into account subscribers' and investors' preferences

\section{Y.P. Yekhlakov, E.K.Malakhovskaya}

Design patterns of communication messages for promoting software products on the corporate market 50

\section{Mathematical methods and algorithms of business informatics}

N.K. Khachatryan, A.S. Akopov, F.A. Belousov

About quasi-solutions of traveling wave type in models for organizing cargo transportation

\section{Business processes modeling and analysis}

L.A. Bulysheva, M.Y. Kataev, N.V. Loseva

System for monitoring the quality of services provided by a public institution based on business processes

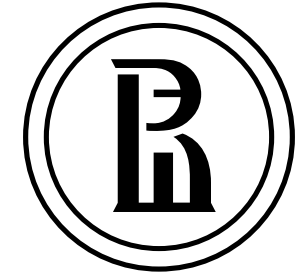

Publisher:

National Research University Higher School of Economics

Subscription index in the «Rospechat» catalog 80870

The journal is published quarterly

The journal is included into the list of peer reviewed scientific editions established by the Supreme Certification Commission of the Ministry of Education and Science of the Russian Federation

\section{Editor-in-Chief: A. Golosov \\ Deputy Editor-in-Chief Y. Koucheryavy \\ Computer Making-up: O. Bogdanovich}

Website Administration: I. Khrustaleva

\footnotetext{
Address:

33, Kirpichnaya Street, Moscow, 105187, Russian Federation

Tel./fax: +7 (495) 771-32-38 http://bijournal.hse.ru

E-mail: bijournal@hse.ru
}

Circulation:

English version - 300 copies, Russian version - 300 copies, online versions in English and Russian open access

Printed in HSE Printing House

3, Kochnovsky Proezd, Moscow, Russian Federation

(C) National Research University Higher School of Economics 


\section{ABOUT \\ THE JOURNAL}

B

usiness Informatics is a peer reviewed interdisciplinary academic journal published since 2007 by National Research University Higher School of Economics (HSE), Moscow, Russian Federation. The journal is administered by School of Business Informatics. The journal is published quarterly.

The mission of the journal is to develop business informatics as a new field within both information technologies and management. It provides dissemination of latest technical and methodological developments, promotes new competences and provides a framework for discussion in the field of application of modern IT solutions in business, management and economics.

The journal publishes papers in the areas of, but not limited to:

$\downarrow$ data analysis and intelligence systems

$\downarrow$ information systems and technologies in business

$\downarrow$ mathematical methods and algorithms of business informatics

$\uparrow$ software engineering

$\downarrow$ Internet technologies

$\checkmark$ business processes modeling and analysis

$\checkmark$ standardization, certification, quality, innovations

$\downarrow$ legal aspects of business informatics

$\downarrow$ decision making and business intelligence

$\downarrow$ modeling of social and economic systems

$\uparrow$ information security.

The journal is included into the list of peer reviewed scientific editions established by the Supreme Certification Commission of the Ministry of Education and Science of the Russian Federation.

The journal is included into Russian Science Citation Index (RSCI) database on the Web of Science platform.

International Standard Serial Number (ISSN): 2587-814X (in English), 1998-0663 (in Russian).

Editor-in-Chief: Dr. Alexey Golosov - President of FORS Development Center, Moscow, Russian Federation. 


\section{EDITORIAL BOARD}

\section{EDITOR-IN-CHIEF}

Alexey Golosov -

President of FORS Development Center, Russian Federation

DEPUTY EDITOR-IN-CHIEF

Yevgeni Koucheryavy -

Professor, Department of Electronics and Communication

Engineering, Tampere University of Technology, Finland

\section{EDITORIAL BOARD}

\section{Habib Abdulrab -}

Professor, Mathematical and Software Engineering Department, National Institute of Applied Sciences - Institut national des sciences appliquées de Rouen (INSA de Rouen), Rouen, France

\section{Sergey Avdoshin -}

Professor, Head of School of Software Engineering,

National Research University Higher School of Economics,

Russian Federation

\section{Andranik Akopov -}

Professor, Department of Business Analytics, National Research University Higher School of Economics, Russian Federation

Fuad Aleskerov -

Professor, Head of Department of Mathematics, National Research University Higher School of Economics, Russian Federation

\section{Anton Afanasyev -}

Leading Researcher, Laboratory of Social Modeling, Central Economics and Mathematics Institute, Russian Academy of Science, Russian Federation

\section{Eduard Babkin -}

Professor, Department of Information Systems and Technologies, National Research University Higher School of Economics, Russian Federation

\section{Alex Bayer -}

Head of KAFAN FX Information Services, New York, USA

\section{Alexander Baranov -}

Deputy Head of Central Scientific and Research Computing Center, Federal Tax Service of Russia, Russian Federation

\section{Jorg Becker -}

Vice-Rector, Professor, Director of European Research Center for Information Systems (ERCIS), University of Munster, Germany

\section{Vladimir Belov -}

Professor, Department of Computational and Applied Mathematics, Ryazan State Radio Engineering University, Russian Federation

\section{Andrey Gribov -}

Director General, CyberPlat Company, Russian Federation

\section{Alexander Gromov -}

Professor, Head of Department of Modeling and Optimization of Business Processes, National Research University Higher School of Economics, Russian Federation

\section{Vladimir Gurvich -}

Invited Professor and Researcher, Rutgers Center for Operations Research, Rutgers, The State University of New Jersey, USA

\section{Laurence Jacobs -}

Professor, Medical School, University of Zurich, Switzerland

\section{Iosif Diskin -}

Academic Supervisor, Chairmen of Scientific and Expert Council, Russian Public Opinion Research Center (VCIOM); Member of the Council, The Russian Public Chamber; Russian Federation

\section{Kurt Sandkuhl -}

Professor, Head of Department of Business Information Systems, University of Rostock, Germany

\section{Nikolay Ilyin -}

Deputy Head, Administration of Special Communication, Federal Security Guard, Russian Federation

\section{Dmitry Isaev -}

Associate Professor, Department of Business Analytics, National Research University Higher School of Economics, Russian Federation

\section{Valery Kalyagin -}

Professor, Head of Department of Applied Mathematics and Informatics, National Research University Higher School of Economics, Russian Federation

\section{Maria Kamennova -}

Director General, BPM Logic, Russian Federation

\section{Tatiana Kravchenko -}

Professor, Head of Department of Business Analytics,

National Research University Higher School of Economics,

Russian Federation

\section{Sergey Kuznetsov -}

Professor, Head of School of Data Analysis and Artificial Intelligence, National Research University Higher School of Economics, Russian Federation

\section{Mikhail Lugachev -}

Professor, Head of Department of Economic Informatics, Lomonosov Moscow State University, Russian Federation

\section{Svetlana Maltseva -}

Professor, Head of Department of Innovation and Business in Information Technologies, National Research University Higher School of Economics, Russian Federation

\section{Peter Major -}

Vice-Chairman, Radiocommunication Advisory Group of International Telecommunication Union (ITU),

Vice-Chairman of the UN Commission on Science and Technology for Development (CSTD), Geneva, Switzerland

\section{Boris Mirkin -}

Professor, School of Data Analysis and Artificial Intelligence, National Research University Higher School of Economics,

Russian Federation

\section{Vadim Mottl -}

Professor, Department of Information Security Management, Tula State University, Russian Federation

\section{Dmitry Palchunov -}

Head of Department of General Informatics, Novosibirsk State University, Russian Federation

\section{Panagote (Panos) Pardalos -}

Distinguished Professor and University of Florida Research Foundation Professor, Director of Center for Applied Optimization, Department of Industrial and Systems Engineering, University of Florida, USA

\section{Albert Silantyev -}

Professor, Department of Information Business Systems, National University of Science and Technology «MISIS», Russian Federation

\section{Victor Taratukhin -}

Managing Director, European Research Center for Information Systems (ERCIS), University of Munster, Germany

\section{Mikhail Ulyanov -}

Professor, School of Software Engineering,

National Research University Higher School of Economics, Russian Federation 


\section{ABOUT THE HIGHER SCHOOL \\ OF ECONOMICS}

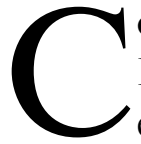

onsistently ranked as one of Russia's top universities, the Higher School of Economics (HSE) is a leader in Russian education and one of the preeminent economics and social sciences universities in Eastern Europe and Eurasia. Having rapidly grown into a well-renowned research university over two decades, HSE sets itself apart with its international presence and cooperation.

Our faculty, researchers, and students represent over 50 countries, and are dedicated to maintaining the highest academic standards. Our newly adopted structural reforms support both HSE's drive to internationalize and the groundbreaking research of our faculty, researchers, and students.

Now a dynamic university with four campuses, HSE is a leader in combining Russian educational traditions with the best international teaching and research practices. HSE offers outstanding educational programs from secondary school to doctoral studies, with top departments and research centers in a number of international fields.

Since 2013, HSE has been a member of the 5-100 Russian Academic Excellence Project, a highly selective government program aimed at boosting the international competitiveness of Russian universities. 
he School of Business Informatics is one of the leading divisions of HSE's Faculty of Business and Management. The School offers students diverse courses taught by full-time HSE instructors and invited business practitioners. Students are also given the opportunity to carry out fundamental and applied projects at various academic centers and laboratories.

Within the undergraduate program, students participate each year in different casecompetitions (PWC, E\&Y, Deloitte, Cisco, Google, CIMA, Microsoft Imagine CUP, IBM Smarter Planet, GMC etc.) and some of them are usually as being best students by IBM, Microsoft, SAP, etc. Students also have an opportunity to participate in exchange programs with the University of Passau, the University of Munster, the University of business and economics in Vienna, the Seoul National University of Science and Technology, the Radbound University Nijmegen and various summer schools (Hong Kong, Israel etc.). Graduates successfully continue their studies in Russia and abroad, start their own businesses and are employed in high-skilled positions in IT companies.

There are four graduate programs provided by the School:

$\downarrow$ Business Informatics (with three specializations - Informational Business Analytics, Information Systems Management and Business Process Modelling and Optimization);

$\downarrow$ E-Business;

$\downarrow$ Information Security Management;

$\downarrow$ Big Data Systems.

The School's activities are aimed at achieving greater integration into the global education and research community. A member of the European Research Center for Information Systems (ERCIS), the School cooperates with leading universities and research institutions around the world through academic exchange programs and participation in international educational and research projects. 



\title{
Cognitive tools for dynamic analysis of enterprise business strategies ${ }^{1}$
}

\author{
Robert A. Karayev \\ Professor, Head of Ecosystems Modeling Laboratory \\ Institute of Control Systems of the Azerbaijan National Academy of Sciences \\ Address: 9, B. Vahabzade Street, Baku, AZ1141, Azerbaijan \\ E-mail:karayevr@rambler.ru
}

\section{Rena N. Mikailova}

Associate Professor, PhD in Economics

Azerbaijan State University of Economics

Address: 6, Istiqlaliyat Street, Baku, AZ1001, Azerbaijan

E-mail:renam3@mail.ru

\section{Islam I. Safarly}

PhD in Economics

Business Development Manager, OIL SUPPLY LLC

Address: 156, Batamdar Highway, Baku, AZ1006, Azerbaijan

E-mail: islamsafarli@gmail.com

\section{Natella Y. Sadikhova}

\section{Researcher}

Institute of Control Systems of the Azerbaijan National Academy of Sciences Address: 9, B. Vahabzade Street, Baku, AZ1141, Azerbaijan

E-mail:natella5@rambler.ru

\section{Xatire F. Imamverdiyeva}

Software Engineer

Institute of Control Systems of the Azerbaijan National Academy of Sciences Address: 9, B. Vahabzade Street, Baku, AZ1141, Azerbaijan

E-mail: imamverdiyeva.x@gmail.com

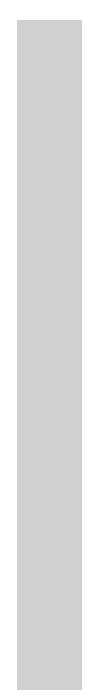

\section{Abstract}

The article discusses the difficulties of long-term dynamic analysis of business strategies of enterprises in present-day complex and unstable economic conditions. We discuss the possibility of solving the problem by means of cognitive modeling, which has opened a new page in the management of complex systems and complex problem situations. We note the phenomenological features of complex systems and complex problem situations that exclude the possibility of their modeling using traditional economic and mathematical methods. Such features are: multifactority, dynamism, uncertainty, the high role of the mentality of the developers of the strategy and the persons making strategic decisions. The urgency of the question of ensuring the reliability of cognitive models, a significant place in which is occupied by heuristic components, is emphasized. Formalization of the latter encounters numerous difficulties ("traps") that arise at all stages of designing cognitive models - the stages of identification, conceptualization, formalization and testing, which constitute the specifics of the development of all knowledge-based support technologies.

Existing methods and models from relevant areas that can be useful for overcoming these difficulties are considered (strategic analysis, strategic planning, scenario analysis, scenario planning,

\footnotetext{
${ }^{1}$ This work was supported by the Foundation for Science Development under the President of the Azerbaijan Republic (grant No. EIF-KETPL-2-2015-1(25)-56/14/1)
} 
SWOT analysis, PEST analysis, SMART technology, methods of knowledge identification, methods of psycho semantics and non-metric multidimensional scaling, methods of expert evaluation).

The article presents a demo version of cognitive tools for dynamic analysis of strategies (cognitive map of strategy and cognitive map analysis methods), based on the ideology of cognitive modeling. Consideration is given to the application possibilities of cognitive tools in the analysis of strategies in the context of possible dynamics of the internal and external environment of the enterprise. An example of the use of cognitive tools is given.

Key words: enterprise business strategy, dynamic analysis, cognitive modeling, cognitive tools.

Citation: Karayev R.A., Mikailova R.N., Safarly I.I., Sadikhova N.Y., Imamverdiyeva X.F. (2018) Cognitive tools for dynamic analysis of enterprise business strategies. Business Informatics, no. 1 (43), pp. 7-16. DOI: 10.17323/1998-0663.2018.1.7.16.

\section{Introduction}

$\mathrm{O}$ ne of the most challenging problems for a management team engaged in formulating an enterprise's development strategy is understanding the complex causal chains that determine the impact of the enterprise's external and internal conditions on the goals and properties of the strategy being formulated. These days this problem is aggravated by the growing complexity and instability of the economic environment, resulting in numerous uncertainties and risks.

In these conditions, the use of known strategic management support tools, such as Total Quality Management (TQM), Business Process Reengineering (BPR), Balanced Scorecard (BSC), Six Sigma, Business Performance Management (BPM), Business Intelligence (BI), Decision Support Systems (DSS), strategic planning systems, etc. is universally accompanied by serious difficulties and constraints. There is a need for new tools that would be relevant to the creative nature of today's management [1] and based on the research approach and long-term dynamic analysis of strategic decisions under different future development scenarios.

Ideas and methods of cognitive modeling presented, for instance, in [2, 3], as well as in the proceedings of International Conferences on Cognitive Modeling (ICCM) Series ${ }^{1}$ offer many opportunities to create such tools.

The key principles of cognitive modeling are described further below, and its basic ontologies - cognitive maps and methods for analyzing cognitive maps - are considered. We give examples of the use of cognitive management elements as management consulting tools and discuss their application possibilities. We also present cognitive tools for dynamic analysis of strategies that take into account the peculiarities of the enterprises' activity in current difficult conditions. These tools can be used to find effective (in one sense or another) strategies in the face of an ever-changing business environment. An example of the application of these tools is given and their application possibilities are discussed.

${ }^{1}$ IEEE Proceedings of the International Conferences on Cognitive Modeling Se ries: ICCM 2017 (Warwick, UK), ICCM 2016 (Pennsylvania State, USA), ICCM 2015 (Groningen, Netherlands), ICCM 2013 (Ottawa, Canada), ICCM 2012 (Berlin, Germany), ICCM 2010 (Philadelphia, USA), ICCM 2009 (Manchester, UK), ICCM 2007 (Ann Arbor, USA), ICCM 2006 (Trieste, Italy), ICCM 2004 (Pittsburgh, USA), ICCM 2003 (Bamberg, Germany), ICCM 2001 (Fairfax, USA), ICCM 2000 (Groningen, Netherlands), ECCM 98 (Nottingham, UK), EuroCog 1996 (Berlin, Germany) 


\section{Key principles of cognitive modeling}

Cognitive modeling is a method of analyzing and managing complex (ill-structured [4]) systems and problem situations implemented through:

a) building a model of a problem situation in the form of a cognitive map;

b) conducting model experiments in order to find effective strategies for managing the problem situation which are implemented using cognitive map analysis methods.

\subsection{Cognitive map}

A cognitive map [5] is a formalized representation of management subjects' mental models [6] of the structure of the problem situation and the patterns of its functioning and development. A cognitive map is a causal network, the vertices of which are the basic factors of the problem situation and the arcs are the cause-and-effect relations between these factors.

In terms of content, basic factors are the factors that define and confine observable phenomena and processes of the situation and are interpreted by management subjects as essential, key parameters of those phenomena and processes.

A common representation of a cognitive map these days is a directed graph $(X, W)$, where $X=\left\{x_{i}\right\}$ is the set of the basic factors of the problem situation; $W=\left\{w_{i j}\right\}, w_{i j} \in[-1 ;+1]$ is the set of the cause-and-effect relations that determine the sign and intensity of impact of casual factors on effectual factors.

The ordered set of linguistic values $Z_{i}$ and a scale representing those values at a point of the number line, $\varphi: Z_{i} \rightarrow Z_{i} \rightarrow X_{i}$, are determined for the factor $x_{i}$.

The factors can be external environmental factors, target factors of a problem situation, controllable and uncontrollable factors of the situation itself. By manipulating controllable factors, one can take the situation from some initial state to the target state.

\subsection{Cognitive map analysis methods}

Cognitive map analysis methods make it possible to carry out model experiments on the cognitive map by changing the composition and values of the basic factors and the nature of the cause-and-effect relations between them. Such model experiments allow us to investigate the spread of external impacts and control actions across the cognitive map and solve a wide range of tasks related to determining priority management decisions, assessing the attainability of management objectives, formulating alternative management strategies, finding effective (in one sense or another) management strategies, etc.

Existing methods of cognitive map analysis are focused on problems of static and dynamic types of analysis. Static analysis, or impact analysis, is a range of objectives aimed at studying the structure of mutual interaction of the factors of a cognitive map. Dynamic analysis underlies the generation and analysis of possible scenarios for situation development in time in the modes of "self-development" and "controlled development."

The theory of dynamic analysis of cognitive maps is based on the apparatus of linear dynamic systems [5]. Dynamics are simulated by setting successive impulse actions on controlled factors (causal factors) at discrete instants of time $t=0,1,2, \ldots$ and by modeling the influence wave of these impacts on the target factors (effectual factors).

A control action on the situation is set by an impulse change in the value of the controlled factor $x_{i n} \in X_{i}$

The variation of the values of effectual factors is determined by the "rule of the impulse process": 


$$
x_{i}\left(t_{0}+1\right)=x_{i}\left(t_{0}\right)+\sum_{i \in I} \operatorname{sgn}\left(x_{j}, x_{i}\right) w_{i j} \Delta x_{j}(t),
$$

where $x_{i}\left(t_{0}\right)$ - the value of the $i$-th factor at the instant $t_{0}$ before the control action;

$x_{i}\left(t_{0}+1\right)$ - the value of the $i$-th factor after the control action at the instant $\left(t_{0}+1\right)$;

$\operatorname{sgn}\left(x_{j}, x_{i}\right)=\left\{\begin{array}{l}+w\left(x_{j}, x_{i}\right), \text { if the arc }\left(x_{j}, x_{i}\right) \text { is positive, } \\ -w\left(x_{j}, x_{i}\right), \text { if the arc }\left(x_{j}, x_{i}\right) \text { is negative, } \\ 0, \text { if the arc }\left(x_{j}, x_{i}\right) \text { is absent. }\end{array}\right.$

$\Delta x_{j}\left(t_{0}\right)$ - the impulse increment of the $j$-th control action at the instant $t_{0}$;

$w_{i j}$ - the weight (force) of the impact of the factor $x_{j}$ on the factor $x_{i}$;

$I_{i}$ - the number of factors that have a direct impact on the factor $x_{i}$.

Thus, the value of the effectual factor at any instant is estimated as the sum of the values of the factor at the previous instant and all the impacts that came from neighboring (associated) factors. In evaluating the resultant value of a factor, both the actual values of the influencing factors and the degree of their impact are taken into account.

In dynamic simulation, along with the values of factors, variation trends of those factors can also be used. A situation development forecast is obtained in the form of vectors of the situation state at successive discrete instants of time $t, t+1, \ldots, t+n$, where $t$ is the number of the simulation step (time-step).

The objective of situation management consists in taking the situation from the initial state to the target state corresponding to the target image of the problem situation.

The target image determines the desired changes in the state of the problem situation from the perspective of management subjects and is formally represented as

$$
C=\left(X^{c}, R\left(X^{c}\right)\right),
$$

where $X^{C}$ - the set of target factors that are the subset of the basic factors of the cognitive map $\left(X^{C} \subseteq X\right)$;

$R\left(X^{\mathrm{C}}\right)$ - the vector of the estimates of the dynamics of the target factors establishing the desired changes in these factors, e.g.,

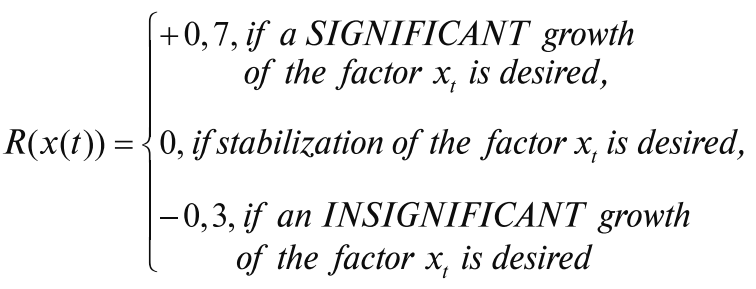

Problem situation management strategy $S$ consists of the strategic moves $S_{i}$, that determine the sequence of the transition of the situation from the initial state $S^{0}$ to the target state $S^{C}$ corresponding to the target image

$$
S: S^{0} \rightarrow S^{1} \rightarrow S^{2} \ldots \rightarrow S^{C} .
$$

Application versions of dynamic analysis models and, in particular, models of dynamic analysis of the enterprise's strategies, require clarification of the concept of "strategic move."

Any strategic move is an act that changes the state of the situation. A change in the situation at every step can be accomplished by means of the operators listed in Table 1. Note that the list of operators for sign cognitive maps (SCM), in which only the signs of mutual interaction are specified, differs from that for weighted cognitive maps (WCM), in which both the sign and the force of mutual interaction are specified.

Using these operators, management subjects can design a variety of strategic alternatives that reflect different scenarios of problem situation development.

Once a fixed set of strategic alternatives is determined, it is possible to clarify the statement of the strategy choice problem. It can have different formulations and, accordingly, different configurations of the target image of the problem situation. 
Table 1. mizes) the values of some vertices (for examOperators of a strategic move

\begin{tabular}{|c|c|c|}
\hline \multirow{2}{*}{ Operators } & \multicolumn{2}{|c|}{ CM type } \\
\hline & WCM & SGM \\
\hline $\begin{array}{l}\text { 1. Changing the value of a controlled } \\
\text { vertex at a given time }\end{array}$ & • & \\
\hline $\begin{array}{l}\text { 2. Adding a new vertex and new arcs } \\
\text { to and from it at a given time }\end{array}$ & - & $\bullet$ \\
\hline $\begin{array}{l}\text { 3. Changing the sign of an arc } \\
\text { at a given time }\end{array}$ & $\bullet$ & $\bullet$ \\
\hline $\begin{array}{l}\text { 4. Changing the weight of an arc } \\
\text { at a given time }\end{array}$ & - & \\
\hline $\begin{array}{l}\text { 5. Adding a new arc between } \\
\text { the existing vertices }\end{array}$ & $\bullet$ & $\bullet$ \\
\hline $\begin{array}{l}\text { 6. Adding a new circuit (increasing } \\
\text { or decreasing the deviation) }\end{array}$ & $\bullet$ & 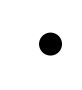 \\
\hline
\end{tabular}

We shall give several examples of the statement of a strategy choice problem.

1. Finding the optimal (shortest, cheapest, etc.) strategy that meets the regulatory constraints on some parameters of the enterprise's internal or external environment;

2. Finding a strategy that maximizes (miniple, enterprise profits, market share, product quality, environmental pollution, etc.) subject to restrictions on the values of some other vertices (e.g. financial resources, time constraints, staff qualifications, etc.);

3. Finding a strategy that does not allow any of the enterprise's variables to take too large or too small values (the so-called "dynamically stable" or "stabilizing" strategies).

The process of strategy building ends when a satisfactory result is obtained, which consists in achieving a state corresponding to the target image of the controlled situation under the given constraints.

However, there is also the possibility of failure in achieving the target image resulting in the need to return to the stage of formation of the target image (revision of the "missiongoal" transition) or complete abandonment of further search.

\section{Dynamic analysis of enterprise strategy}

Let us consider the possibilities of using the cognitive modeling technology in dynamic analysis of an enterprise's strategy.

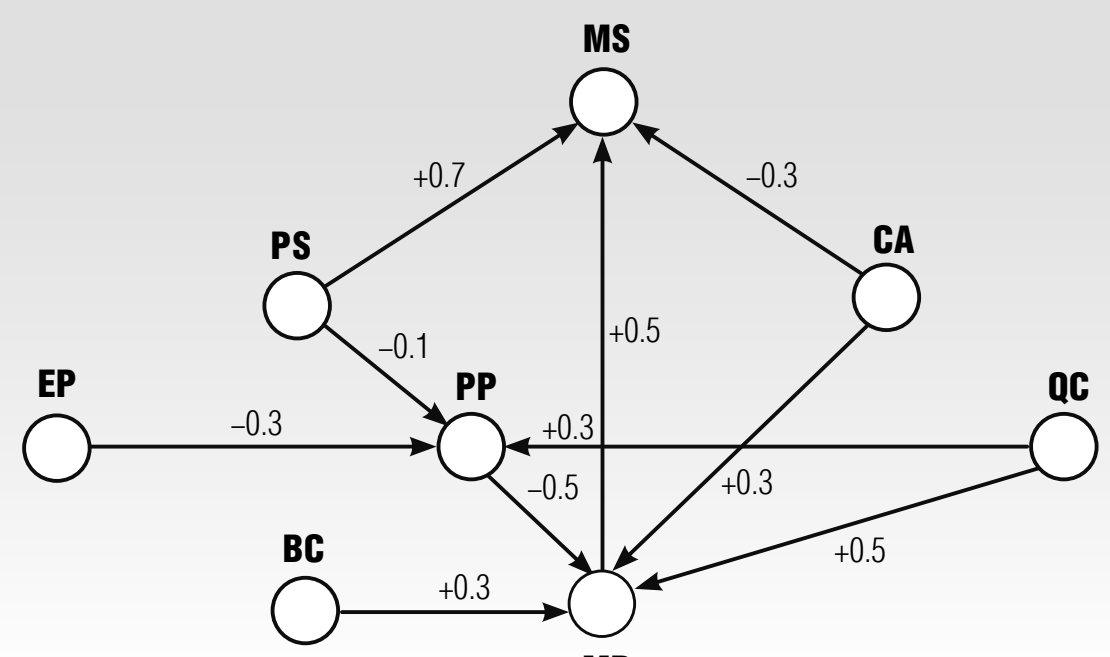

MD

Fig. 1. Cognitive map for the enterprise's customer relations management strategy analysis (demo version) 
We shall take as our example the cognitive map (Figure 1) built for analyzing a customer relations management strategy (the "client" level of Kaplan and Norton's strategy map [7]). A weighted cognitive map is used.

The basic factors of the cognitive map are:

$\diamond$ "Product competitiveness" (PC);

$\diamond$ "Enterprise's productivity" (EP);

$\diamond$ "Business conditions" (BC);

$\diamond$ "Market demand" (MD);

$\diamond$ "Product price" (PP);

$\diamond$ "Market share" (MS);

$\diamond$ "Quality control” (QC);

$\diamond$ "Competition's advertising" (CA).

On the set of basic factors, we have:

$\checkmark$ target factors: $<\mathrm{MS}, \mathrm{PP}\rangle$;

$\diamond$ controllable factors: $\langle\mathrm{PC}, \mathrm{QC}, \mathrm{EP}\rangle$;

$\star$ factors of external environment: $<\mathrm{BC}$, $\mathrm{CA}, \mathrm{MD}>$.

This breakdown of factors allows us to conduct a wide range of model experiments, e.g.:

1) designing different strategy variants, including the enterprise's "self-development" strategy and various "controlled development" strategies;

2) forecasting the enterprise's behavior (its target image) for each of the strategy variants;

3) forecasting the enterprise's behavior (its target image) under different dynamics of factors (different development scenarios) of external environment, etc.

Let us illustrate this with the results of model experiments with the strategy variant given in Figure 1. We shall investigate the strategy dynamics for different initial states (activity levels) of the factors.

The activity levels of the factors and the intensity of their interaction will be estimated using the linguistic scale given in Table 2.
Linguistic scale for estimating the values and the intensity of interaction of factors of a cognitive map

\begin{tabular}{c|l}
\hline$X$ & \multicolumn{1}{|c}{ Linguistic estimates (Z) } \\
\hline 0.1 & VERY_LOW | VERY_POOR | VERY_WEAK \\
\hline 0.3 & LOW | POOR | WEAK \\
\hline 0.5 & AVERAGE | MODERATE \\
\hline 0.7 & HIGH | GOOD | STRONG \\
\hline 0.9 & VERY_HIGH | VERY_GOOD | VERY_STRONG \\
\hline
\end{tabular}

Note the following:

1. For the factors that can be estimated quantitatively, each linguistic estimate is put in correspondence with the value of a factor from the "interval scale", e.g.: "Market share" VERY_LOW - below 4\%, LOW 5-10\%, AVERAGE - 11-20\%, HIGH 21-40\%, VERY_HIGH - over $40 \%$.

2 . The values of the factors and the characteristics of interfactorial relations are set for a specific enterprise and for a specific period of time (horizon of analysis).

Example. Assume that the management goal in the strategy fragment in Figure 1 is to find and implement such management (changing the controllable factors) that would lead to an increase in the enterprise's "Market share." The possibility of achieving this goal is affected by:

1) the initial state of the internal and external factors forming the analyzed strategy fragment;

2) the management implemented by the enterprise's management team through changes in the dynamics of the controllable factors.

Scenario. Assume that the enterprise intro- 
duces a new product to the market, i.e. its "Market share" at the initial moment of time is almost imperceptible: MS $=0.1$ (VERY LOW). The enterprise introduces a new product to the market in stable economic conditions: $\mathrm{BC}=0.9$ (VERY_GOOD). These conditions create a high demand for the product: $\mathrm{MD}=0.7(\mathrm{HIGH})$.

The objective of seeking the optimal strategy is to find such dynamics of management of internal factors that would increase the enterprise's "Market share" without increasing or, better yet, lowering the activity of the "Product price" factor.

Such management is shown in Figure $2 a$. It reflects the dynamics of the activity of the "Quality control," "Enterprise's productivity" and "Product competitiveness" factors, which gradually improve over time (the activity of these factors grows). The result of such management is the growth of the enterprise's "Market share," on the one hand, and the drop in the "Product price" on the other (Figure 2b).

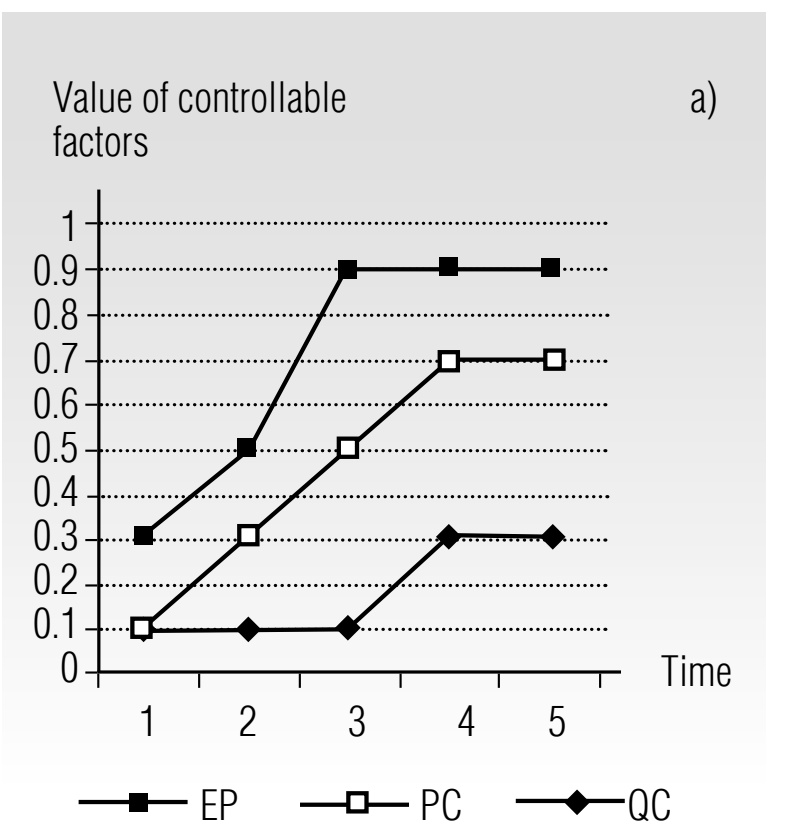

We can see from Figure $2 a$ that to increase the enterprise's "Market share" and reduce the "Product price" for the product being introduced, it is necessary to increase the activity of all three controllable factors, but in different orders and to different degrees. First of all, the "Enterprise productivity" in terms of output needs to be significantly increased. The emphasis needs to be on the outstripping growth of this controllable factor; the growth of its activity has to be at its fastest and best (reaching a level above 0.9) by the end of the simulation period.

The rest of the controllable factors are distributed as follows in terms of their impact on the result. The second most important factor is "Product competitiveness" in the market of similar products. At the very beginning of the simulation, the activity rate of this factor is a little inferior to that of the "Productivity" factor, but it significantly exceeds the rate of the "Quality control" factor. In order to achieve the target (an increase in the "Market share" of the new product), "Quality control" should be focused on only in the third step of the sim-

Fig. 2. Management strategy dynamics for the introduction of a new product by an enterprise with a small market share 
ulation, when the initial increase in market share will be achieved. After the fourth step, the requirements for the activity of the "Quality control" factor can be lowered again (after this moment, the growth rates of the "Product competitiveness" and "Quality control" factors are equalized).

The results of modeling with the cognitive map in Figure 1 show that its expansion is possible even for an enterprise with small market share. This requires stable economic conditions and a certain sequence of steps to control and regulate the control actions on the internal factors of the "client" level.

\section{Applied possibilities of cognitive models}

The above example is a demo. In real-life projects, cognitive maps can have a more complex structural and functional organization [8-10]. The issue of reliability of cognitive maps is of great importance in cognitive modeling of strategies. Its solution largely depends on the correct choice of the basis factors and the cause-and-effect relations of the map being built. This issue remains open in the theory of cognitive modeling to date. At the same time, substantial assistance in solving the issue can be provided by:

$\downarrow$ D. Waterman's excellent guide to expert systems [11] that helps a knowledge engineer avoid numerous "traps" arising in the planning and designing of cognitive models and working with experts. In the development of cognitive models, as with all other knowledge-based technologies, the key role belongs precisely to a knowledge engineer rather than mathematicians, psychologists or programmers [11];

$\checkmark$ known expert evaluation methods (interviewing, questionnaire survey, Delphi method, "round table" and "brainstorming" methods);

$\downarrow$ various versions of PEST analysis of the external environment by groups of conditions: $\mathrm{P}$ - political and legal, $\mathrm{E}-$ economic, $\mathrm{S}$ - social, $\mathrm{T}$ - technological;

$\downarrow$ various versions of SWOT analysis ( $\mathrm{S}$ strengths, W - weaknesses, O - opportunities, $\mathrm{T}-$ threats) widely used to assess an enterprise's strengths and weaknesses in interaction with threats and opportunities of the external environment;

$\downarrow$ known models of strategic analysis and strategic planning: the Kaplan-Norton strategic map, BCG matrix, ADL/LC, Hofer/ Schendlel, Shell/DPM models, etc.;

$\downarrow$ methods and models of scenario analysis [12] and scenario planning [13];

- SMART-technology of goal setting [14];

methods of extracting knowledge in knowledge-based technologies [15];

- methods of psychosemantics [16] and non-metric multidimensional scaling [17] that allow one to assess the degree of consistency of opinions of strategy developers (top managers, business consultants, subject experts) at the most debatable stages of strategic analysis (translation of the mission into strategic goals, building a cognitive map, parameterization of a cognitive map, verification of goals for completeness and inconsistency, reduction of the cognitive map in order to eliminate insignificant details, etc.).

The technique of cognitive model building (like all other knowledge-based models) is specific and involves a gradual and multistage design: developing a demonstration prototype, developing a research prototype, then an operational prototype and, finally, creating an industrial prototype suitable for solving real-life problems [11]. We believe it is necessary to emphasize once again that in the paper, we present a demonstration prototype of a cognitive model, which, in our opinion, gives quite a convincing indication of the high potential of the application possibilities of this class of models. The creation of indus- 
trial prototypes that take into account the numerous features of a specific enterprise and its external environment is usually labor-consuming and expense-wise can significantly exceed the costs of developing a demonstration prototype.

\section{Conclusion}

Cognitive tools offer great opportunities for solving critical problems of modern management. First of all, these are issues related to the generation of alternative strategies and the assessment of their effectiveness in the context of the multifactor dynamics of an enterprise's internal and external environment.

The emerging possibility of purposeful generation of effective strategies significantly broadens the scope of strategic search and creates the prerequisites for shifting to a new paradigm of strategic choice: not choosing the best available alternative (the paradigm of RAND Corporation, USA) but building a better one.

An important (and possibly unique) advantage of cognitive tools is the opportunity that they reveal - that of exploring the delicate structure of management strategies (the nec- essary sequence of the inclusion of managerial impacts, the necessary degree of activity of these impacts, the study of the dynamic stability of strategies, etc.). None of the known strategic management support tools is capable of that. Another important advantage of cognitive models is that they allow one to study the dynamics of strategies at a qualitative level without using hard-to-access and not always reliable quantitative statistics. This is extremely important in the context of today's rapidly changing business environment and the growing pace of technological innovation.

Cognitive dynamic analysis significantly expands the tool base of strategic management which is based today mainly on the tools of static situational analysis and prescriptive decision-making schemes.

The possibilities of cognitive modeling also open new prospects for the "cognitive school" of management [18]. The latter, say the authors of this book, "is characterized more by its potential than by its contribution," and they use the term "cognitive school" not because it really exists today, but because "its importance can lead to creation of such a school."

\section{References}

1. Druker P.F. (2001) Management challenges for the 21st century. N.Y.: Harper Business.

2. Walliser B. (2008) Cognitive economics. Berlin Heidelberg: Springer-Verlag.

3. Hodginson G. (2011) Cognitive process in strategic management: Some emerging trends and future direction. Handbook of Industrial, Work \& Organizational Psychology. Vol. 2. Organizational Psychology (eds. N. Anderson, D.S. Ones, H.K. Sinangil, C. Viswesvaran). London: SAGE Publication, pp. 401-441.

4. Simon H. (1973) The structure of ill-structured problems. Artificial Intelligence, no. 4, pp. 181-202.

5. Roberts F.S. (1976) Discrete mathematical models with application to social, biological and environmental problems. New Jersey: Rutgers University, Prentice-Hall, Englewood Cliffs.

6. Johnson-Laird P.N. (1980) Mental models in cognitive science. Cognitive Science, no. 4, pp. 71-115.

7. Kaplan R.S., Norton D.P. (1996) The balanced scorecard: Translating strategy into action. Boston: Harvard Business School Press.

8. Karayev R.A. (2004) Nechetkie kognitivnye karty dlya generatsii i analiza khozyaystvennykh strategiy predpriyatiya: Obshchaya kontseptsiya [Fuzzy cognitive maps for the generation and analysis 
of business strategies of the enterprise: General concept]. Theses and reports of the Fifth All-Russian Symposium "Strategic Planning and Enterprise Development", Moscow, 13-14 April 2004. Moscow: CEMI RAS, pp. 68-80 (in Russian).

9. Karayev R.A., Safarly I.I., Abduragimov T.F., Aliyev K.A. (2014) Cognitive modeling of management strategies of the enterprises: The experience of developing and testing. Archives of Business Research, vol. 2, no. 4, pp. 94-105.

10. Karayev R.A. (2015) Cognitive approach and its application to the modeling of strategic management of enterprises. Knowledge engineering: Principles, methods and applications (ed. A. Perez Gama). N.Y.: Nova Science Publisher, pp. 79-95.

11. Waterman D.A. (1986) A guide to expert systems. Reading, MA: Addison-Wesley.

12. Ansoff H.I. (2007) Strategic management. N.Y.: Palgrave Macmillan.

13. Ogilvy J.A. (2002) Creating better futures: Scenario planning as a tool for a better tomorrow. Oxford: Oxford University Press.

14. Bogue R.L. Use S.M.A.R.T. goals to launch management by objectives plan. TechRepublic, 2005. Available at: https://www.techrepublic.com/article/use-smart-goals-to-launch-management-by-objectives-plan/ (accessed 20 November 2013).

15. Milton N.R. (2007) Knowledge acquisition in practice. A step-by-step guide. London: Spinger-Verlag.

16. Petrenko V.F. (1997) Osnovy psikhosemantiki [Fundamentals of psychosemantics]. Moscow: MSU (in Russian).

17. Tolstova Y.N. (2006) Osnovy mnogomernogo shkalirovaniya [Fundamentals of multidimensional scaling]. Moscow: University Publishing House (in Russian).

18. Mintzberg H., Alstrand B., Lampel J. (2009) Strategy safari. London: Prentice Hall. 


\title{
Competence-based approach to managing staff in public administration on the basis of ontologies
}

\author{
Natalia F. Altukhova \\ Associate Professor, Head of Department of Business Informatics \\ Financial University under the Government of the Russian Federation \\ Address: 38, Scherbakovskaya Street, Moscow, 105187, Russian Federation \\ E-mail:nfaltuhova@fa.ru
}

\section{Elena V. Vasileva}

Professor, Department of Business Informatics

Financial University under the Government of the Russian Federation

Address: 38, Scherbakovskaya Street, Moscow, 105187, Russian Federation

E-mail: evvasileva@fa.ru

\section{Mariam V. Mirzoyan}

Doctoral Student, Department of Business Informatics

Financial University under the Government of the Russian Federation

Address: 38, Scherbakovskaya Street, Moscow, 105187, Russian Federation

E-mail:mvmirzoyan@fa.ru

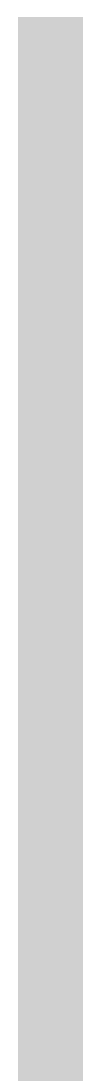

\begin{abstract}
The introduction of new management principles in public administration is in many countries linked to the introduction of client-orientation and evaluation by results. In this connection, a good deal of attention should be directed to raising the quality of work of public administration civil servants. This problem is inextricably bound with the task of raising the qualifications and competency level of workers in public administration.
\end{abstract}

In this work, we present an analysis of the current situation in management of public administrations. We distinguish between the problems of managing the competences of public servants. As part of the research, we polled more than 365 public servants from the rank of specialist to chiefs of sections. We highlighted the competences in highest demand among public servants. These are general professional skills, regulatory-legal, competences of results orientation and work efficiency. Least in demand were groups of competences such as change management, self-management and professional growth. The respondents also noted the high demand for renewal of their professional knowledge. However, there remains a problem with exchange of knowledge, when the knowledge received by employees in the best case turns up in conferences but mostly remains only for personal use and is not attached to a single carrier of information.

We present proposals for applying an ontological approach to evaluation of the competences of public servants. The set of competences makes it possible with sufficient precision to describe the work behavior which is required for successful performance of the work in the given position or in a group of similar positions. The application of ontologies makes it possible to link the task of evaluating competences through transformation of the enquiry into a set of terms and concepts with the concrete requirements of the project of the planned task or performed function. Computerization is one of the main components in the strategy for developing the public services. Creation of a system of decision 
support on the basis of mathematical methods to ensure alignment of competences of public servants with the demands made on their functions allows Human Resources to efficiently make its selection of personnel for vacancies in the public organization.

Key words: public servant, public administration, public administration efficiency, professional development, training, ontology, competence, competence-based approach.

Citation: Altukhova N.F., Vasileva E.V., Mirzoyan M.V. (2018) Competence-based approach to managing staff in public administration on the basis of ontologies. Business Informatics, no. 1 (43), pp. 17-27.

DOI: $10.17323 / 1998-0663.2018 .1 .17 .27$.

\section{Introduction}

$\mathrm{T}$ The term "public function" in legislative acts and documents is normally understood by the implementing body of executive authority to mean the activity of performing or ensuring performance of the government's powers. "Functions" in translation from Latin means the circle (area) of activity directed towards achieving a certain objective. The functions of public civil service include law enforcement, legal, legal defense, regulatory and organizational functions. Auxiliary functions of public service are intended to service the activities of public bodies. They include workflow, legal services, material-technical support.

Besides performing public functions, the activity of government bodies is also connected with providing state services. The difference between the concepts of public functions and state services comes down to highlighting the initiator of interaction of the state and society. Thus, if the initiator is a government body (for example, in the case of performing an inspection), then a public function is carried out. If the citizen or an organization addresses himself to the public administration (for example, to receive a passport, a license for some activity, etc.), then a state service is rendered to them.

Understanding the public administration in a broader sense as performance by the citizen of obligations relating to a replaced government position, we highlight three groups of functions: informational (cognitive-analytical, evaluation-expert, goal forecasting, moral-legal, documentation-archival), organizational (corporative-technological security and communicative-computer security) and technological (preparation of state decisions and their implementation, adoption and realization of administrative decisions). Thus, the public civil service can be seen as an independent form of service cum work activity performed in accordance with the competences of the public servants who ensure performance of the mandate entrusted to the state authorities [1].

\section{Analysis of the structure of the federal bodies of executive power}

In the Decree of the President of the Russian Federation dated 21 May 2012 No. 636 "The Structure of Federal Bodies of Executive Power" (version 21.07.2015) as of September 2015 there were 77 federal bodies of executive power (BEP): ministries (21 units), services (31 units) and agencies (25 units.).At the end of 2015 in state bodies, bodies of local self-rule and electoral commissions at municipal levels of Russia there were a total of $2,176,400$ people employed, which is 1.87 times more than in the year $2000^{1}$. Moreover, $86.8 \%$ of the total number of workers were engaged in bodies of executive power, $10.7 \%$ - in bodies of judicial power and prosecutors, $1.5 \%$ - in bodies of legislative power. In total at the end of 
2015 1,434,100 people were employed in federal government bodies, which, respectively is 2.75 times more than they numbered in the year 2000. Some 261,900 persons work in the state bodies of the subjects of the RF, which is 1.35 times more than in 2000. The number of employees in positions of state civil service and municipal service of the Russian Federation grew over the period 1999-2013 1.6 times (786,400 persons in 2013), including the number of workers of executive power - which grew 1.57 times $(624,035$ persons in 2013). The number of employees holding state positions and positons in the federal civil service grew 1.47 times $(564,490$ persons in 2013$)$, including employees of the executive power by 1.48 times $(442,602$ persons in 2013).

Such growth in the personnel of the public administration signifies a need to arrange stable interaction on the horizontal and vertical levels, an effective process of workflow in the subdivisions and also to reduce time expended (including on work with documents) on low productivity activities, purposeless discussions, etc.

At present, the complexity of interaction between employees of public administrations is one of the more topical problems. Among the characteristic aspects of this problem are complexity, redundancy, non-transparency and contradictions of the system of control and supervisory functions, which lead to an increase in administrative pressure and limitations which spread across the activity of organizations, in particular in the sphere of entrepreneurship. In the context of reform, there is a delimitation of these functions. Thus, the control functions (investigation, inspection, expert evaluation, analysis of primary information, etc.) overlap with supervisory functions (carrying out checks, imposing fines, licensing, issuing permits, registration, halting activity, etc.).
In this case, the function of control is to carry out tests, measurements, and expert evaluations performed by organizations accredited by the executive bodies. The supervisory functions are attached to the very bodies of executive power.

The solution of the task of simplifying administrative procedures and administrative actions is linked to the need to reduce the number of documents that must be presented by citizens and organizations for a state service, the application of new forms of documents which make it possible to eliminate multiplicity of presentation of identical information, including arranging the placement of blank applications and forms of documents on the server of the body of executive power and the development of a system for remotely providing a state service as well as reducing the number of interactions between citizens (organizations) and officials, including by use of the "single window" system. In accordance with the requirements of administrative reform, the description of administrative procedure should be included in the administrative regulations. The given description can be presented in electronic form.

At the same time, it is no less important to maintain the staff structure of public service and to adopt measures to create a personnel reserve. The requirements for professional preparation have made it possible compared to the early 2000s to secure professional staff for public service. However, the high requirements of staff structure which lowered the level and volumes of preparation of new specialists, the absence of a system of assigning graduates of the professional educational institutions have caused a shortage of professional employees at all levels, in any field and especially a shortage of directors and project managers. This underscores the importance of understanding that

${ }^{1}$ Federal Service of Statistics of Russia: http://www.gks.ru/wps/wcm/connect/ rosstat_main/rosstat/ru/statistics/state/\# 
for effective reproduction of personnel in a field it is necessary to pay attention to the conditions of preparation of personnel reserves in each sector of the economy.

In scientific research into the problems of public administration, there is mention of a high percent of turnover in personnel among civil servants, and that finding qualified replacements for them is becoming ever more complicated [2-5].

Not only in the world at large but also (for some time now) in Russia as well there is the concern over the appearance of the "revolving door syndrome" - the practice of migration of professionals between public service and business. Moreover, there arises a consequence of the move, when the civil servants lobby for the interests of those organizations where they worked before their transfer to the state institutions (the "flip-flop effect") or, the opposite, to where they recently went after leaving public service [6]. There arises a problem of security of confidential information, for example, about future plans of the government in one or another sphere, about the nature of pending orders, etc. In connection with this, for example, in Great Britain they introduced legal restrictions: those serving in the highest three grades during the two years following retirement have the right to go to work outside the state bureaucracy only with the permission of the government, while for the first two grades permission is granted on the level of a committee of advisers under the prime minister. As regards officials of lower grades, they are obliged to receive similar permission in cases when they intend to go to work for companies with which they had connections in the service, or when they had access to confidential information about the competitors to their proposed employers [6].

We note than in Russia citizens holding positions in the public administration listed in legal regulatory acts of the RF, are obliged during the two years after release from public service to communicate to their employer information about their last work place when concluding work contracts. When concluding a work contract with citizens who held positions in the public service, the employer is obliged within ten days to communicate about the conclusion of such a contract to the representative of the employer of the public servant at his last work place in the manner established by the legal regulatory acts of the Russian Federation (in accordance with article 12 of the Federal Law of the RF "On combatting corruption," art. 17, p. 3.1 of the Federal law of the RF "On the state civil service of the Russian Federation," art. 64.1 of the Labor Code of the Russian Federation). In case of potential conflict of interests, this information is reviewed in the Commission on Compliance with the Requirements of Service Conduct of Public Servants and Resolution of Conflict of Interests.

These tasks intersect with the need for development of the overall level of efficiency of the public administration and raising the qualifications competence level of employees in the state service. The problems of managing personnel, maintaining staff potential and creating a personnel reserve in public service at present are priority and critical issues [7-9]. These problems are especially acute in relation to the explosive nature of the changes which are occurring as a result of the development of Information Technologies, digital transformation of processes of organizations in all fields, computerization of society and digitalization of the economy. The development of the potential of public servants as a whole is directed towards the efficient development of the organization and its ability to adapt to the new conditions of the digital society. Under these conditions one must be certain that for realization of its strategic goals a state organization has to possess the necessary complement of personnel possessing certain qualifications and the necessary competence both in the given period of time and looking to the future. 


\section{Knowledge management in the bodies of public administration: the results of a poll}

In the process of research into the condition of information sufficiency for performance of state functions, the authors carried out a poll of public servants and employees of a number of institutions including self-governing bodies and the State Institution "Zhilishchnik" of the regions of Moscow and the Moscow Region, the prefecture of one of the districts of Moscow, the bodies of the state authorities in Penza Region, the Federal Supervisory Service in the Sphere of Health, the Department of Information Technologies in the sphere of managing state and municipal finance and ensuring information needed for the budget process at the Ministry of Finance of the Russian Federation, as well as several other state institutions.

In total, the research entailed polling more than 360 public servants occupying positions ranging from specialist to departmental directors. We analyzed variations on the organization of joint work on common tasks, control of the achievement of objectives and managing teams We determined the number of projects in which as a rule public servants participate simultaneously, the volume of urgent and non-urgent tasks solved. We reviewed the problems of excessive expenditure of working time in the period when the project was being performed, as well as the conditions of automation of administrative processes [10].

The results of the interviews confirmed the existence of common problems, including lack of clear strategy for saving knowledge and developing the competency potential of employees in the public administration.

Today the most widespread problem preventing autonomous development of the competences of employees is the problem of dissemination of knowledge among employees, including newcomers, and the further moti- vation of personnel. New knowledge received by officials in the process of training and refresher courses is not passed along to their colleagues.

Only $9.5 \%$ of the polled public servants responded that their professional knowledge is entirely adequate in their work; more than $75 \%$ were uncertain about that; and $11 \%$ of the respondents acknowledged the inadequacy of their professional knowledge. The respondents noted that the last time they were sent for training or refresher courses when choosing the topics consideration was given to the tasks which will be given to them in the organization in the future (in $46 \%$ of cases), as well as the personal characteristics of the employee $(25 \%)$. Precisely these factors were highlighted by the employees as the most significant and, consequently, the ones that should be taken into account when the directors decide about the training of their personnel. In $7 \%$ of the cases, evaluation was made of the possibility that they receive new knowledge in teaching organizations. Moreover, $17.4 \%$ of the respondents replied that they never underwent training or refresher courses.

Among the competences in greatest demand, the respondents named general professional competence $(81.9 \%)$, regulatory-legal competence $(80 \%)$, as well as competences of results orientation and work efficiency $(72.4 \%)$. The competences in least demand were "knowledge management" $(14.3 \%)$, which is not surprising insofar as business processes in state bodies are established "top down" and the working documentation of the highest levels of management often have the status of regulatory-legal documents. We also should mention the low level of demand for the group of competences around self-management and professional growth $(21.9 \%)$, which can be attributed to shortcomings of the existing competence approaches in the state structures (Table 1). 
Table 1.

Frequency of mention of groups of competences as being in greatest demand

\begin{tabular}{l|c}
\multicolumn{1}{c|}{ Groups of competences } & Frequeney \\
\hline General professional & $81.90 \%$ \\
\hline Organizational-management & $59.05 \%$ \\
\hline Informational-communicative & $60.00 \%$ \\
\hline Regulatory-legal & $80.00 \%$ \\
\hline Results-oriented and efficiency of work & $72.38 \%$ \\
\hline Project activity & $18.10 \%$ \\
\hline Change management & $14.29 \%$ \\
\hline Working in a team & $40.95 \%$ \\
\hline Self-management and professional growth & $21.90 \%$ \\
\hline Organization of workflow & $63.81 \%$ \\
\hline Ethics and behavioral culture of public & $67.62 \%$ \\
\hline servants &
\end{tabular}

In the opinion of the public servants polled, the most significant factors when selecting and promoting personnel to the top post in the organization are professional and personal qualities, as well as work experience. At the same time, authority in the group and personal desires are not given much weight. These evaluations are not in any way connected with group activity and self-development (Table 2).

Table 2.

\section{The most significant factors considered when choosing and promoting personnel to leadership positions}

\begin{tabular}{l|c}
\multicolumn{1}{c|}{ Responses } & Frequency \\
\hline Special education & $55.24 \%$ \\
\hline Personal qualities & $60.00 \%$ \\
\hline Experience of working as a specialist & $50.48 \%$ \\
\hline Experience with leadership work in public & $58.10 \%$ \\
\hline administration positions & $79.05 \%$ \\
\hline Professional qualities & $24.76 \%$ \\
\hline Authority in the group & $47.62 \%$ \\
\hline The opinion of the top managers & $22.86 \%$ \\
\hline Personal wishes &
\end{tabular}

\section{Approach to creation of a model of competences of Russian public servants}

With reference to the results of the research, one can say that for creation of a model of competences of Russian public servants it is possible to use two models of competences based on the experience of foreign countries and Russia. One of them presupposes a grouping of competences and consideration of categories of positions. In particular, as grouping of competences we can highlight general professional, organizational-management, information-communicative and other competences presented in Table 1. As categories of positions we can highlight directors, assistants (advisers), specialists and those supporting the specialists. Each group and position is juxtaposed with certain knowledge and skills [11, 12].

The merits of such a model include the direct connection with official instructions. However, in the opinion of the authors, this is what leads to the fact that the majority of groups of competences which to a greater degree are linked with effectiveness of communications and personal initiative turn out to be not in demand (below this will be confirmed by statistical data). In this connection, instead of categories of positions in the civil service it would be more correct to use the groups of positions in the civil service (higher, main, etc.). The groups and categories (art. 8 of the second chapter "Positions of the civil service" of the Federal Law dated 27 July 2004, No. 79-FZ "On the state civil service of the Russian Federation") are not hard linked with one another (Table 3), which allows the public servant to temporarily hold a higher or lower position with the same competences. Such practice to a great degree corresponds to European experience [12-14].

At present in the Ministry of Labor and Social Protection of the RF a lot of work is being carried on with respect to methodological support for qualifications requirements. In particular, there is the proposal to highlight the following 
Correspondence of groups and categories of positions of the state public servant

\begin{tabular}{l|l|l|l|l} 
& Directors & Assistants (advisers) & Specialists & Supporting specialists \\
\hline Highest positions of civil service & & & & \\
\hline Chief positions of the civil service & & & & \\
\hline Leading positions of the civil service & & & & \\
\hline Senior positions of the civil service & & & & \\
\hline Junior positions of the civil service & & & & \\
\hline
\end{tabular}

professional and personal qualities necessary for a public servant: general, applied and managerial. Precisely these qualities may be used to group competences at a high level [15].

\section{Management of competence of state public servants on the basis of the ontological approach}

Nowadays many researchers are busy with the problem of the approach to building a model of competence based on ontologies [16-18]. The application of ontologies allows us to connect the task of evaluation of competences directly with the requirements for them when fulfilling a concrete project, function, task. At the stage of preparing a request with a manager using ontology the request is transformed into a set of terms and concepts united by logical ties, such as "synonym," "homonym," "type - form," "part - whole," "association," "means for," "cause," "result."
For personal support of the leader during selection of personnel for a position from among the personnel reserve, you need a built-up system in which all information about competences, characteristics, job functions, requirements and rules for evaluation of candidates for the post are structured and formalized. The lower level of architecture of such a system [19] (Figure 1) ensures obtaining knowledge from diverse sources of structured (data bank and knowledge storage) and unstructured (documents, questionnaires) information through annotation of diverse sources of information by means of ontology, with application of computer software means of automatic extraction of information from the text and databases, the creation, merger, evaluation of quality and classification of documents by ontology.

Within the framework of this research, as a standard of the level of organization of data we selected ontology insofar as it represents a precise specification of the subject field, e.g., on

User interface (search and visualization, interaction of apps, exchange of knowledge)

\section{Presentation of data}

Requests and transfer of data (interaction with external systems and storages)

Storage of ontologies and metadata

Management of versions, access and security

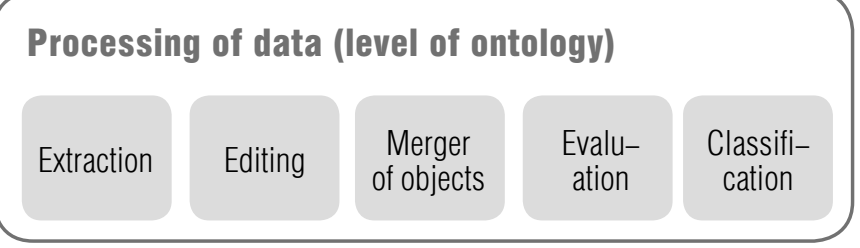

Fig 1. Architecture of a system for managing data and knowledge 
the basis of the set of metadata elements Dublin Core (DC) [20] which is built on the basis of a dictionary of terms by means of formalization of rules defining the relations between them. Ontology is a directed graph built from nodes and arcs of a graph in which is collected a full specification of the subject field, concepts, unified terms and rules for interpretation of information [20]. A visualization of ontology can be created with the help of any graphic editor, and as notation one can use the popular standard for constructing ontologies IDEF5. The elements of the ontology are exemplars (physical or abstract objects), concepts and classes (sets of objects), the attributes of objects (name, significance, etc.), relations (correlations between objects of the ontology), as well as metadata describing the form and content of documents, objects and services and establishing the connection of the level of the organization of data with levels of the system. In this way the ontology is the mechanism for organizing information using the possibility of creating subject fields, terms and connections between the terms. The formation of the ontology also allows us to create missing elements of the system content. Among the wellknown approaches to building ontologies one can name On-To-Knowledge, Methontology, CommonKADS, the languages of conceptual modeling of ontology UML and IDEF5, the formal languages for describing ontology KIF, LOOM, OWL and RDF, the means of developing ontologies - OntoEDIT, ODE, Protégé and OilEd.

The ontologies obtained and the metadata are presented with the help of the special languages OWL and RDF. At the level of presentation of the data, there is interaction with external systems and storages, management of the versions, access and storage of ontologies. At the level of the application (user interface), there can be an exchange of links to resources, support for management of data via the languages of requests (SPARQL). The ontology must react to user requests for search of the needed information via the terms and navigation in it. Thus, on the basis of the ontology a single knowledge space of the organization is formed and the risk of non-correctness of the terms used is eliminated, while the function of exchange of knowledge between employees is simplified [21-23].

In Figure 2, we present a general diagram of the level of ontology of the support system for selection of personnel to a post from the personnel reserve. When developing the given diagram we took into account publications devoted to automation of the process of search for specialists with the given set of competences by a natural language description of the required competences on the basis of applying linguistic information technologies.

On the basis of models of competences developed to describe the characteristics of public servants, an ontological model is formed of the system of support to selection of personnel for positions from the personnel reserve [24-26]. A fragment of the level of competences of the given model for the "leader" category of position is presented in Figure 3.

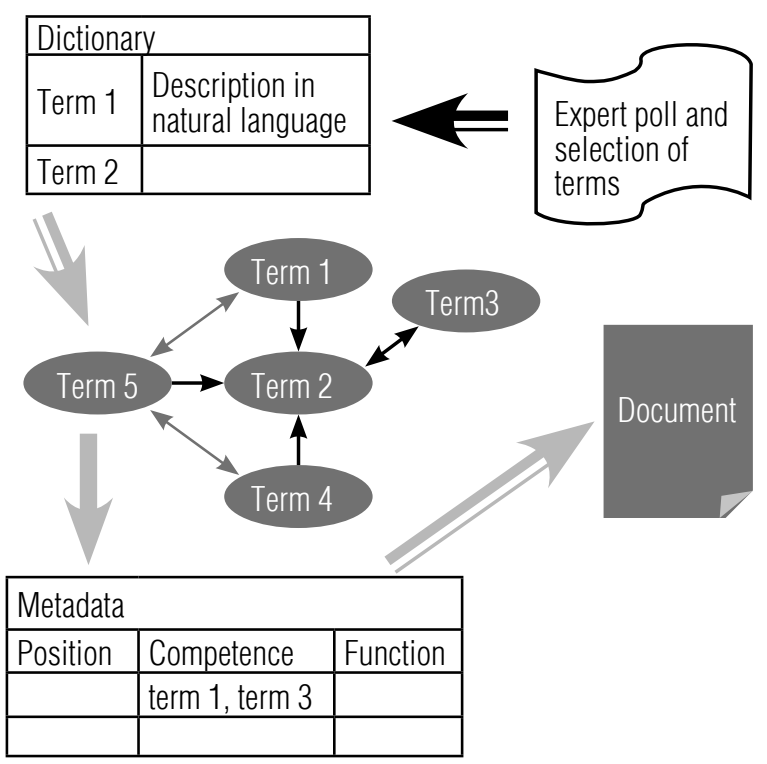

Fig. 2. Model level of the ontology of a system for evaluating the competences of public servants when selection personnel for a position 

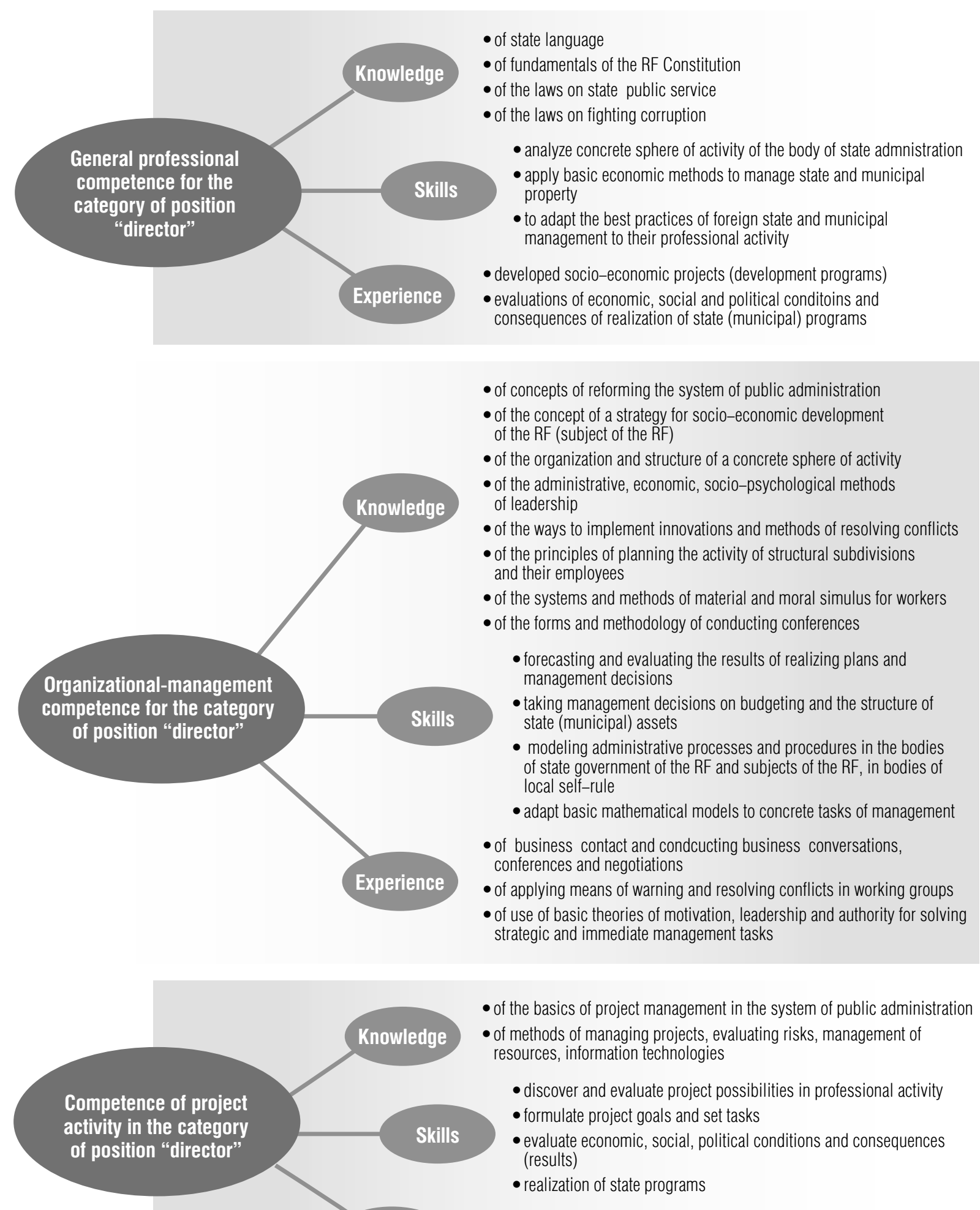

Experience developments of project documentation

- applications in practical activity of methods of managing projects

- forming and managing programs and project portfolios

Fig. 3. Level of content of general professional, organizational-management and project competences for the category of position "director" 
In order to obtain a list of criteria of basic elements of the system, it is necessary to bring in experts. It is proposed to evaluate the results of expert opinions with the help of the Delphi procedure, and to evaluate the significance of the selected criteria using the method of index grouping.

For example, if in the ontology on the structures of data are reflected the relations "type form" between the concepts "Contracts for carrying out checks" (type), "Expert opinion of documents" (form), "Inspection" (form), "Analysis of primary information" (form) and the relation "synonym" between the concepts "Personnel department" (synonym) and "HR" (synonym), then the request "What contracts are there for carrying out verifications in the organization?" will be turned into the form: "Expert evaluation of documents" and "Inspection of the object" and "Analysis of primary information," and the request "Personnel department: into the form "Personnel department" and "HR." However, this method requires a full, and at the same time simple and understandable description of the competences depending on the working situation, business process, functions carried out by the public servant, as well as a strategy for develop- ing the whole organization [16]. In the model of competence of the public servant involved in executing a certain project on fulfillment of a state function, for the information-communicative competence we highlight experience and knowledge in categories of positions, groups and categories of positions of public civil servants, as well as, depending on the concrete task, being fulfilled at the given moment in time.

\section{Conclusion}

A competence approach presupposes carrying out an evaluation of personnel by comparing results, the quality and complexity of work with standard specifications of the respective position [17]. Thus a set of competences allows us with sufficient accuracy to describe the work conduct which is required for successful performance of the job in the given position or in a group of similar positions. This set is reflected in the model of competences. At the same time, one should recall that for formation of a reserve, as a rule, it is not enough just to select employees for promotion. It is important that you correctly prepare them for the position and organize the career advancement.

\section{References}

1. Rykhlova E.A. (2014) Ponyatie, tseli i funktsii gosudarstvennoy grazhdanskoy sluzhby kak faktory, opredelyayushchie ee effektivnost', v period reformirovaniya gosudarstvennoy sluzhby [Nature, objectives and functions of the civil public administration as factors determining its efficiency, in the period of public administration reforms]. Science and Education: Property and Economy; Entrepreneurship; Law and Management, no. 4 (47), pp. 92- 99 (in Russian).

2. Haque S.M. (1998) Legitimation crisis: A challenge for public service in the next century. International Review of Administration Sciences, vol. 64, no. 1, pp. 13-26.

3. Gray A., Jenkins B. (1995) From public administration to public management: Reassessing a Revolution? Public Administration, vol. 73, no. 1, pp. 75-99.

4. Kettl D., Ingraham P., Sanders R., Horner C. (1996) Civil service reform. Building a government that works. Washington, DC: Brookings Institution.

5. Kozina M. (2010) Kadrovyy rezerv [Personnel reserve]. HR Service and Personnel, no. 3, pp. 15-18 (in Russian).

6. Obolonsky A.V. (2002) Byurokratiya dlya XXI veka? Modeli gosudarstvennoy sluzhby: Rossiya, SShA, Angliya, Avstraliya [Beurocracy for the XXI century? Models of public administration: Russia, USA, England, Australia]. Moscow: Delo (in Russian).

7. Stader J., Macintosh A. (2000) Capability modelling and knowledge management. Applications and innovations in intelligent systems (eds. R. Ellis, M. Moulton, F. Coenen). London: Springer, pp. 33-50. 
8. Biesalski E., Abecker A. (2005) Integrated processes and tools for personnel development. Proceedings of the 2005 IEEE International Technology Management Conference (ICE), Munich, Germany, 20-22 June 2005, pp. 1-8.

9. McClelland D.C. (1973) Testing for competence rather than for "intelligence". American Psychologist, vol. 28 , no. 1 , pp. 1-14.

10. Altukhova N.F., Vasileva E.V., Gromova A.A., Slavin B.B. (2016) Klyuchevye pokazateli pribornoy paneli gosudarstvennoy sluzhby [Key indicators of a dashboard of public administration]. Vestnik Universiteta (State University of Management), no. 10, pp. 10-17 (in Russian).

11. Teece D.J., Pisano G., Shuen A. (1997) Dynamic capabilities and strategic management. Strategic Management Journal, vol. 18, no. 7, pp. 509-533.

12. Lane D.C., Sterman J.D. (2011) Jay Wright Forrester. Profiles in operations research: Pioneers and innovators (eds. S. Gass, A. Assad). New York: Springer, pp. 363-386.

13. Blackman D., Connelly J., Henderson S. (2004) Does double loop learning create reliable knowledge? The Learning Organization, vol. 11, no. 1, pp. 11-27.

14. RF Ministry of Education and Science (2010) Metodika formirovaniya na konkursnoy osnove iz chisla federal'nykh gosudarstvennykh grazhdanskikh sluzhashchikh i inykh grazhdan Rossiyskoy Federatsii kadrovogo rezerva Ministerstva obrazovaniya i nauki Rossiyskoy Federatsii dlya zameshcheniya dolzhnostey federal'noy gosudarstvennoy grazhdanskoy sluzhby Rossiyskoy Federatsii [Methodic of personnel reserve formation on competitive basis from a number of federal public civil servants and other Russian Federation citizens for the RF Ministry of Education and Science, for appointing federal public civil servants posts]. Available at: https://минобрнауки.pф/state_service/227/file/471/\%D0\%A0\%D0\%B5\% D0\%B7\%D0\%B5\%D1\%80\%D0\%B2-\%D0\%BC\%D0\%B5\%D1\%82\%D0\%BE\%D0\%B4\%D0\%B8\%D0 \%BA\%D0\%B0.pdf (accessed 10 December 2015) (in Russian).

15. Kibanov A.Y. (ed.) (2017) Upravlenie personalom organizatsii [Personnel management in an organization]. Moscow: INFRA-M (in Russian).

16. Rizvanov D.A., Sen'kina G.V. (2009) Ontologicheskiy podkhod k podderzhke prinyatiya resheniy po upravleniyu kompetentsiyami organizatsii [Ontological approach to decision making in the field of organizations' competences management]. Vestnik of RSREU, no. № 4 (30), pp. $79-84$ (in Russian).

17. Blackman D., Henderson S. (2007) Being and knowing - Ontological perspectives on knowledge management systems. Electronic Journal of Knowledge Management, vol. 5, no. 3, pp. 283-290.

18. Kozlov A.N., Kozlova O.V. (2012) Otsenka kachestva obrazovaniya s ispol'zovaniem neyronnykh setey [Evaluating education quality using neural networks]. Izvestia of Samara Scientific Center of the Russian Academy of Sciences, vol. 14, no. 4 (5), pp. 1454-1456 (in Russian).

19. Mika P., Akkermans H. (2004) Towards a new synthesis of ontology technology and knowledge management. Knowledge Engineering Review, vol. 19, no. 4. pp. 317-345.

20. Borovikova O.I., Zagorul'ko Y.A. (2002) Organizatsiya portalov znaniy na osnove ontologiy [Organization of knowledge portals relying on ontologies]. Proceedings of the International Seminar "Dialog 2002. Computer-based Linguistic and Intelligent Technologies", Protvino, Russia, 31 May - 3 June 2002, vol. 2, pp. 76-82 (in Russian).

21. Staab S. (2001) Human language technologies for knowledge management. Intelligent Systems, vol. 16, no. 6, pp. 84-94.

22. Maybury M.T. (2006) Expert finding systems. MITRE Technical Report. Bedford, MA: MITRE Corp.

23. Zahlebin I.V., Fomichov V.A. (2015) Razrabotka metoda semanticheskogo poiska spetsialistov v korporativnoy baze dannykh po estestvenno-yazykovym zaprosam [Development of a method for semantic search of specialists in corporate databases using natural language queries]. Information Technologies, vol. 21, no. 5, pp. 323-331 (in Russian).

24. Kharsky K.V. (2010) Tsennostnoe upravlenie dlya biznesa [Value based management for business]. Saint Petersburg: Polytechnica-Service (in Russian).

25. Allin O.N., Salnikova N.I. (2005) Kadry dlya effektivnogo biznesa. Podbor i motivatsiya personal [Staff for efficient business. Personnel selection and motivation]. Moscow: Genesis (in Russian).

26. Ugra Administration (2014) Professional'naya model' kompetentnosti gosudarstvennykh sluzhashchikh Khanty-Mansiyskogo avtonomnogo okruga - Yugry [Professional competence model for civil servants of Khanty-Mansiysk Autonomous Okrug - Ugra. Methodical recommendations]. Khanty-Mansiysk (in Russian). 


\title{
Detection of patterns and trends in patient behavior while using electronic applications and Internet resources for self-diagnosis
}

\author{
Galina A. Polynskaya \\ Associate Professor, Department of Marketing \\ Lomonosov Moscow State University \\ Address: 1, Leninskie Gory, Moscow, 119991, Russian Federation \\ E-mail: g.polinskaya@outlook.com
}

\section{Margarita G. Mesropyan}

Doctoral Student, Economic Sociology and Demography Specialty Financial University under the Government of the Russian Federation Address: 49, Leningradsky Prospekt, Moscow, 125993, Russian Federation

E-mail:m.mesropyan.93@gmail.com

\begin{abstract}
Information and communication technologies have changed the world, affecting all sectors of the national economy including the medical industry. There is rapid growth in the dependence of the quality of medical services on the use of information systems. Gradually, information systems are beginning to take over part of doctors' work. Digitalization also has affected ordinary citizens. There is a growing popularity of electronic applications and Internet resources in the health care industry among users of the network. As a result, self-diagnosis and self-treatment are improving with their use. Therefore, it is important to assess the possibilities for the coexistence of traditional medicine with modern digital technology opportunities that the citizens are facing these days.

The authors of this research have carried out a series of studies to identify the patterns of patient behavior using electronic applications and Internet resources for self-diagnosis, as well as factors that contribute to or impede the development of such use. The following actions were performed: high-quality content analysis of medical web applications, 40 in-depth interviews with doctors and pharmacists, a mini focus group with representatives of the health service, as well as an online survey of two hundred respondents in the social network Facebook.

As a result of the study, patients were segmented according to typical behavioral patterns with regard to the use of electronic applications and Internet resources in the field of medicine. We identified the attitude towards Internet self-diagnosis of doctors and pharmacists on the one hand and patients, on the other, as well as factors contributing to or impeding the growth of Internet diagnostics.
\end{abstract}

Key words: digitization of health care, electronic technologies, Internet applications, clinical diagnostics, mobile software, digital medicine.

Citation: Polynskaya G.A., Mesropyan M.G. (2018) Detection of patterns and trends in patient behavior while using electronic applications and Internet resources for self-diagnosis. Business Informatics, no. 1 (43), pp. 28-38. DOI: 10.17323/1998-0663.2018.1.28.38. 


\section{Introduction}

I nformation and communication technologies have changed the world, affecting all sectors of the economy. The economy has become directly dependent on software, computer and network equipment, as well as systems for obtaining, analyzing, storing and distributing information, largely built on network technologies. These changes among other things affected the health care sphere radically.

While working with information in medical practice, paper (solid) carriers are still largely used, but information technology is rapidly supplanting this approach. The time is approaching when all medical information will be transformed into digital. Likewise, the approach of decision making in diagnosis and treatment is changing. Whereas previously, besides instrumental research and analysis, the knowledge and experience of the doctor were determinants, now, for instance, digital information systems with elements of decision support are of great importance for qualitative diagnostics and solving problems of patients. These changes have also been used by pharmaceutical companies, which brought a large number of medical applications into "virtual space." As a result, not only doctors, but also patients were able to participate in the diagnosis of their own diseases. This confirms the relevance of the study, namely:

$\downarrow$ the gradual digitalization and distribution of information systems in health care, and the growing dependence of the quality of medical services on digital technologies;

- the growing popularity among users of electronic applications and Internet resources in the field of medicine, and as a consequence the growth of self-diagnosis and self-treatment. Back in 2012, Deloitte looked into the online segment of consumers in health care, estimating it to be $17 \%$ [1]. These are active users of electronic applications and Internet resources in the field of medicine; $\downarrow$ consequently, there is a need to assess the possibilities for the coexistence of traditional medicine and the new opportunities that citizens face with modern digital technologies.

As the purpose of our study, we focused on identifying the patterns of patient behavior using electronic applications and Internet resources for self-diagnosis, as well as factors contributing to or impeding the development of such use.

To achieve this goal, the following tasks were accomplished:

$\diamond$ study of the existing models of citizens' behavior in case of medical problems in conditions of medical information digitalization;

clarification of the views of these models among doctors, pharmacists and consumers of medical services (patients).

The research methodology consisted of several stages:

1. Conducting high-quality content analysis of medical web applications through the Yandex search system.

2. Interviewing doctors and pharmacists. The study was conducted from 22.10.2016 to 10.11.2016 in a city with a population of more than one million people, and consisted of interviews with:

- twenty general practitioners working in 18 polyclinics, both private and public. All respondents were women between the ages of 35 and 60 ;

- twenty pharmacists working in pharmacies of the city, of which $95 \%$ were women and $5 \%$ were men, aged 25 to 40 years;

- one mini focus group consisting of three doctors and one pharmacist working in the health services control department.

3. An online survey of users in the social network Facebook. The study was conducted during the period from 28.01.2017 to 20.02.2017. As a result, 200 respondents were interviewed. Distribution by gender was uneven: the female audience is $63 \%$ of the respondents. It was taken into account that the female population is more 
concerned with their health and makes up the majority of the population (according to FSSS data, about $54 \%$ of the total population of the Russian Federation in 2017). The distribution of respondents by age groups is also uneven: $59 \%$ of respondents fall in the range of 18 to 24 years old, $29 \%$ of respondents are from 25 to $35,6 \%$ are from 36 to $45,4 \%$ are from 46 to $55,2 \%$ - over 55 years old. The sample was voluntary, so the age distribution of respondents does not correspond to the general population, but is similar to the distribution of active users of the network.

The research is exploratory; the researchers did not set a task of identifying exact data, but only of identifying existing problems and trends.

\section{Factors affecting the market development for electronic and Internet applications in the medical field}

The main factors affecting the development of electronic applications and Internet resources market in the medical field are:

$\downarrow$ the wide penetration of the Internet in Russia, comparable with developed countries; a significant increase in the use of the Internet on mobile devices;

$\checkmark$ gradual smoothing of age and geographical differentiation of Internet users in Russia;

$\checkmark$ rapid growth of "digital" health care.

According to a study conducted by consulting company Arthur D. Little [2], the world market of "digital" health care will grow by more than three times by 2020 and reach $\$ 233.3$ billion [2]. In this case, according to company analysts, mobile solutions will be successful in the near future. Thus, the growth of mobile health in the period from 2017 to 2020 will be more than $130 \%$. The main advantages of mobile health care are ubiquitous access to health services and individual health solutions [3], which facilitates faster delivery of medical services, provides lower costs and provides wider access to health services of higher quality. Therefore, it is expected that mobile health care will improve the quality of medical services for consumers [4].

\subsection{Growth of electronic and Internet applications in the field of medicine announced and distributed by pharmaceutical companies}

Many leading pharmaceutical companies have managed to develop and test electronic and Internet applications for the diagnosis and prevention of diseases. Currently, there are more than 20,000 medical applications available only in the App Store. Applications in the "mobile health care" category are the third fastest growing category of applications both for iOS and Android. It is expected that by 2018, more than $50 \%$ of 3.4 billion users of smartphones and tablets will download mobile applications from the health care field [5].

\subsection{Free access to professional electronic and Internet applications for diagnosis of diseases}

A. Yutel (Victoria University) and D. Lupton (University of Canberra) in 2013 conducted a content analysis of medical applications available in the Google Play Store and the App Store. The task was to determine which applications for medical diagnostics are offered in the net. The search for applications was carried out by the key phrase - "medical diagnosis," and the result produced 176 applications. In the aftermath, only applications in English focusing on traditional methods of treatment were chosen. As a result, 131 applications remained, 57 of which belonged to the clinical diagnosis type [6]. Runet offers no fewer applications in the field of medicine, while the range of tasks they solve is growing every day. The most typical applications are shown in Table 1 (author's scheme, compiled based on the results of content analysis).

\subsection{Increased involvement of patients in the health sector}

The concept of empowerment of patients is spreading everywhere (Figure 1). The focus is on encouraging patient's individual selection 


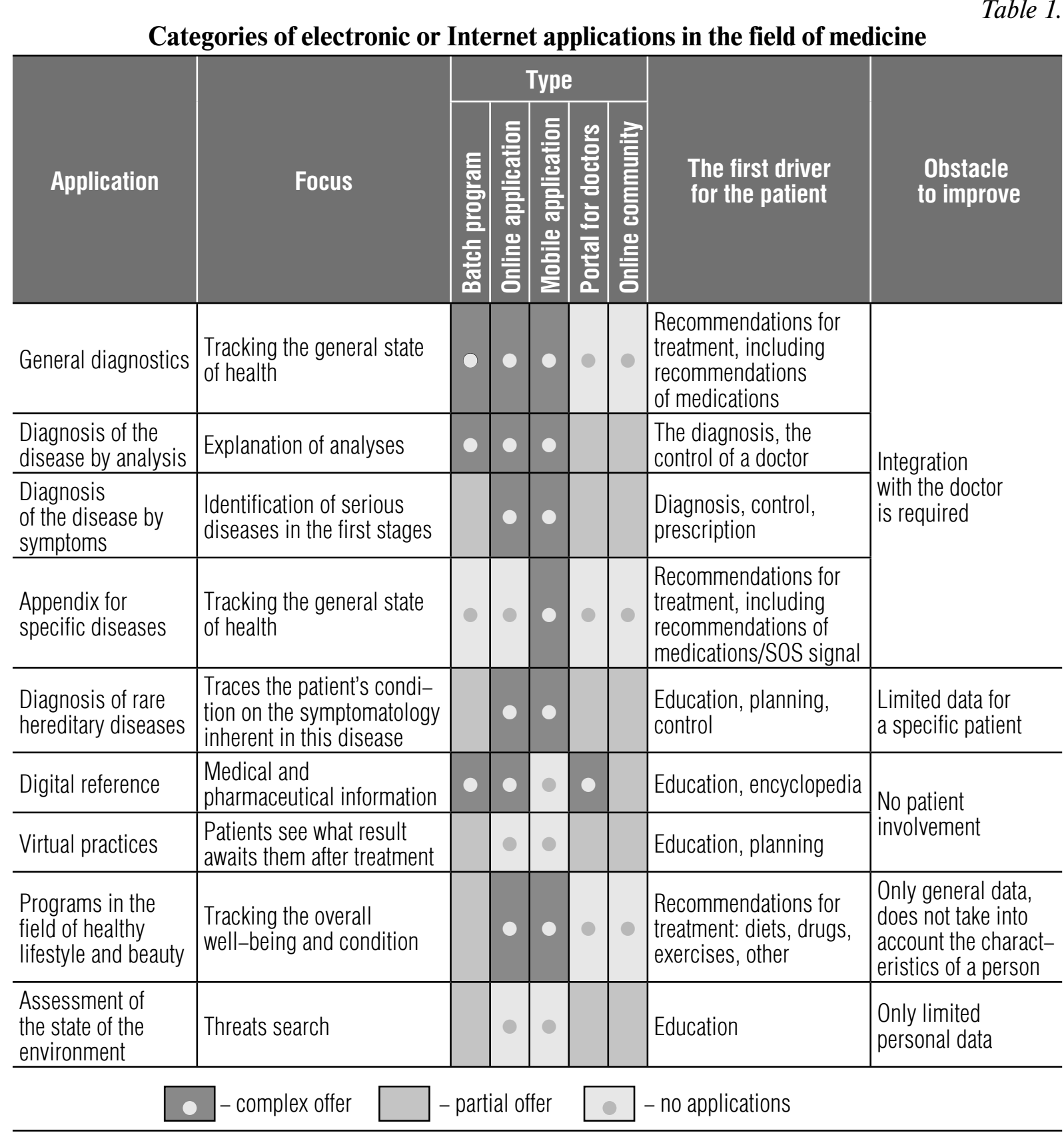

in the field of treatment [7] and involving public organizations to develop mechanisms for providing quality medical care [8].

\section{Consumer behavior perception analysis in the opinion of doctors and pharmacists}

Based on the analysis of in-depth interviews with doctors and pharmacists, several schemes of consumer behavior were drawn up. The estimates presented in the schemes were accomplished by the Delphi method. The con-sumers (patients) were classified into three groups: "traditionalists" (with "doubters" sub-group), "searchers," and "generation Y."

Many consumers buy medications from the nearest pharmacies without first visiting a doctor, based on previous experience, or on the 


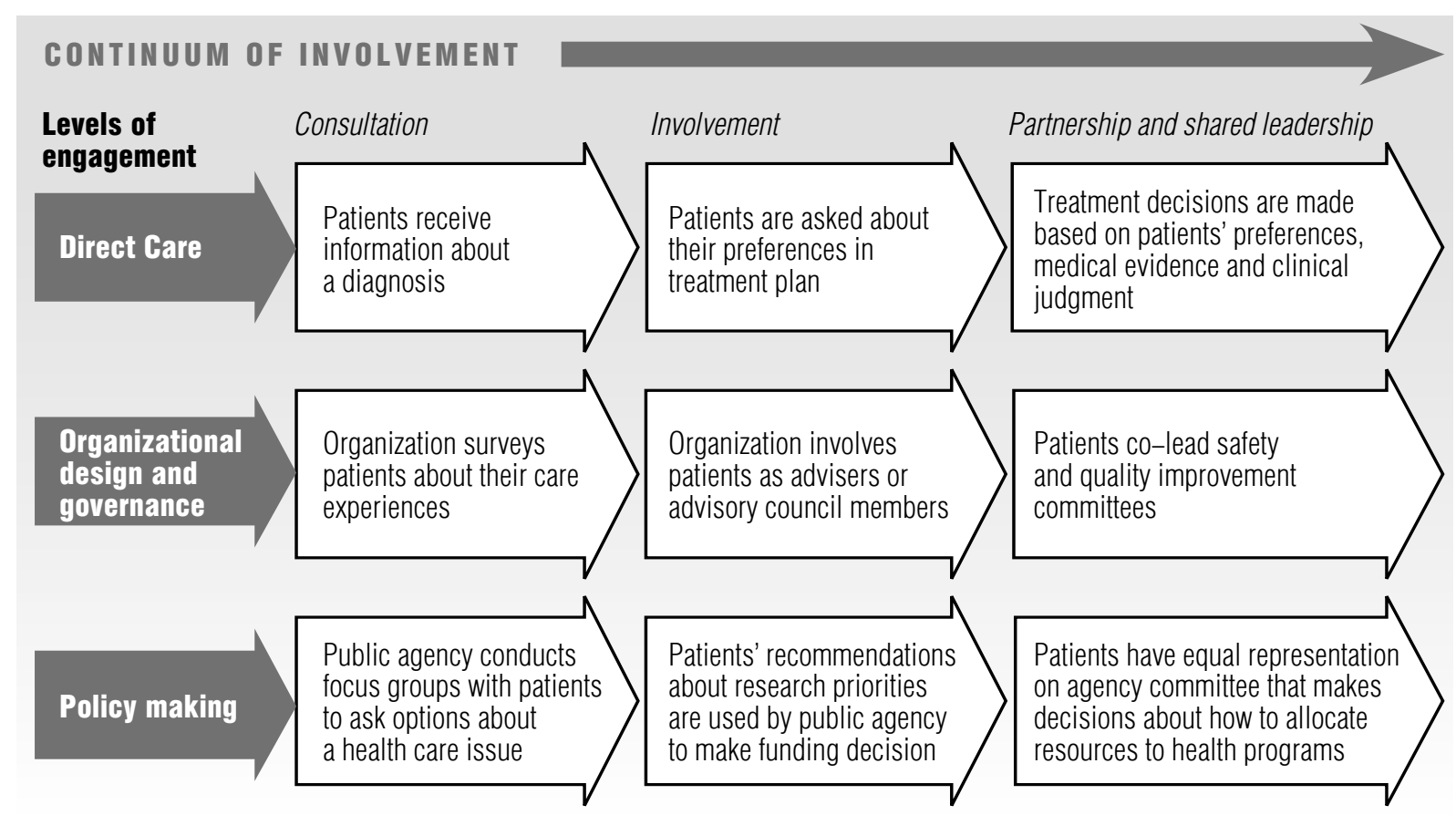

Fig. 1. Possible participation of patients in health care

recommendations of the nearest environment, or after consulting a pharmacist. If the use of medications does not have a positive effect, then the behavior of consumers may be different:

"Traditionalists" (Figure 2) trust traditional methods of treatment; they will turn to the doctor.

After the diagnosis is established, the majority of patients will start the course of treatment without questioning the authority of the attending physician, and fulfilling most of the prescriptions, including the intake of medications. However, some patients "doubters" - after going to the doctor will necessarily visit virtual space in order to learn more about the diagnosis and read reviews about the drugs. According to respondents, over time the share of "doubters" among "traditionalists" will only increase. If the information obtained from the Internet meets the recommendations of doctors, the patient proceeds to the course of treatment. Otherwise, the patient may question the diagnosis or a treatment that may lead to an unpredictable reaction. For example, he or she will still break into the course of treatment, or replace some of the drugs with others, using recommendations received on the Internet, or consult with pharmacists (pharmacy workers very often change the drugs).

"Searchers" (Figure 3) is a subgroup of people who are trying to find out independently about problems, including medical problems.

After an unsuccessful attempt at self-treatment, representatives of this group seek advice in the Internet, trying to solve the problem on their own. If, in their opinion, the answer is found, they bravely buy or order the recommended medications. Only if the use of medicines does not have a positive effect do they turn to the doctor. At the same time, they are sure to search the Internet for information about the diagnosis and prescribed medications. Only if the information received on the Internet meets the recommendations of doctors, the patient proceeds to the course of treatment, fulfilling most of the prescriptions, including the intake of medications.

"Generation Y" (Figure 4) - patients of the "new rhythm of life" who value their time and freely own modern gadgets, "living in the web." Over time, according to respondents, this group of patients will only increase. 


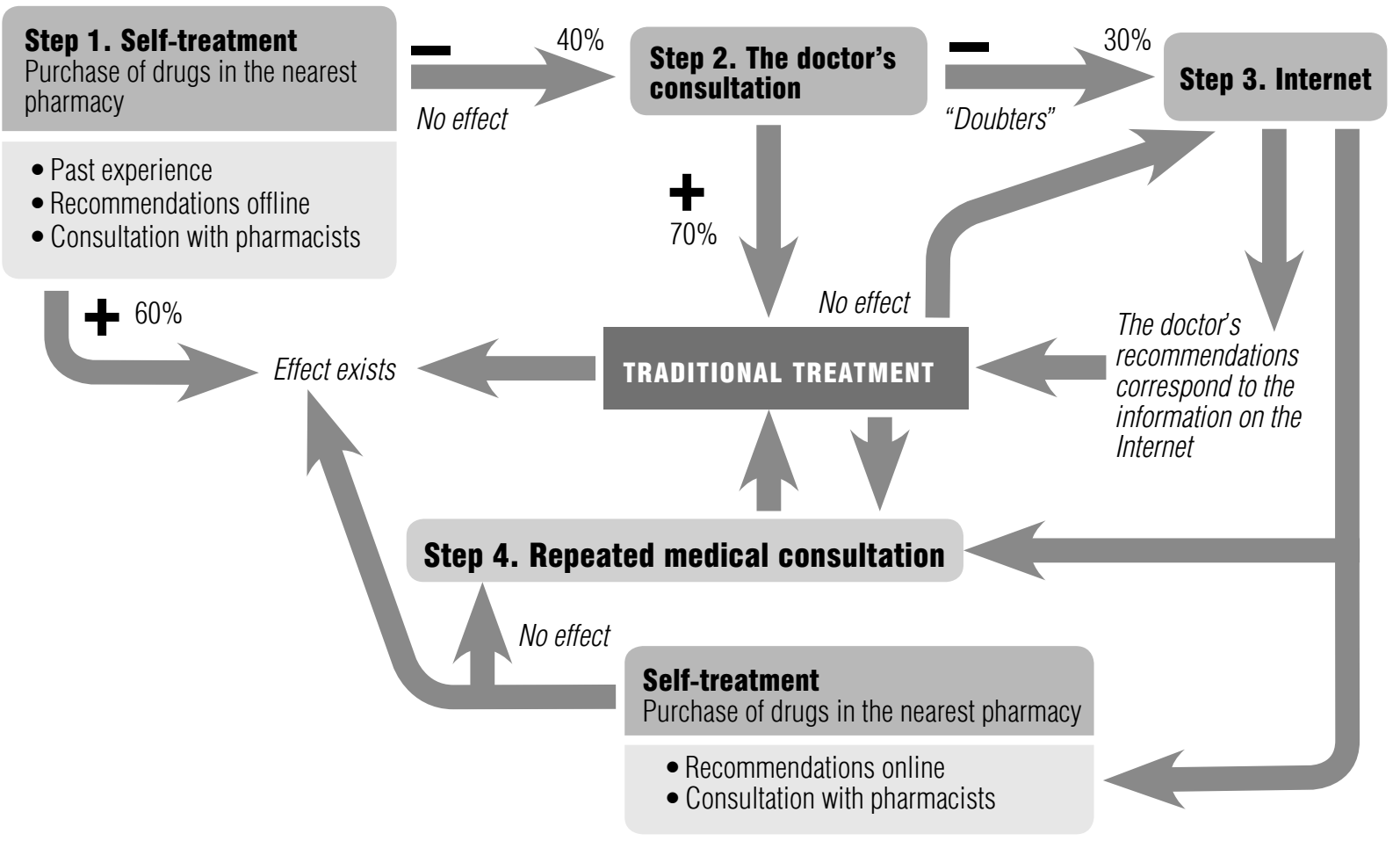

Fig. 2. The scheme of consumer behavior with a short-term implicit manifestation of the disease, "traditionalists"

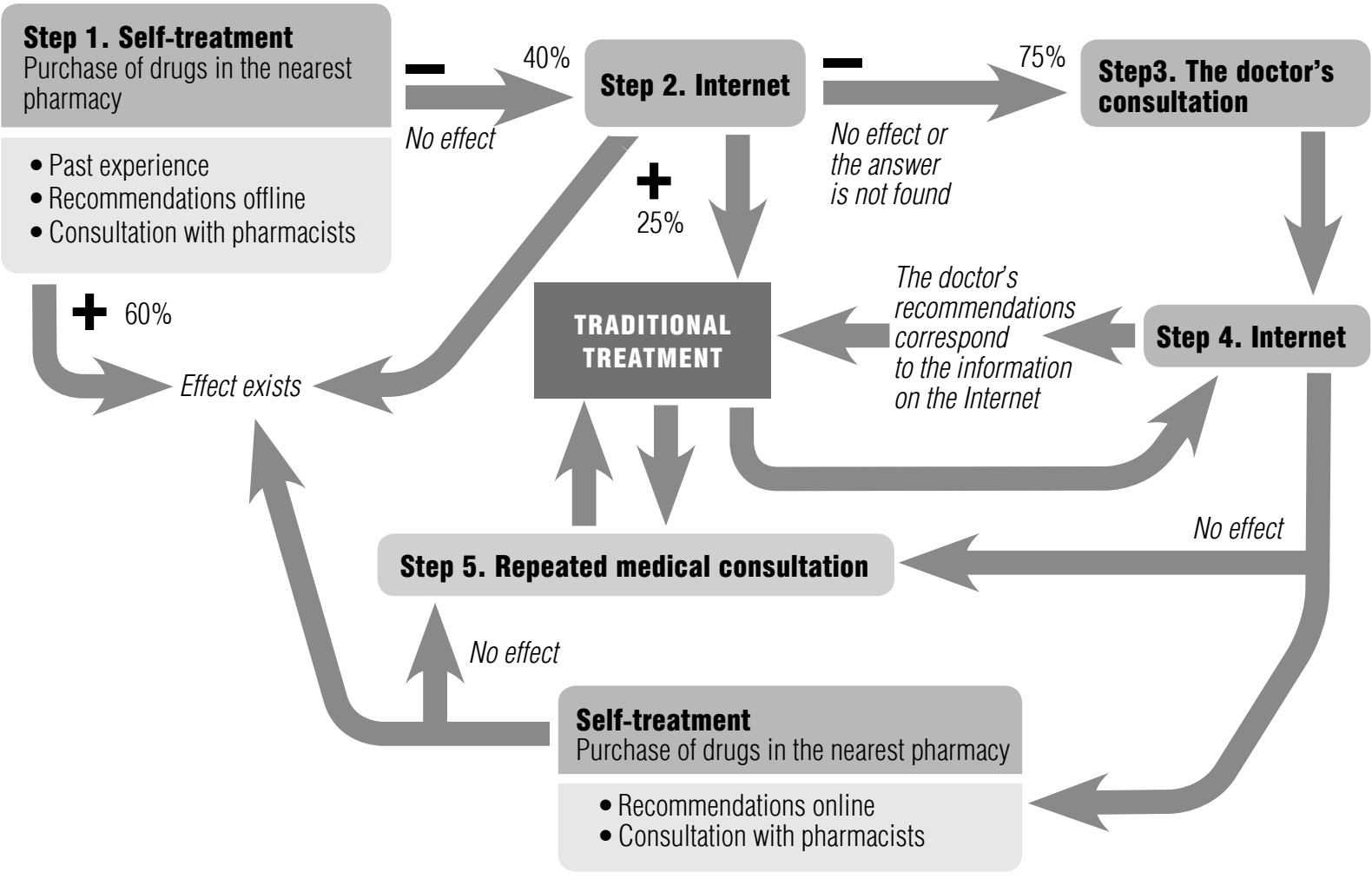

Fig. 3. Scheme of consumer behavior with a short-term implicit manifestation of the disease, "searchers" 


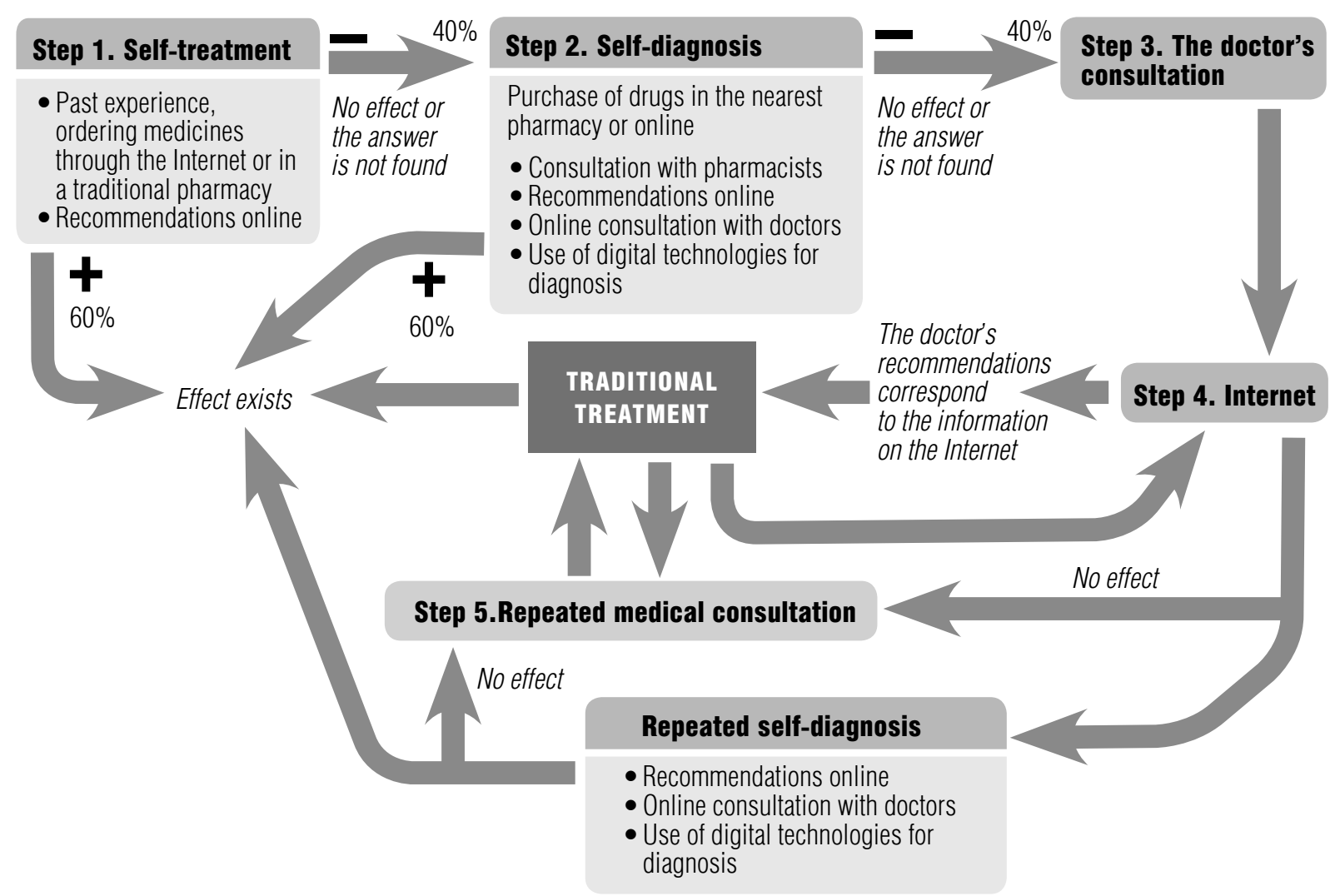

Fig. 4. Scheme of consumer behavior with a short-term implicit manifestation of the disease, "generation Y"

If there is experience in the treatment of these diseases, representatives of this group buy medication often in online stores. In the case of unusual symptoms, the first thing they do is go to the Internet to search for information: they conduct self-diagnostics through Internet services, read instructions and reviews on recommended medications. Often, after an unsuccessful attempt at self-treatment, they continue their independent diagnosis, while they can go to the pharmacy for clarifying advice. Only if there is no positive effect, will they go to the doctor, while often questioning the diagnosis.

The behavior of patients varies greatly if syndromes are pronounced. In this case, patients refuse to self-cure and immediately call the doctor at home, regardless of their opinion. This does not exclude the possibility of consulting with pharmacists and searching the net for information about the disease.
Strong differences in the analysis of in-depth interviews with doctors and pharmacists are not observed. In general, doctors are supportive of Internet diagnostics of patients, believing that this trend is the future. At the same time the following are considered to be the main factors when choosing a method of treatment and diagnosis (Table 2).

Table 2.

\section{Factors affecting the pattern of patient behavior in the search for treatment}

\begin{tabular}{|c|c|c|}
\hline $\begin{array}{l}\text { Consultation with } \\
\text { doctors }\end{array}$ & $\begin{array}{c}\text { Consultation } \\
\text { with } \\
\text { pharmacists }\end{array}$ & $\begin{array}{l}\text { Information } \\
\text { searchthrough } \\
\text { the Internet }\end{array}$ \\
\hline $\begin{array}{l}\text { - fear of complications; } \\
\text { - moral support; } \\
\text { - belief in professiona- } \\
\text { lism and competence. }\end{array}$ & $\begin{array}{l}\text { - fast receipt } \\
\text { of advice; } \\
\text { - availability; } \\
\text { - trust. }\end{array}$ & $\begin{array}{l}\text { - informative; } \\
\text { - fast information } \\
\text { retrieval; } \\
\text { - availability. }\end{array}$ \\
\hline
\end{tabular}




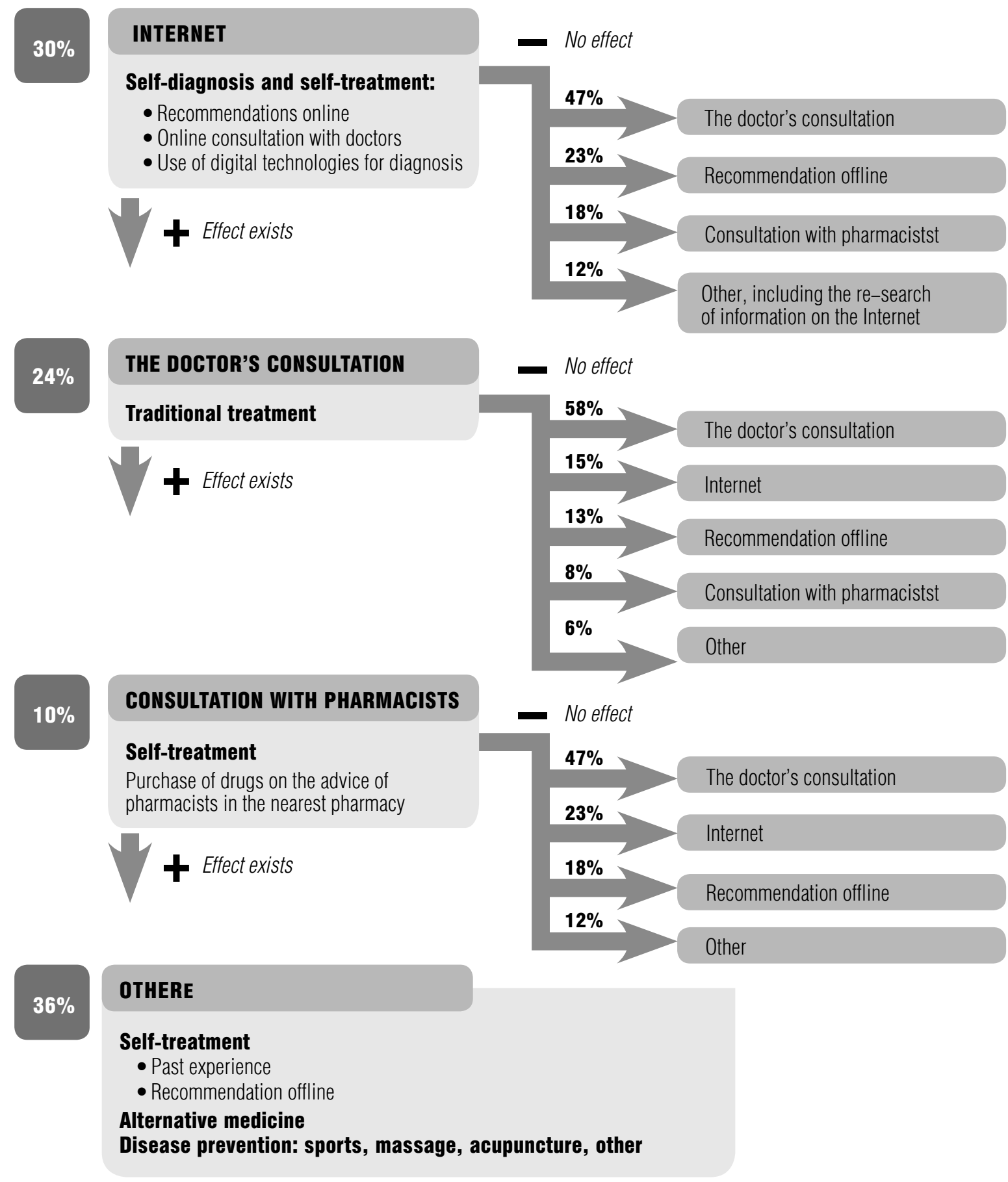

Fig. 5. The scheme of consumer behavior

Factors that prevent the development of selfdiagnosis using electronic applications and Internet resources are a high risk of misdiagnosis, which can be the result of (1) incorrect assessment of one's own condition, (2) incomplete collection of anamnesis, (3) incom- plete or incorrect semiotics (not all or excessive signs of the disease have been introduced), (4) application failures. The consequence may be the incorrect diagnosis or misapplication of drugs with the help of the program (allergy, excessive use, the use of incompatible drugs). 
That is why the main opponents of Internet diagnostics are government officials. The focus group members noted, “... that this practice is very dangerous for use, as it is directly related to the health of citizens and can cause great harm." In addition, the authorities remind us that it is illegal to buy certain medications without a doctor's prescription.

\section{Patients' consumer behavior analysis based on consumer survey results}

For the primary segmentation of respondents by behavior, the following question was used: "If you have any painful symptom or other manifestation of a disease, what will you do?" The respondent had to choose one answer. The results were distributed as follows: "I will read information on the Internet" (30\% of respondents), "I'll go straight to the doctor" (24\%), "I'll consult with friends or acquaintances" (15\%), "I'll take a pain reliever that I consider appropriate for the situation" (12\%), "I'll go to the pharmacy" (10\%), "Difficult to answer"(9\%).

On the basis of primary segmentation, a scheme of consumer behavior was drawn up (Figure 5). It does not take into account extremely heavy or light conditions, since we assume that self-treatment with an implicit pain syndrome is applied more often, i.e. in the case of a mild headache, the majority of respondents (98\% of respondents) will simply take an analgesic pill. With a strong pain syndrome or in case of fear for one's health, all respondents will immediately turn to a doctor.

The compiled scheme confirms the results obtained by analyzing in-depth interviews with physicians and pharmacists detailing them. In other words, we can assume that "traditionalists" make up only $24 \%$ of respondents, while $65 \%$ of this group can be classified as "doubters." To the question about their readiness after the doctor's diagnosis to visit virtual space to learn more about the diagnosis and read the reviews about the drugs, only $30 \%$ of the respondents answered negatively, and $15 \%$ expressed absolute readiness for this solution. At the same time, $24 \%$ of respondents are likely to look for information on the network, and $26 \%$ will probably look for information.

The share of "generation Y" is $30 \%$. As anticipated by doctors and pharmacists, this group is likely to grow soon, since the following question "Do you think it's right to read information on the Internet about the illness or carry out an Internet diagnosis of the disease before visiting a doctor?", $50 \%$ of the respondents answered that they consider this to be correct behavior.

An interesting fact is that $28 \%$ of respondents already use Internet applications for diagnosis of diseases based on symptoms.

The remaining $46 \%$ of respondents, unfortunately, cannot be accurately divided into segments, but form the following mixing groups:

४ "searchers";

४ "healthy lifestyle" - respondents who lead a healthy lifestyle and as a result prefer not to take any medications without strong need, often turning to alternative medicine, main-taining proper nutrition or diets and participa-ting in sports;

४ "indifferent" - a group of people who take painkillers, consult pharmacists at the nearest pharmacy and, if the pain subsides, will not take further actions.

In general, respondents are supportive of Internet diagnostics, believing, like doctors, that this trend is the future. Respondents were asked to select the factors contributing or impeding the development of Internet diagnostics (multiple binary response). The proposed factors were previously derived from analysis of the in-depth interviews with physicians and pharmacists. The majority of respondents easily noted the factors behind the development of Internet diagnostics and only one third of respondents noted the factors "against" it ( Table 3).

In order to identify the most significant factors that affect the willingness to use electronic or Internet applications for disease diagnosis, factor analysis was performed (Table 4). 


\section{Factors contributing to or impeding the development of Internet diagnostics}

\begin{tabular}{|c|c|}
\hline Factors impeding the development & Factors contributing to the development \\
\hline $\begin{array}{l}\text { - Fear of technical problems (39.5\% of respondents); } \\
\text { - Self-treatment (35\%); } \\
\text { - Incorrect diagnosis (35\%); } \\
\text { - Misleading: intentional or accidental (32\%); } \\
\text { - Incorrect state assessment ( } 30.5 \%) ; \\
\text { - Incorrect use of medicines (dosage) (22.5\%); } \\
\text { - The use of drugs that are incompatible with each } \\
\text { other ( } 21.5 \%) ; \\
\text { - Excessive use of the drug, possible allergy (20\%) }\end{array}$ & $\begin{array}{l}\text { - "Digital" generation (23\% of respondents); } \\
\text { - Maintenance of a healthy life style (26.5\%); } \\
\text { - Control of doctors' work (28\%); } \\
\text { - Unwillingness to consult a doctor (28\%); } \\
\text { - Development of self-diagnosis and self-education (34\%); } \\
\text { - Reviews and instructions of preparations }(52 \%) \\
\text { - Availability: saving time and money; in any place: } \\
\text { both at work and at home (53\%); } \\
\text { - Informative / incomplete information from doctors (56\%). }\end{array}$ \\
\hline
\end{tabular}

\section{Rotated component matrix}

\begin{tabular}{|c|c|c|c|c|c|}
\hline \multirow{2}{*}{ № } & \multirow{2}{*}{ Factors } & \multicolumn{4}{|c|}{ Component } \\
\hline & & 1 & 2 & 3 & 4 \\
\hline 1 & $\begin{array}{l}\text { Availability: saving time and } \\
\text { money; in any place: both at } \\
\text { work and at home }\end{array}$ & .613 & & & \\
\hline 2 & Informative & .595 & & & \\
\hline 3 & $\begin{array}{l}\text { Maintenance of a healthy life } \\
\text { style }\end{array}$ & .579 & & & \\
\hline 4 & $\begin{array}{l}\text { Development of self-diagnosis } \\
\text { and self-education }\end{array}$ & .551 & & & \\
\hline 5 & Incomplete information & .511 & & & \\
\hline 6 & Control of the work of doctors & & .583 & & \\
\hline 7 & $\begin{array}{l}\text { Reviews and instructions } \\
\text { of preparations }\end{array}$ & & .564 & & \\
\hline 8 & Unwillingness to consult a doctor & & .532 & & \\
\hline 9 & $\begin{array}{l}\text { Incompleteness of information } \\
\text { from doctors: lack of information } \\
\text { about the threats of the disease } \\
\text { and the possible consequences } \\
\text { of treatment }\end{array}$ & & .503 & & \\
\hline 10 & $\begin{array}{l}\text { Excessive use of the drug, } \\
\text { possible allergy }\end{array}$ & & & 622 & \\
\hline 11 & $\begin{array}{l}\text { Misleading: intentional } \\
\text { or accidental }\end{array}$ & & & .568 & \\
\hline 12 & Incorrect state assessment & & & .565 & \\
\hline 13 & Self-treatment & & & .517 & \\
\hline 14 & $\begin{array}{l}\text { Incorrect use of medicines, } \\
\text { the use of incompatible drugs }\end{array}$ & & & .512 & \\
\hline 15 & Incorrect diagnosis & & & .502 & \\
\hline 16 & Fear of technical problems & & & .480 & \\
\hline 17 & $\begin{array}{l}\text { Rapid growth of Internet } \\
\text { self-diagnostics }\end{array}$ & & & & 561 \\
\hline 18 & Digital generation & & & & .501 \\
\hline
\end{tabular}

Table 4. The final factors were included in the regression model demonstrating the impact of factors on the willingness to use electronic or online applications for disease diagnosis (willingness to use, WTU):

$$
\begin{aligned}
W T U= & 5.765+0.341 \cdot V_{1}+0.385 \cdot V_{2}- \\
& -0.275 \cdot V_{3}+0.291 \cdot V_{4},
\end{aligned}
$$

where $V_{1}$ - usefulness of electronic and/or Internet applications for diagnosis;

$V_{2}$ - control of doctors and treatment;

$V_{3}-$ incorrect diagnosis via electronic and/or Internet applications;

$V_{4}$ - commitment to the Internet.

In other words, some respondents are afraid to incorrectly diagnose or determine treatment with the help of electronic or Internet applications, which can cause a deterioration of their condition. Thus, all the conclusions made earlier are confirmed.

\section{Conclusion}

In our study, we identified the patterns of patient behavior when using electronic applications and Internet resources for selfdiagnosis, as well as factors that contribute to or impede the development of such use. To this end, the authors of the paper carried out a number of studies: qualitative content analysis of medical web applications, 40 in-depth interviews with doctors and pharmacists, a mini focus group with representatives of the health service and an online survey of two hundred respondents in the social network Facebook. 
Typical (the most common) patterns of patients' behavior regarding the use of electronic applications and Internet resources in the medical field are "traditionalists" (with "doubters" subgroup), "searchers," and "generation Y".

The percentage of citizens who are ready to practice self-diagnosis and self-treatment using electronic applications and Internet resources is significant. Thus $50 \%$ of respondents consider it right to read information about the disease or conduct a self-diagnosis before visiting the doctor, $28 \%$ of respondents have already used professional electronic applications and Internet resources in the field of medicine. "Generation Y" group, which is mostly focused on the new pattern of behavior, reaches a significant share of $30 \%$ and continues to grow rapidly.

The main drivers of growth in the use of electronic applications and Internet resources for self-diagnosis are:

$\diamond$ reluctance to see doctors (mistrust, long queues, poor service, the prescription of expensive or ineffective drugs);

increasing awareness of patient and, as a consequence, doctors' work control;

accessibility of electronic applications and Internet resources in the field of medicine;
$>$ dependence on Internet technologies and the desire to deal with the problem independently, thereby "saving time and money."

The main factors impeding the development of self-diagnosis using electronic applications and Internet resources are a high risk of incorrect diagnosis, which can be the result of (1) incorrect assessment ofone'sowncondition, (2) incomplete collection of anamnesis, (3) incomplete or incorrect semiotics (not all or excessive signs of the disease have been introduced in the program), (4) application failures. The consequence may be incorrect diagnosis or misapplication of drugs with the help of the program (allergy, excessive use, the use of incompatible drugs).

Doctors, pharmacists and consumers of medical services are favorably disposed towards Internet diagnostics, believing that this is the future of medicine.

In conclusion, considering the substantial percentage of citizens willing to engage in selfdiagnosis and self-treatment practice (using electronic applications and Internet resources and its anticipated growth), it is important to develop a set of measures to control the spread and possibly the certification of developed applications and Internet resources to minimize possible negative consequences for patients.

\section{References}

1. Greenspun H., Coughlin S. (2012) mHealth in a mWorld. How mobile technology is transforming health care / Deloitte Center for Health Solutions. Available at: https://www2.deloitte.com/content/dam/Deloitte/us/ Documents/life-sciences-health-care/us-lhsc-mhealth-in-an-mworld-103014.pdf (accessed 01 October 2017).

2. Arthur D. Little (2016) Succeeding with digital health. Winning offerings and digital transformation. Available at: http://www.adlittle.com//sites/default/files/viewpoints/ADL_2016_Succeeding_With_Digital_Health. pdf (accessed 01 October 2017).

3. Ventola C.L. (2014) Mobile devices and apps for health care professionals: Uses and benefits. Pharmacy and Therapeutics, vol. 39, no. 5, pp. 356-364.

4. Lee E., Han S. (2015) Determinants of adoption of mobile health services. Online Information Review, vol. 39, no. 4, pp. 556-573.

5. Laws D. (2015) What value does the pharmaceutical industry bring to health care? Journal of Creating Value, vol. 1, no. 1, pp. 79-90.

6. Jutel A., Lupton D. (2015) Digitizing diagnosis: a review of mobile applications in the diagnostic process. Diagnosis, vol. 2, no. 2, pp. 89-96.

7. Khuntia J., Yimb D., Tanniru M., Lim S. (2017) Patient empowerment and engagement with a health infomediary. Health Policy and Technology, vol. 6, no. 1, pp. 40-50.

8. Carman K.L., Workman T.A. (2017) Engaging patients and consumers in research evidence: Applying the conceptual model of patient and family engagement. Patient Education and Counseling, vol. 100, no. 1, pp. $25-29$. 


\section{Developing a new tariff plan of a telecommunications company taking into account subscribers' and investors' preferences}

\section{Tatiana K. Bogdanova}

Associate Professor, Department of Business Analytics

National Research University Higher School of Economics

Address: 20, Myasnitskaya Street, Moscow, 101000, Russian Federation

E-mail: tanbog@hse.ru

\section{Dmitry Y. Neklyudov}

Data Analyst, Department of Big Data, StandardProject Ltd.;

Senior Lecturer, Department of Business Analytics

National Research University Higher School of Economics

Address: 20, Myasnitskaya Street, Moscow, 101000, Russian Federation

E-mail:dyuneklyudov@hse.ru

\section{Olga M. Uvarova}

Leading Expert, Laboratory of Enterprise Competitiveness Problems Analysis

Senior Lecturer, Department of Business Analytics

National Research University Higher School of Economics

Address: 20, Myasnitskaya Street, Moscow, 101000, Russian Federation

E-mail: ouvarova@hse.ru

\section{Abstract}

The market of telecommunication services and its evolution has an essential impact on development strategies of all industries. In recent times, we observe a tendency for the operators' business to shift from providing communications services to supplying integrated ICT services. A positive trend line of market growth is predicted for the coming five years. However, the problem of keeping and even expanding the subscriber base is an ongoing task of all telecom companies. One of the possible solutions to this problem is developing a rational tariff policy, which may take into consideration not only the interests of the company and its investors, but also the subscribers' preferences. One of the main components of the tariff policy is developing new tariff plans, which meet the afore-mentioned requirements.

In the paper, a new concept of tariff plan development is proposed. It is based on identifying stable groups of existing tariff plans and subscribers' preferences that are non-linearly related with tariff plan characteristics. The proposed method is based on the concept of client lifetime value (CLV) that characterizes discounted profit received from a customer during all the time he consumes services from the company. This approach gives us an opportunity to build-up a CLV forming model, relying on subscriber's consumption of mobile services and price characteristics of tariff plans. This seems quite important in the conditions of volatility of the high tech market and intensive changes in patterns of subscribers' consumption of services.

Within the proposed concept, an info-logical model for developing and evaluating a new tariff plan is developed. The model is based on the synthesis of neural networks and genetic algorithm. The proposed model allows us to make assessment of combinations of tariff plans' price characteristics 
created by telecom company specialists, and to determine an optimal combination representing local or global maximum of CLV in the given time interval. This may be done for each subscriber's consumption profile and for the given period.

The approach gives us an opportunity to choose a tariff plan (from existing and newly created tariffs) for every subscriber cluster, which satisfies subscribers and investor preferences while providing maximum company profit.

Key words: telecommunications company, telecommunications service market, tariff plan, subscribers' preferences, subscriber consumption profile, client life-time value, intelligent methods of data analysis, clustering, modeling, tariff policy, neural network, genetic algorithm.

Citation: Bogdanova T.K., Neklyudov D.Y., Uvarova O.M. (2018) Developing a new tariff plan of a telecommunications company taking into account subscribers' and investors' preferences.

Business Informatics, no. 1 (43), pp. 39-49. DOI: 10.17323/1998-0663.2018.1.39.49.

\section{Introduction}

$\mathrm{I}$ $\mathrm{n}$ the opinion of most analysts, the market of telecommunications services is one of the most technological and competitive markets in Russia. Its development has an extremely high impact on the economy of the whole country. Most telecom operators have come to the conclusion that the future belongs to wireless networks. The technology of $5 \mathrm{G}$ networks is still under development: approval of the standards is planned not earlier than in 2019, and availability of commercial applications - only in 2020. However, telecom operators are actively promoting this technology because they understand that in the future it may provide essential competitive advantages.

According to the TMT Consulting analytical agency, after the long recession the growth rate of telecommunication companies' income has shown positive trends over the last two years [1]. Such accelerated rates became possible because of the growth of the mobile communications segment, which was caused by several reasons: refusal to engage in price competition, avoiding unlimited tariffs, as well as high dynamics of profit from additional services in the segment of corporate clients. For these reasons, in Q3 2017 all the "big three" operators for the first time showed the positive growth of average revenue per user (ARPU) [2], which is the most important metric for the commercial activity of a telecommunications company (Figure 1).

At the same time, the trend of 2016 towards reducing inter-operator services and fixed phone communications is continuing to exert a negative influence on market dynamics. We see this in declining popularity of fixed communications services and falling ruble profit from rendering inter-operator services to foreign operators (Figure 2).

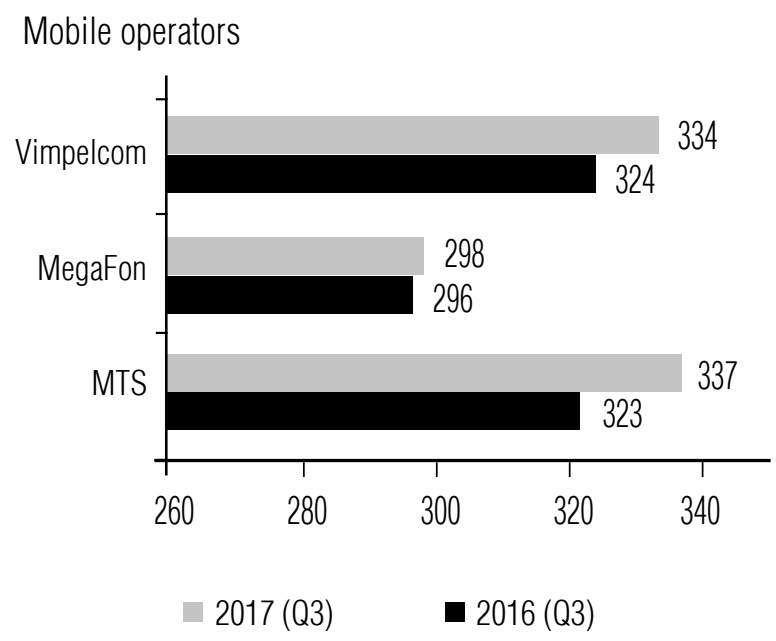

Fig. 1. ARPU of the federal mobile operators Russian Federation (rubles) 


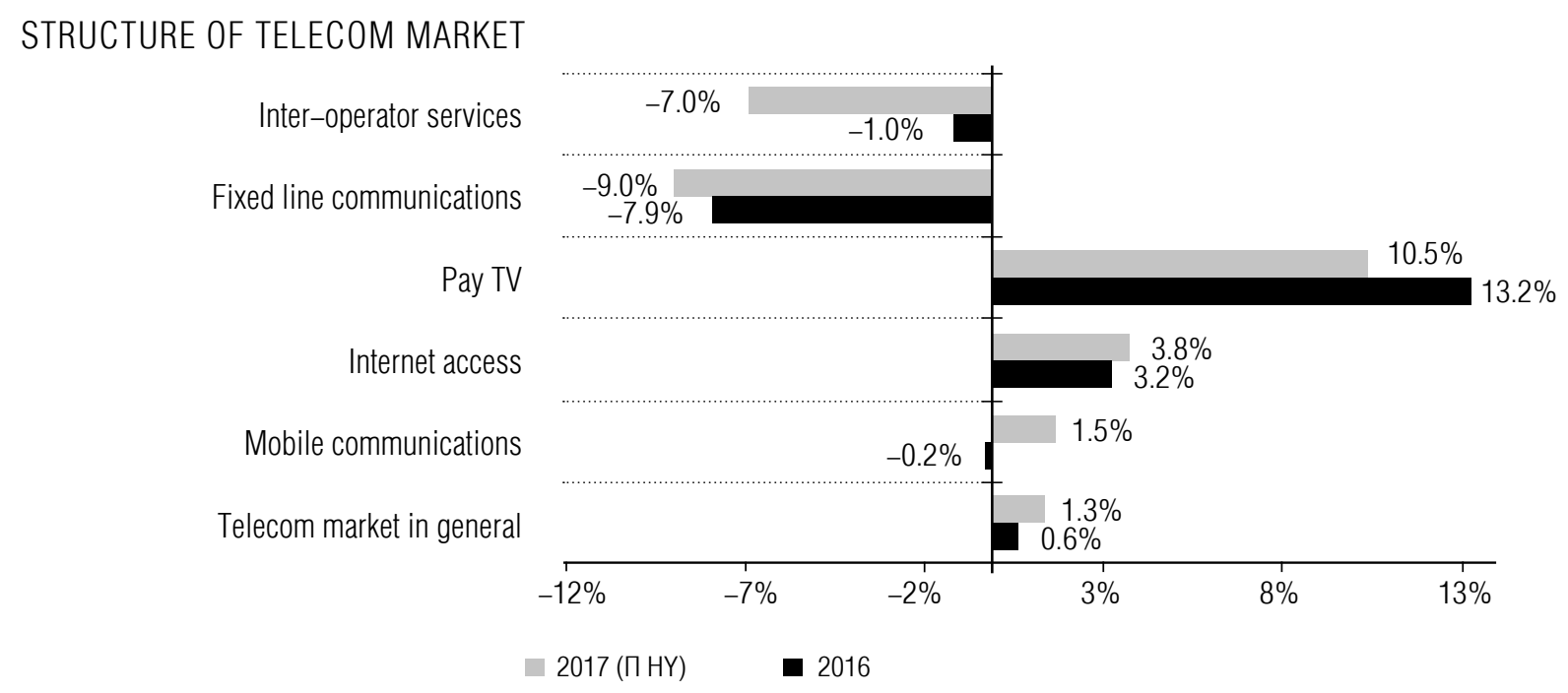

Fig. 2. Trend lines of the various segments of the telecommunication service market

According to preliminary data provided by TMT Consulting [1], subscriber base growth is continuing: in 2016 it was only $0.6 \%$, but in 2017 the number of mobile communications subscribers increased by $1.7 \%$ to 260 million. For all the mobile operators, there is a tendency of transformation from communications providers into suppliers of integrated ICT services including system integration, services of data centers and cloud computing among others. Service packages allow subscribers to pay less for each of the components and provide growth of profit per user, as well as increasing subscribers' loyalty to the operator. The tactics for keeping subscribers, as well as expanding the client base and offering them more attractive (in comparison with competitors) conditions on a permanent basis (instead of short-term marketing actions) strengthens price rivalry on the telecommunications services market. Forming a rational regional tariff policy of a telecommunications company, taking into consideration consumption profiles of subscriber clusters and investors' preferences is the main task for any company to gain competitive advantages. For that reason, it is an timely task to develop tariff plans which, taking into consideration subscribers' preferences, will not only earn profits for a telecommunications company but also will contribute to keeping subscribers, i.e. retaining the subscriber base [3].

The process of developing a new tariff plan is very labor consuming. As a rule, it isn't formalized; rather it depends on experience and intuition of the developer, who also has some information about competitors' novelties. So any even partial automation of this process provides an opportunity not only to reduce the development time, but also to receive an instrument that helps to assess quite objectively the target audience for which the new tariff plan can be attractive. Therefore, it is an opportunity to reduce the company's expenses related to new tariff plan development and implementation.

\section{Clustering of subscribers}

It is argued in [3] that shaping the tariff policy of a telecommunication company requires taking into consideration not only interests of certain subscribers, but also interests of subscriber groups having similar consumption characteristics and profiles. Additionally, it is necessary to consider investors' 
requirements regarding time intervals during which their profit should be maximized. A distinguishing feature of this method is that forming the subscriber profile is based only on quantitative characteristics of the traffic used, as well as shares reflecting the internal structure of telecom services consumption. Subscribers' socio-demographic characteristics are not taken into consideration. This method relies on the fact that the subscriber base is not a range of individual customers with certain socio-demographic characteristics, but a set of SIM (subscriber identification module) cards, any of which is characterized by a certain set of parameters. This allows us to avoid possible mistakes of clustering using subscribers' socio-demographic characteristics, because each person can have several SIM cards and, on the other hand, a registered user and a real customer may be different persons.

Information about consumer characteristics of each subscriber, which is available in any telecommunications company, contains factors which often are closely interrelated. Thus, when describing consumer profiles of the subscribers it is reasonable to make clustering using not information stored in a telecommunications company's data base, but independent latent variables (factors) which can be received using factor analysis or the method of principal components.

The procedure of forming subscriber clusters with similar consumption characteristics includes two steps. In the first step, relying on subscribers' initial characteristics (duration of voice calls within the same cellular network or using competitor networks, volume of SMS messages, traffic volume, etc.) and with the use of factor analysis, independent behavioral factors are identified. In the second step subscribers' consumer profiles, which represent a basis for subscriber clustering, are identified.

Each telecommunications company tries to maximize the profit it earns through its tar- iff policy. As the main metric for determining profitability of a telecommunication company, in the paper [3] a client life-time value (CLV) is proposed. This indicator shows discounted profit received from the client during all the time he consumes the company's services. On the one hand, CLV characterizes profitability of a telecommunication company (i.e. represents the company's interests), on the other hand, the indicator reflects subscriber preferences that are characterized by outflow of customers. Subscriber outflow is the main point showing the loyalty of the company's subscribers, because it is directly related with subscribers' level of satisfaction with the company's activity.

\section{Clustering of tariff plans}

The characteristic of subscriber preferences is the price of those tariff plans which are used by any company subscriber. However calculating the real price of a tariff plan is a tough task because it includes many subtleties of the mobile services offering, for example, bonuses, discounts, as well as different services and packages modifying the tariff plan price. Furthermore, tariff plans are permanently corrected by the company. From time to time modifications are issued, and new tariff plans are developed. Therefore, there are a number of tariff plans offered by a telecommunications company, which may exist simultaneously. However, not all of them are available by open access for subscribers.

It is proposed in [3] that instead of the declared prices of tariff plans selected by subscribers, it is reasonable to use the ratio of total charges from every subscriber to the total traffic consumed by the client. Therefore, it is possible to get the real price of each product consumed by all the subscribers for any tariff plan. Like in the case of subscriber clusters formation, developing tariff plan groups is related to the problem of multi-collinearity of primary financial characteristics of a tariff plan. Thus, 
for identifying tariff plan groups with similar characteristics it is recommended to perform clustering relying on latent independent variables (factors) determined using the principal components method.

The procedure of tariff plan clustering includes two steps. In the first step, independent pricing factors are determined, using factor analysis based on tariff plans initial characteristics (cost of one minute of voice traffic within the mobile network or using competitors' networks, cost of SMS messages, cost of Internet traffic, etc.). In the second step, stable tariff plan groups (clusters) are identified with the help of clustering methods.

Execution of this model gives us an opportunity to form a few permanent tariff plan clusters with significant differences in pricing characteristics.

Using different tariff plans has impact on clients' satisfaction and on the company's profitability. Therefore, CLV should be different for the same subscriber when using different tariff plans. In order to determine a tariff plan that is optimal for a certain subscriber (and that, in turn, increases mutual benefits from the collaboration between a mobile company and the subscriber), it is necessary that the subscriber use each of the tariff plans within the same conditions. However, for a certain subscriber such a practice seems impossible.

That is why, instead of considering how different tariff plans are used by a certain subscriber, it is possible to analyze consumption profiles that characterize a subscriber group with similar behavioral features. This allows us to compare different tariff plan using subscriber groups with similar consumption characteristics. From the point of view of the mobile company and its subscribers, a tariff plan that provides maximal CLV for each subscriber cluster is optimal, because its characteristics take into account subscriber preferences, while the company earns maximum profit.

\section{Developing a new tariff plan}

All of the foregoing considerations concern already existing tariff plans. However, one of the main streams in a telecommunications company's tariff policy is developing new tariff plans. The reasons that force the company to develop new tariff plans are serious rivalry on the telecommunications market, the high-tech nature of the market, as well as active changing of subscribers' consumption paradigms relating to services on offer.

The concept for formation of new tariff plans of a telecommunications company proposed by the authors is based on identifying stable groups of existing tariff plans, as well as subscriber preferences that are non-linearly related with the tariff plan characteristics. This allows us to create a CLV forming model that relies on consumption of mobile services by subscriber and tariff plan pricing characteristics. This concept is based on subscriber value (CLV) analysis according to subscriber consumption profile, tariff plan characteristics and planning period. The planning period characterizes investors' preferences because when setting it the investor determines the period within which he intends to get a return on his investments.

For implementation of a new tariff plan, it is necessary to have a formalized understanding of subscriber preferences regarding tariff plans. In other words, it is necessary to know the price of a single traffic unit and average traffic per subscriber for each subscriber consumption profile and for each existing tariff plan. Using regression analysis [4-6] and a pre-defined set of a tariff plan characteristics, it is possible to develop a model for predicting CLV. The model would determine discounted profit gained from the subscribers of a certain consumption profile, during all time they consume the company's services [7]. The CLV indicator also characterizes subscriber satisfaction regarding relations with the company, because it allows us to account for the 
share of subscribers outflows during the analyzing time period [8]. The developed regression model also provides useful information for a telecommunications company about the tariff plan characteristics that are most important for each subscriber cluster.

Using tariff plan groups for regression model based CLV forecasting would give results that are more precise. However, if the total number of tariff plan groups is relatively small, it is preferable to develop a model relying on all the company's existing tariff plans.

Assessment of a new tariff plan is performed relying on CLV calculation for each subscriber cluster according to the formula:

$$
C L V_{i}^{\prime}=\sum_{e=1}^{E_{i}} w_{e i} \cdot x_{e i},
$$

where $C L V_{i}^{\prime}$ - projected CLV of the $i$-th subscriber cluster, $i=1, \ldots, I$;

$w_{e i}$ - coefficient of multiple linear regression, based on the sample of existing tariff plans in the $i$-th subscriber cluster, $e=1, \ldots, E_{i}, i=1$, ..., I;

$x_{e i}$ - regressor showing one of the tariff plan's pricing characteristics that is valuable for the $i$-th subscriber cluster, $e=1, \ldots, E_{i}, i=1, \ldots, I$;

$E_{i}$ - number of valuable regressors of the $i$-th subscriber cluster, $i=1, \ldots, I$;

$I$ - total number of subscriber clusters.

If financial characteristics are unrestricted, description of pricing preferences using regression functions do not allow us to develop a new tariff plan. A new tariff plan includes hardly formalized parameters, and it makes the task of automated formation quite difficult. The number of pricing characteristics that describe a tariff plan can be large. At the same time, subscriber attitudes to pricing characteristics are variable depending on their level. This probably will be expressed by a non-linear relationship between CLV and the tariff plan's pricing characteristics. Solution of this task is possible using a neural network $[9,10]$ because this method automatically allows us to consider nonlinear relations between parameters. Mathematical principles incorporated in the algorithm are similar to the working of the human brain, and this feature provides greater flexibility of data analysis. Another considerable advantage of the neural network is the universality of its application for processing data of different types. Therefore, application of this method allows us to develop a neural network based model which may help to discover interrelations between tariff plan financial characteristics and CLV for all subscriber clusters.

There are two main disadvantages of neural networks. The first is the high probability of retraining the algorithm, because of considering too precise characteristics of nonlinear relationships. This problem is especially relevant for small datasets. For formation of the neural network, information is used that characterizes tariff plans for all planning sub-periods and for all consumer profiles of subscribers (i.e. the sample is quite small), so the problem of re-training is timely.

The second disadvantage is complexity of understanding and logical analysis of the identified relations, even if the number of neurons is equal to three. Taking into consideration that the number of neurons depends on the number of parameters and, as a rule, is much more than three, description of the neural network and analysis of its parameters are practically impossible.

As a result of the second disadvantage for the task "creating an optimal tariff plan for each subscriber cluster and for all the periods, using neural network," it is impossible to calculate combinations of financial characteristics which are estimated by the neural network as CLV maximum. However, for this task this disadvantage of the neural network algorithm is not so important, because the purpose of the research is not to explain the influence of financial characteristics on CLV, but to determine the optimal group of tariff plans for subscribers, with subsequent forming of tariff policy. 
It is possible to get an optimal combination of financial characteristics applying an heuristic algorithm that is able to select such a combination of financial parameters, which will be considered by a trained neural network as CLV maximum for given subscriber clusters during the given planning period. The task may be solved using any heuristic algorithm, including genetic algorithm that at present is quite popular.

The most valuable advantages of genetic algorithms include the possibility of global extremum search, universality in working with indicators being optimized, as well operating speed.

A genetic algorithm is a mechanism of evolutionary calculations (or heuristic optimization) which is developed by analogy with the natural selection process created by the nature. The main mechanism of genetic algorithms includes several steps.

In the first step, a set of genes described by the set of chromosomes (for example, the tariff plan characteristics) is formed. All the characteristics are defined randomly.

In the second step, it is necessary to assess each gene (for example, it is possible to analyze tariff plan characteristics with the help of a trained neural network) and to get a quantitative measure of this gene's quality (it is usually called the "gene's fitness").

In the third step, a new set of genes (or a new generation) based on the previous gene generation is formed. Each gene has its own probability to put its chromosomes into genes of the next generation. This probability depends on the results of assessment of this gene's quality. The formation of each descendant of a new generation is based on two predecessors of the previous generation. Descendants' genes are crossed (usually it is said that crossover is available), and a new unique chromosome set of a new gene, composed by the predecessors' elements, is created.

In the fourth step, formed gene descendants in casual chromosomes are stochastically changed (or mutated). It is the step which gives new information included into genes.

All the steps from the second to the fourth are processed iteratively, while a pre-defined stopping criterion will be reached [11].

There are many variants to make the algorithm more complicated. They allow us to search the optimum faster and to increase the probability of finding the global extremum. However, the general principle of the algorithm remains the same.

The general procedure for forming a new tariff plan is as follows. First of all, relying on determined earlier sets of subscriber clusters and tariff plans, as well as identified investor preferences, a CLV calculation is performed. This is done for each tariff plan cluster and each subscriber cluster, and for all the periods of tariff policy planning. Then formation and training of a neural network for CLV prediction is executed. It is done for each subscriber cluster according to the planning period and tariff plan financial characteristics. Then, using a trained neural model, existing and possible new tariff plans are assessed. The tariff plans characteristics are entered into the trained model. Then with the help of the genetic algorithm we heuristically select the optimal combination of tariff plan characteristics. This may become a basis for forming a new tariff plan of the mobile company.

\section{Approval of the method of developing a new tariff plan for a telecommunication company on the real data}

Approval of the proposed method of developing a new tariff plan for a telecommunications company was executed using IBM SPSS Modeler 19.0 on an informational base containing $2,356,753$ observations of 232,451 unique subscribers in Moscow and the Moscow Region, which is $2.5 \%$ of the subscriber base of the company. This sample represents monthly collected data for the period from 1 January 2011 to 31 December 2014. 
The total number of variables characterizing subscriber consumption which were used for identifying subscriber profiles equal 103. To determine profiles of subscriber consumption (subscriber clusters) 34 characteristics were used. They represent main traffic channels (voice traffic, Internet traffic, SMS traffic) and are described by the following set of properties:

$\downarrow$ direction of communications: incoming or outgoing traffic;

$\downarrow$ subscriber geography: local area connection, national roaming, international roaming;

v call geography: local area call, call in Russia, international call;

$\checkmark$ receiving operator: call in the same mobile network, call using competitor networks, call to stationary phone numbers.

Each characteristic may be expressed either in natural units, or by a ratio.

As the primary characteristics are multi-collinear, relying on them, using principal components method, 14 independent latent variables (factors) were identified. On the basis of these 14 factors and self-organized Kohonen cards [12] subscriber clustering was done. It allowed us to discover 24 profiles of different subscriber behavior, with significant differences ( $p$-value $<0.01$ ) regarding both the 14 factors and 34 source variables.

For identifying tariff plan groups with similar financial characteristics, 14 indicators of subscriber traffic tariffing were used. They include: cost of one megabyte of Internet traffic, cost of one SMS, cost of one minute of local and international calls, etc. The total number of tariff plans considered was 198. For identifying permanent groups of tariff plans relying on these financial characteristics, in the paper [3] it is recommended to use independent latent variables (factors). Using the method of principal components, five independent factors characterizing a tariff plan were identified:

$\diamond$ factor $1-$ the need for extensive cheap communications within Moscow; factor 2 - the need for extensive cheap communications and roaming within Russia and CIS;

$\diamond$ factor 3 - the need for international communications and roaming (except CIS countries);

$\diamond$ factor $4-$ cost of SMS messages;

$\diamond$ factor $5-$ cost of access to Internet.

Relying on these independent factors and using Kohonen maps [12] clustering of the 83 most popular tariff plans from 198 existing ones was executed. As a result, 11 permanent groups of tariff plans were discovered. These groups differ considerably from each other and have similar internal cluster characteristics.

There are the following tariff plans groups that were identified:

$\diamond$ unlimited and packaged tariff plans;

$\checkmark$ packaged tariff plans that includes direct city area phone number;

$\downarrow$ per-minute tariff plans with a common rate;

$\checkmark$ per-minute tariff plans targeted to CIS;

$\diamond$ Internet tariff plans;

$\downarrow$ Internet tariff plans with possibility of voice calls, targeted on regions;

$\uparrow$ per-second tariff plans;

$\checkmark$ tariff plans targeted to Moscow city;

$\downarrow$ two groups of specific non-popular tariff plans.

Analysis of the determined clusters according to major characteristics (Internet traffic, voice traffic, CLV, average subscriber lifetime) allowed us to draw the following conclusions. Subscribers of the 11-th cluster consume only Internet traffic: 6.8 GB per month in average, which is significantly more than in any other cluster. Meanwhile, voice traffic consumption is 10 minutes, CLV is 730 rubles and average subscriber lifetime is 20.5 months. Subscribers from clusters with numbers $4,6,8,10,15,18$ and 21 have high voice traffic consumption (from 338 till $601 \mathrm{~min}$ - 
utes) and very low Internet traffic consumption (from 74 till $200 \mathrm{MB}$ ). Subscribers from clusters 22,23 and 24 are characterized by very low consumption of telecommunications services (less than 72 minutes of voice traffic and less than $124 \mathrm{MB}$ of Internet traffic). Subscribers from clusters 1, 2 and 3 have the greatest need of telecommunications services consumption: average voice traffic consumption is from 739 to 909 minutes, and Internet traffic consumption - from 329 to 462 MB. As parameters for clustering, we used the characteristics of telecommunications services consumption, while all the clusters also significantly differ from each other by CLV.

Calculations of CLV for different planning horizons according to identified subscriber clusters and tariff plan groups showed that Z-values of average CLV for different tariff plans groups are very different for the same subscriber cluster than is characterized by certain type of consumption. For example, for the first subscriber cluster Z-value of average CLV varies from -0.4 to 6.3 , for the 3 -rd cluster - from -0.4 to 5.9 , for the 4 -th - from -0.4 to 5.4 . It should be noted that there are groups of tariff plans which have permanently low Z-value of average CLV, regardless the subscriber cluster. For example, for the 9-th group of tariff plans the confines are from -0.8 to 0.4 , and for the 10 -th group - from -0.8 to -0.1 .

Table 1 shows us that the same group of tariff plans provides maximum profit for the majority of the subscriber clusters, regardless of the specified period. However, there are clusters where maximum profit is gained with the use of different groups of tariff plans (e.g. clusters 1 and 20).

Thus, for the first subscriber cluster and planning periods of one to three years, the maximum value of CLV is reached using the 3-rd tariff plan group. However, for the four years planning period the 1 st tariff plan group is preferable, as the most profitable. For the 20 -th subscriber cluster and planning period of one year, the maximum value of CLV is reached using the first tariff plan group, and for other periods - using the 9-th tariff plan group. The results partially confirm the advanced hypothesis that for different planning periods and for each subscriber cluster the most profitable tariff plans groups may be different.

For tariff plans groups with numbers 2, 4, 6, 8,10 and 11 for all the subscriber clusters the maximal CLV is not greater than average value for any of the planning periods. Hence, it is possible to draw the conclusion that the mobile operator should consider replacing these tariff plans with other ones which, on the one hand, may bring maximum profit in any planning period and, on the other hand - take into account subscriber preferences.

The model of CLV estimation depending on financial characteristics of tariff plans was realized in practice using IBM SPSS Modeler 19.0 software. The model included the following stages. First of all, $5 \%$ of the most unpopular tariff plans for each subscriber cluster were excluded from subsequent consideration. Then, for each subscriber cluster and each planning period, a neural network was developed for CLV forecasting taking into consideration tariff plan financial characteristics, as well as subscriber and investor preferences regarding new tariff plans. Then this neural network was used by a genetic algorithm developed as a Windows application on $\mathrm{C} \#$ language, to discover optimal combination of tariff plan financial characteristics that provide maximum value of CLV.

By analyzing the results received, it is possible to make a justifiable decision regarding reasonability of using a certain tariff plan for each subscriber cluster. This allows management to focus marketing activities on popularization of these tariff plans among subscribers of the appropriate subscriber clusters. 
Relations between subscriber clusters, tariff plan groups

Table 1. and $Z$-values of the average CLV for different periods of profit calculation

\begin{tabular}{|c|c|c|c|c|c|c|c|c|}
\hline \multirow{3}{*}{$\begin{array}{l}\text { Subscriber } \\
\text { clusters }\end{array}$} & \multicolumn{8}{|c|}{ Profit calculation period } \\
\hline & \multicolumn{2}{|r|}{1 year } & \multicolumn{2}{|r|}{2 years } & \multicolumn{2}{|r|}{3 years } & \multicolumn{2}{|r|}{4 years } \\
\hline & $\mathrm{TP}^{1}$ & $\begin{array}{l}\text { Z-values of } \\
\text { average CLV }\end{array}$ & TP1 & $\begin{array}{l}\text { Z-values of } \\
\text { average CLV }\end{array}$ & TP1 & $\begin{array}{l}\text { Z-values of } \\
\text { average CLV }\end{array}$ & TP1 & $\begin{array}{l}\text { Z-values of } \\
\text { average CLV }\end{array}$ \\
\hline 1 & 3 & 1.6 & 3 & 2.5 & 3 & 3.0 & 1 & 3.2 \\
\hline 2 & 1 & 0.6 & 1 & 0.9 & 1 & 1.2 & 1 & 1.4 \\
\hline 3 & 1 & 0.7 & 1 & 1.1 & 1 & 1.4 & 1 & 1.7 \\
\hline 4 & 1 & 0.9 & 1 & 1.3 & 1 & 1.5 & 1 & 1.7 \\
\hline 5 & 1 & 0.1 & 1 & 0.3 & 1 & 0.4 & 1 & 0.6 \\
\hline 6 & 1 & 0.1 & 1 & 0.4 & 1 & 0.5 & 1 & 0.5 \\
\hline 7 & 1 & 0.1 & 1 & 0.4 & 1 & 0.6 & 1 & 0.7 \\
\hline 8 & 1 & 0.6 & 1 & 1.0 & 1 & 1.5 & 1 & 1.8 \\
\hline 9 & 1 & -0.1 & 1 & 0.1 & 1 & 0.3 & 1 & 0.4 \\
\hline 10 & 1 & -0.2 & 1 & -0.0 & 1 & 0.1 & 1 & 0.2 \\
\hline 11 & 7 & 0.3 & 7 & 0.6 & 7 & 0.7 & 7 & 0.8 \\
\hline 12 & 5 & -0.1 & 5 & 0.1 & 5 & 0.2 & 5 & 0.2 \\
\hline 13 & 1 & -0.1 & 1 & 0.1 & 1 & 0.2 & 1 & 0.3 \\
\hline 14 & 5 & -0.2 & 5 & -0.0 & 5 & 0.1 & 5 & 0.1 \\
\hline 15 & 1 & 0.0 & 1 & 0.2 & 1 & 0.4 & 1 & 0.5 \\
\hline 16 & 1 & -0.4 & 1 & -0.3 & 1 & -0.3 & 1 & -0.3 \\
\hline 17 & 5 & -0.3 & 5 & -0.2 & 5 & -0.1 & 5 & -0.0 \\
\hline 18 & 1 & -0.1 & 1 & 0.1 & 1 & 0.2 & 1 & 0.4 \\
\hline 19 & 1 & -0.2 & 1 & -0.1 & 1 & 0.0 & 1 & 0.1 \\
\hline 20 & 1 & -0.3 & 9 & -0.2 & 9 & -0.1 & 9 & -0.1 \\
\hline 21 & 1 & -0.3 & 1 & -0.2 & 1 & -0.1 & 1 & 0.0 \\
\hline 22 & 1 & -0.6 & 1 & -0.5 & 1 & -0.5 & 1 & -0.4 \\
\hline 23 & 5 & -0.7 & 5 & -0.6 & 5 & -0.6 & 5 & -0.5 \\
\hline 24 & 1 & -0.6 & 1 & -0.6 & 1 & -0.6 & 1 & -0.6 \\
\hline
\end{tabular}

${ }^{1}$ Group number of tariff plans that ensured maximum profit for the specified period 


\section{Conclusion}

During the research, we developed models of forming subscriber clusters (relying on the set of subscriber characteristics) and clustering tariff plans (relying on financial characteristics), using smart methods of data analysis. In contrast with other approaches, the set of subscriber characteristics includes only financial characteristics of subscribers' consumption and does not take into account socio-demographic characteristics of a company's clients.

Relying on the CLV characteristic, we discovered a relationship between clusters of subscriber consumption and tariff plans groups. As a result, we have proposed an approach to form- ing and estimating a tariff plan which provides the maximum value of CLV. The approach is based on subscriber profiles and investor preferences. We also have developed an IT tool (a Windows application written on $\mathrm{C} \#$ language) for assessing identified preferences of subscribers and investors of telecommunications companies while forming new tariff plans.

A proposed model for developing new and assessing existing tariff plans of a telecommunications company is based on the synthesis of a neural network and a genetic algorithm. The model was approved on a sample of $2,356,735$ observations covering the period from 1 January 2011 to 31 December 2014.

\section{References}

1. TMT Consulting (2018) Rossiyskiy rynok telekommunikatsiy: predvaritel'nye itogi 2017 goda [Russian telecom market: Preliminary results of 2017]. Available at: http://tmt-consulting.ru/wpcontent/uploads/2017/12/\%D0\%A2\%D0\%9C\%D0\%A2-\%D1\%82\%D0\%B5\%D0\%BB\%D0\%B5\%D0 $\%$ BA\%D0\%BE\%D0\%BC-20171.pdf (accessed 15 January 2018) (in Russian).

2. Kuzovkova T.A., Timoshenko L.S. (2009) Analiz i prognozirovanie razvitiya infokommunikatsiy [Analysis and forecasting of info-communications development]. Moscow: Hot Line - Telecom (in Russian).

3. Bogdanova T.K., Neklyudov D.Yu. (2016) Improvement of a telecommunications company tariff policy taking into account subscribers' preferences. Business Informatics, no. 2 (36), pp. 7-15.

4. Aivazyan S.A., Mhitaryan V.S. (1998) Prikladnaya statistika i osnovy ekonometriki [Applied statistics and fundamentals of econometrics]. Moscow: UNITY (in Russian).

5. Ershov E.B. (2008) Vybor regressii, maksimiziruyushchey nesmeshchennuyu otsenku koeffitsienta determinatsii [Selecting regression maximizing unbiased estimate of coefficient of determination]. Applied Econometrics, vol. 12, no. 4, pp. 71-83 (in Russian).

6. Kryshtanovsky A.O. (2000) Ogranicheniya metoda regressionnogo analiza [Limitations of regression analysis method]. Sociology: Methodology, Methods, Mathematical Modeling, no. 12, pp. 96-112 (in Russian).

7. Berger P.D., Nasr N.I. (1998) Customer lifetime value: Marketing models and applications. Journal of Interactive Marketing, vol. 12, no. 1, pp. 17-30.

8. Andreeva A.V. (2012) Optimal'noe upravlenie klientskoy bazoy na osnove pokazatelya dolgosrochnoy stoimosti klienta [Optimal control of a company's customer base using the customer lifetime value parameter]. Business Informatics, no. 4 (22), pp. 61-68 (in Russian).

9. Osowski S. (2002) Neyronnye seti dlya obrabotki informatsii [Neural networks for information processing]. Moscow: Finance and Statistics (in Russian).

10. Haykin S. (2006) Neyronnye seti: polnyy kurs [Neural networks: A comprehensive foundation]. Moscow: Williams (in Russian).

11. Kureychik V.V., Kureychik V.M., Rodzin S.I. (2012) Teoriya evolyutsionnykh vychisleniy [Theory of evolutionary computations]. Moscow: Fizmathlit (in Russian).

12. Kohonen T. (2008) Samoorganizuyushchiesya karty [Self-organizing maps]. Moscow: BINOM. Laboratory of Knowledge (in Russian). 


\title{
Design patterns of communication messages for promoting software products on the corporate market ${ }^{1}$
}

\author{
Yuriy P. Yekhlakov \\ Professor, Head of Department of Data Processing Automation \\ Tomsk State University of Control Systems and Radioelectronics \\ Address: 40, Prospect Lenina, Tomsk, 634050, Russian Federation \\ E-mail: upe@tusur.ru
}

\section{Elena K. Malakhovskaya}

Assistant Professor, Department of Data Processing Automation

Tomsk State University of Control Systems and Radioelectronics

Address: 40, Prospect Lenina, Tomsk, 634050, Russian Federation

E-mail:elena_tusur@mail.ru

\begin{abstract}
On the basis of conditions of low-budget software product promotion on the market, applied aspects of semiotics, methods of artificial intelligence and the results of practical experience of advertising agencies with Internet advertising for promotion on the corporate market of goods and services, this article proposes a method for developing design pattern for creating the content of communication messages (CM). The article presents a semantic network which describes the model for developing CM design patterns. It identifies key network concepts: the software product, consumer properties, positioning strategy, potential consumers, consumer preferences, features of information perception, a unique proposal, message distribution tools. Associative links between concepts are described. Elements of a semantic network dictionary are offered: the object of definitions, the characteristics of objects, the semantic units of characteristics; semantic unit description of lexical construction dictionary elements - target, key, alternative. Target lexical constructions describe and specify the format of the advertising message in the template. Key lexical constructions determine unique characteristics of the objects' concept. Alternative lexical constructions are designed to strengthen the influence of semantic units and to exert additional impact on potential users. Communication message templates are combinations of semantic units with suggested messages that are most likely to motivate consumers to take certain actions.

For practical approval of the use of templates for designing $\mathrm{CM}$ in product promotion to the corporate market, a multi-layered production semantic network has been developed. Network layer multiplicity matches a variety of concepts. Each layer consists of a set of objects that reflect the qualitative composition of the layer. The procedure for selecting variants of communication message templates is a non-cyclic chain of the semantic network using production rules. There are consistently selected elements: the representative of the target audience, the type of consumer behavior, the positioning strategy, the tool for disseminating communication messages, the structural element of communication messages. The results obtained can be useful for directors and managers of small IT companies in organizing Internet advertising of their products.
\end{abstract}

\footnotetext{
${ }^{1}$ The work is conducted under the government assignment of the Ministry of Education and Science of the Russian Federation, project No. 8.8184.2017/8.9
} 
Key words: marketing communications, software product, low-budget advertising techniques, corporate market, communications report, design pattern, semantic network.

Citation: Yekhlakov Y.P., Malakhovskaya E.K. (2018) Design patterns of communication messages for promoting software products on the corporate market. Business Informatics, no. 1 (43), pp. 50-60.

DOI: $10.17323 / 1998-0663.2018 .1 .50 .60$.

\section{Introduction}

T The financial health of any IT company greatly depends on the quality of their advertising activities when promoting their products and/or services. One of the ingredients of success in this matter is an effective marketing communication strategy which not only draws attention of the target audience to the software and communicates its competitive advantages but also encourages its approval and purchase. A key component of communication is a communication message, which should be understood as information disseminated by an advertiser while communicating with potential customers to get their attention and produce a certain type of response. The main challenge of designing communication message content consists in selecting the proper information which will reach a potential customer in a particular form via particular channels and by use of particular instruments [1].

Larger IT companies with bigger budgets hire marketing specialists or specialized agencies to address this issue [2]. At the same time, there are small IT companies (groups of like-minded people, "startups", etc.) on the market which have neither the financial resources nor the marketing expertise to make a quality promotion for their software: self-made ads usually describe the software's functionality, use the language of developers, while they do not communicate the product's competitive advantages to the consumers. Low-budget marketing, an increasingly popular technique, could be one of the promising solutions for this problem [3, 4].

Inline with the aforementioned conditions, this article proposes an approach to organizing lowbudget marketing communications to promote software products to the corporate market. This approach is based on ideas of semiology as one of the key parts of communication theory, methods of artificial intelligence and communication message patterns to promote software products within a field of expertise.

The essentials of semiology as the study of signs and the formation and functionality of sign-systems that can store and communicate information between a "sender" (seller) and a "recipient" as they build their relationship, have been outlined in the works of such scientists as R. Barthes, A.F. Losev, Y.M. Lotman, F. de Saussure among others. The applied aspects of semiotics play a crucial part in forming a communication message and assessing the effectiveness of its impact on recipients; they have been amply described in various works [5-8]. The use of certain syntactic units in the content of a communication message, the semantics and pragmatics of which are matched for given (specific) target groups, allows us "to include the subconscious" of its recipients, all of which significantly increases advertising effectiveness [5].

The concept of a pattern as a tool for construction and development was described for the first time in "A pattern language: Towns, buildings, construction", which outlines the concept of pattern language as "a structured method of describing good design practices within a field of expertise" [9]. Within the scope of the subject field, the main idea of using patterns is not to duplicate thoughtlessly the results of other people's work (advertising texts), but rather to use them to select a type of communication message content that best matches the basic characteristics of the software product for consumers on the corporate market (target audience); it is an essential condition for the effective communication and, as a result, leads to an increase in the 
probability of obtaining positive results by using proven problem-solving methods [10].

The ontology as a methodology for describing the subject field [11] and the mathematical apparatus of production systems [12] are used as a formal apparatus for presenting a model of creating design patterns of communication messages for promoting software products to form an effective communication message out of many variants of semantic units taking into account the special characteristics of the various consumer groups.

\section{Semantic network of creating design patterns for communication messages promoting soft- ware products}

According to the main rules of marketing, the communication message content should reflect the characteristics of consumer preferences of the target audience, as well as of a product and/or service and channels and tools for disseminating information. Moreover, to satisfy the expectations and needs of the target audience, the communication message should present a unique product offering, urge the target audience to perform a certain act and state whether any constraints apply (time, quantity, etc.) [3-5]. The content of a communication message also depends on the elements of its composition: header, beginning, information block, reference information, echophrase (slogan), and format of presentation of the advertising message (news, recommendation, etc.) [13]. Consequently, creating design patterns of communication messages for promoting software products should be based on these provisions.

Given the foregoing and as was done in other works $[14,15]$, we present a model for designing the content of a communication message in the form of a semantic network where the previously identified marketing elements and factors affecting them are denoted by vertices with corresponding concepts and the linkages or associations between them, expressed in a verbal form, are denoted by edges (Figure 1).
"Software" (product) and "consumer" (target audience) are the key concepts of the semantic network. The notion of "software" corresponds to the information about the group to which the promoted software belongs (category, type of software). Each software has certain properties that can be expressed in terms describing its characteristics: price, functionality, quality, delivery options and support, etc. "Consumer" combines the target groups of potential users of software (recipients of the communication message) with similar consumer preferences and similar reaction to the methods used to draw attention to the product. Problems of software product consumers on the corporate market are caused by dissatisfaction either with the existing product or with the current state of business processes. Some target groups are viewed from a marketing standpoint as carriers of "goals", i.e. the desired outcome from the practical use of software. Goals are often attributable to a "problem" that a consumer wants to (can) resolve using the software product.

In the corporate sales market, the role functions in relation to the characteristics of the software identify direct users of the software product, IT specialists responsible for the installation, adaptation and maintenance of the software product, as well as the company's executives [16]. Each group of potential consumers with their specific goals has special consumer preferences (expectations) with respect to software. "Direct users", for example, are interested in the information on the functionality of the advertised software, the possibility of adding extensions, simplicity and clarity of the interface, etc. to be presented in accessible form. IT professionals, in turn, are looking for professional information on software installation services, the software's ability to integrate with other software, the degree of protection from unauthorized access, etc. It is important to communicate to company executives the software price and the possibility of providing discounts, as well as how the software will improve the efficiency of the company's business [16]. 


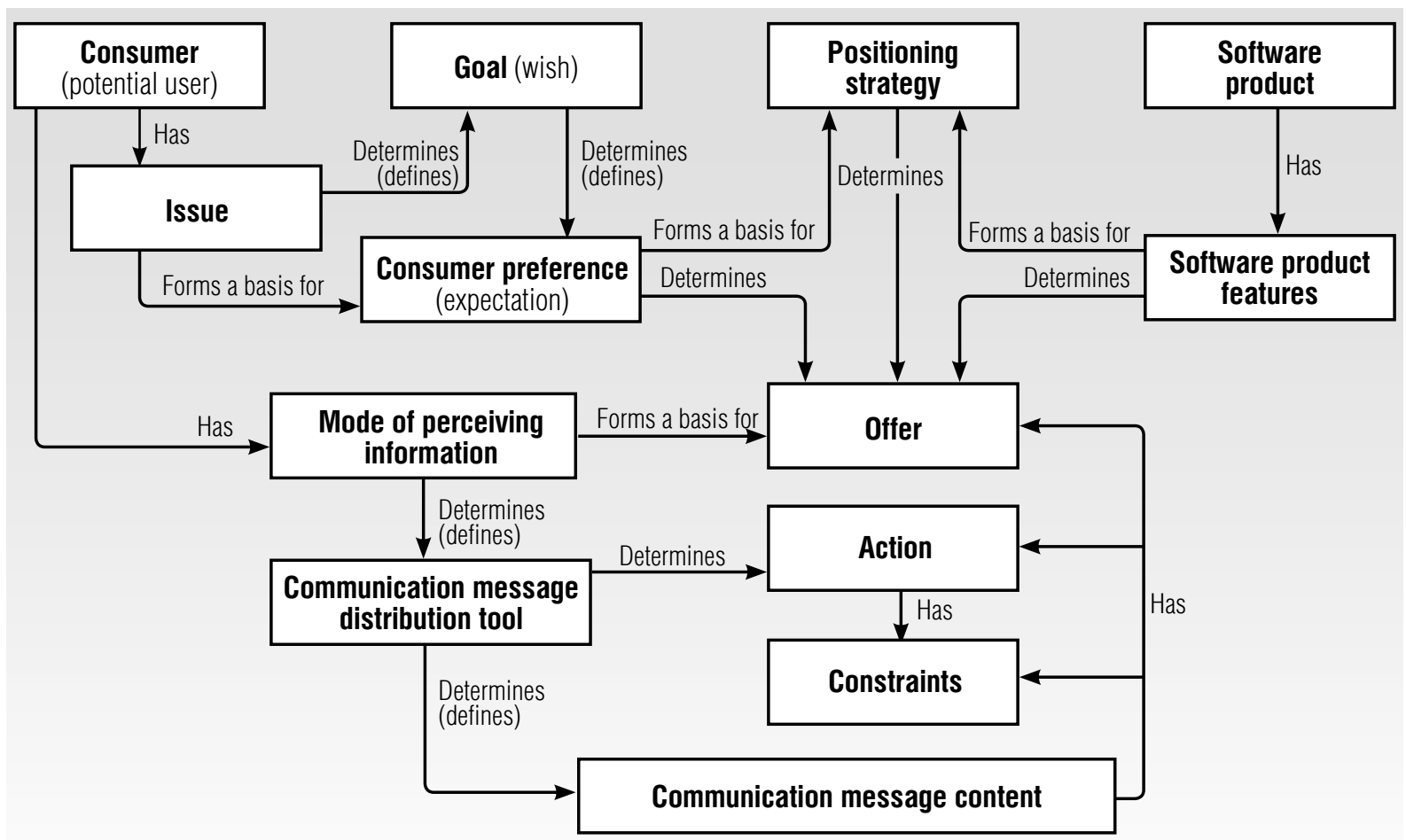

Fig. 1. Semantic network for designing content of a communication message

The software product features that reflect consumer preferences of some target groups form a basis for an "offer". The information that details this concept in the context of the communication message content allows us, on the one hand, to inculcate in minds of a specific group of consumers beneficial and distinguishable properties of the software versus competing products' consumer properties, and on the other hand, aims at solving specific problems and/or achieving the desired result. The description of the offer can be delivered in an interrogative format, a newsletter format, in the form of a recommendation or a solution to a problem, etc.

Representatives of the target groups are distinguished by psychological characteristics that allow us to classify them with one or another type of consumer behavior. For example, the diffusion of innovations theory [17] distinguishes between innovators, pioneers (early adopters), an early majority and later majority (sometimes they are grouped together), and laggards. These types of consumers have different modes of perceiving information, therefore, they are attracted to different characteristics and properties of both the software and communication message, which, of course, should be considered when crafting a promotional communication message and choosing its design, form and format as well as tools for disseminating information.

An important element of the model for creating design patterns of communication messages to promote software products is the "action". It is revealed mostly by the verbs that aim to persuade the reader of a communication message to perform a certain act: "call (right now)", "download" or "buy", "click this button to complete the payment", etc. It is important to note that tools for disseminating communication messages influence the choice of a particular verb: for example, the verb "click" (here) is usually used in banner advertising to take visitors to a "landing page"; in printed brochures, it is more appropriate to urge readers to call or come personally to the company (to get a gift). In addition, the time and place in the description of the action can indicate where and when the potential consumer should act: the organi- 
zation's address or website, time or dates of the promotion, sale, prize-giving, etc. The content of the communication message includes such an element as "constraint", which aims to strengthen the effectiveness of the communication message by stimulating the "consumer" to take an "action" in the near future ("right now", "for only 3 days"). Time ("only for 3 days", "only in December", "from June 1 to June 15", etc.), quantity of product or services ("only to the first three customers", "last three copies at a reduced price", etc.) can serve as a constraint.

The presented semantic network is a conceptual model of the subject field and serves as a basis for creating patterns of communication messages and selecting elements of their content.

\section{Structure and content of design patterns for communication messages}

A set of concept dictionaries of the semantic network forms a basis for creating design patterns of communication messages for promoting software products. The dictionary of each concept includes such elements as objects that determine the concept's composition, a description of the objects' properties, and also semantic units (words, phrases) used to form a communication message and selected to reflect the objects' properties. An example of a description of concept dictionaries used in creating design patterns of communication messages is presented in Table 1 .

Design patterns of communication messages are meant to specify such combinations of semantic units that are most likely to stimulate the target groups of consumers to perform the acts necessary for the seller (advertiser) which will become an indicator of the high advertising effectiveness [18]. To describe the formation of semantic units, we propose to use three types of lexical constructions: target, key, and alternative [19]. Metacharacters are introduced to identify lexical constructions: target lexical constructions are in parentheses, key lexical constructions are in square brackets, alternative lexical constructions are in triangular brackets.

Target lexical constructions describe and define the format of the advertising message in the communication message pattern in the following way: (Sentence: = question, recommendation, solution to a problem, etc.).

Key lexical constructions determine the unique characteristics of concept objects of the "software product" (specific software properties in the categories of price, quality, functionality, etc.) or "consumer" (indicate consumer preferences that should be considered when specifying semantic units). If necessary, the lexical construction can indicate the concept objects (modes of perceiving advertising information) which sets the tone of an appeal to the target audience. Key lexical constructions generally look like this: <Software product features: = price, quality, software functions: Mode of perceiving information: = innovators, early adopters, etc. $>$.

Alternative lexical constructions, based on the modes of perceiving advertising information of representatives of the target audience, are designed to strengthen the influence of semantic units and to exert additional impact on potential users. In general, alternative lexical constructions define a semantic unit of a certain part of speech or a full phrase (word collocation) related to a certain concept object and selected according to the modes of perceiving advertising information by a certain type of user, in a pattern: [Part of speech: = adjective, noun, adverb, participle, phrase, etc.: Concept: = concept objects to which the part of speech refers : Mode of perceiving information: $=$ innovators, early adopters, etc.]. This lexical construction is supposed to provide several variants of semantic units that meet the specified requirements.

In view of the above, a design pattern of a communication message is set by a structured sequence of different combinations of lexical constructions grouped according to the presentation format of the advertising message. Possible variants of the patterns of communication message headings are presented in Table 2.

The sequence, composition, and content of the lexical constructions that form communica- 


\section{Excerpt from concept dictionaries of communication messages' patterns}

\begin{tabular}{|c|c|c|c|}
\hline Concept & $\begin{array}{l}\text { Concept } \\
\text { objects }\end{array}$ & Description of the object property & Semantic units \\
\hline \multirow{2}{*}{ 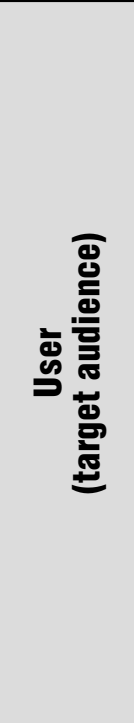 } & Executives & $\begin{array}{l}\text { Interested in: } \\
\text { - strengthening the position of the company on the } \\
\text { market, increasing competitiveness, improving } \\
\text { economic performance; } \\
\text { - growth of business reputation, image and investment } \\
\text { attractiveness of the company; } \\
\text { - the initial cost of the software and the dynamics } \\
\text { of pricing policy during updates; } \\
\text { - operating and maintenance costs for the software. }\end{array}$ & $\begin{array}{l}\text { - "Ensures that your organization } \\
\text { complies with..."; } \\
\text { - "Reduces costs of your organization } \\
\text { and allows..."; } \\
\text { • "Your company will reach a new } \\
\text { level..."; } \\
\text { - "If you plan to become part of } \\
\text { a new... system..."; } \\
\text { • "New standards aimed at... emerge...". }\end{array}$ \\
\hline & $\stackrel{\text { IT }}{\text { specialists }}$ & $\begin{array}{l}\text { Interested in: } \\
\text { - types of software delivery services; } \\
\text { - ease of software installation; } \\
\text { - documentation quality; • operational reliability; } \\
\text { - software's ability to integrate with other software; } \\
\text { - maintenance and technical support; } \\
\text { - protection from unauthorized access; } \\
\text { - recovery time in case of software malfunction } \\
\text { and integrity violation. }\end{array}$ & $\begin{array}{l}\text { - "Reliable"; } \\
\text { - "Characterized by fluid } \\
\text { responsiveness to user requests"; } \\
\text { - "24/7 technical support from our } \\
\text { team". }\end{array}$ \\
\hline \multirow{3}{*}{ 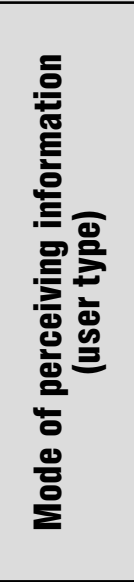 } & Innovators & $\begin{array}{l}\text { Marketing strategy focuses on raising product } \\
\text { awareness. } \\
\text { Focus: new products and services that have } \\
\text { new attributes. } \\
\text { Product life cycle stage: market entry (launch). }\end{array}$ & $\begin{array}{l}\text { - "New"; } \\
\text { - "For the first time"; } \\
\text { - "You've never seen anything like this"; } \\
\text { - "Just for you"; } \\
\text { - "Cutting-edge". }\end{array}$ \\
\hline & $\begin{array}{l}\text { Early } \\
\text { adopters }\end{array}$ & $\begin{array}{l}\text { Marketing strategy: reasoning. } \\
\text { Focus: new products that are already being used } \\
\text { by some consumers. } \\
\text { Product life cycle stage: growth. }\end{array}$ & $\begin{array}{l}\text { - "Trending"; } \\
\text { - "Popular"; } \\
\text { - "The best"; }\end{array}$ \\
\hline & Majority & $\begin{array}{l}\text { Marketing strategy: stimulation. } \\
\text { Focus: reliable, established "classic" goods, } \\
\text { traditional consumer choice. } \\
\text { Product life cycle stage: maturity. }\end{array}$ & $\begin{array}{l}\text { - "Trusted"; • "Quality through ages"; } \\
\text { - "Everyone's favorite"; } \\
\text { - "Already implemented in hundreds } \\
\text { of companies in Russia and abroad"; } \\
\text { • "Approved by professionals". }\end{array}$ \\
\hline \multirow{3}{*}{ 흘 } & $\begin{array}{l}\text { Call } \\
\text { to action }\end{array}$ & $\begin{array}{l}\text { A verb (phrase) that urges the reader of } \\
\text { a communication message to perform a certain act. }\end{array}$ & $\begin{array}{l}\text { •"Buy"; } \\
\text { •"Install"; "Download"; } \\
\end{array}$ \\
\hline & $\begin{array}{l}\text { Place } \\
\text { of action }\end{array}$ & $\begin{array}{l}\text { The place in which (in relation to which) the } \\
\text { specified action should be taken. }\end{array}$ & $\begin{array}{l}\text { •"Address..."; } \\
\text { •"Phone..."; • "Fax...". }\end{array}$ \\
\hline & $\begin{array}{l}\text { Time } \\
\text { of action }\end{array}$ & The time within which an action should be taken. & $\begin{array}{l}\text { • "Business hours..."; } \\
\text { • "Daily"; • "24/7". }\end{array}$ \\
\hline
\end{tabular}

tionmessage patternsanddefinesemanticunitsare determined by subject-matter specialists together with knowledge engineers based on consolidating successful practices of companies' marketing departments and specialized advertising agencies and analyzing advertising texts that were created and published in traditional and electronic media to promote goods and services to the corporate market. The resulting set of communication message patterns grouped according to the format of the advertising message forms the basis of the variants database of communication message patterns allowing marketing experts to select a content pattern for an effective communication message for a specific target group of potential users of software products. 


\section{Excerpt from a presentation of design patterns for communication messages according to the presentation format of the advertising message}

\begin{tabular}{|c|c|c|}
\hline $\begin{array}{l}\text { Presentation } \\
\text { format of the } \\
\text { advertising message }\end{array}$ & $\begin{array}{l}\text { Example of a communication } \\
\text { message pattern }\end{array}$ & $\begin{array}{l}\text { Type of a communication message } \\
\text { pattern(without specifying } \\
\text { the user or software product type) }\end{array}$ \\
\hline \multirow{2}{*}{ Question } & $\begin{array}{l}\text { (Offer: question) [verb : question : consumer] } \\
\text { <software: type }>\text { ? [phrase : price : question] }\end{array}$ & $\begin{array}{l}\text { [Are you searching for, waiting for, looking for, } \\
\text { want, etc.] <type of software>?[Why overpay?] }\end{array}$ \\
\hline & $\begin{array}{l}\text { (Offer: question) [phrase : consumer : issue] } \\
<\text { Consumer: issue }>\text { ? }\end{array}$ & $\begin{array}{l}\text { [You, your organization, your colleagues] } \\
<\text { formulation of the consumer's problem }>\text { ? }\end{array}$ \\
\hline News & $\begin{array}{l}\text { [Adjective: software : consumer expectations] } \\
\text { and [Adjective: software : consumer expecta- } \\
\text { tions] <software: type }><\text { software name>. } \\
\text { (Phrase : consumer properties : innovator]. }\end{array}$ & $\begin{array}{l}\text { [High-quality, new, expensive, reliable] and } \\
\text { [High-quality, new, expensive, reliable] <type } \\
\text { of software }><\text { software name }>\text {. [Work beyond } \\
\text { the bounds of the format]. }\end{array}$ \\
\hline
\end{tabular}

\section{Semantic model for selecting variants of communication message patterns}

The process of choosing a variant of the content pattern for a communication message that describes the process of creating the communication message text with the aim of promoting a particular software product to a certain group of consumers, can be presented as a multilayer production semantic network: $G=(X, U)$ where the set of layers $X$ corresponds to the selected concepts of the semantic network. Each layer consists of a set of objects $X i=\{P i j\}$ that reflect the qualitative composition of the layer. The set of directed $U$-graphs reflect the associative relationships between the objects. An excerpt from a description of the layers of the multilayer production semantic network is presented in Table 3.

The associative relations between objects of different layers are represented in the form of adjacency matrices; there are no associative relations between objects of the same layer. An excerpt from an adjacency matrix describing the associative relations between two objects of different layers is presented in Table 4. According to [20], if the software product's life cycle stage is "market entry", the advertising message should be targeted at users who exhibit psychological characteristics and the consumer behavior patterns of the "innovator" type who mainly prefer new products or their updated functionality. In this regard, it is advisable to use such positioning strategies as "Solution to a problem" or "Competitive advantage" to promote the software. The "Solution to a problem" strategy is effective if potential consumers have real problems that they can solve with the help of the product offered, and the consumer has a desire and possibilities to solve them. When using the "Competitive advantage" strategy, it is necessary to focus the consumer's attention on the distinctive features of the software that make it individual and special $[4,5,7,21]$. The choice of a specific strategy should be based on a competitive analysis of a specific software product.

The mechanism of choosing a variant of the content pattern for a communication message lies in forming a non-cyclic chain of the semantic network using a product rule like: $<$ If the object $P 1,1$ is selected in the $S 1$ class, then in the $S 2$ class, the object $P 2,1$ should be selected... and so on $>$. For example, according to the product rule from Table 4, a fragment of a non-cyclic chain will be as follows: <If the object $P 2,1$ is selected in the $S 2$ class, then in the $S 3$ class, the object $P 3,2$ or $P 3,3$ should be selected $>$.

The proposed model is the basic one; the authors admit the possibility of dividing some concepts into smaller parts in the light of experience. Adjustment of the semantic 


\section{Excerpt from a description of the layers of the production semantic network}

\begin{tabular}{|c|c|}
\hline Layer & Layer Objects \\
\hline $\begin{array}{l}S 1 \text { - Consumer } \\
\text { target audience }\end{array}$ & $\begin{array}{l}P 1,1 \text { - companies' executives; } \\
P 1,2 \text { - IT professionals; } \\
P 1,3 \text { - users. }\end{array}$ \\
\hline $\begin{array}{l}S 2 \text { - Types } \\
\text { of consumer } \\
\text { behavior }\end{array}$ & $\begin{array}{l}P 2,1 \text { - innovators; } \\
P 2,2 \text { - early adopters; } \\
P 2,3 \text { - majority; } \\
P 2,4 \text { - laggards. }\end{array}$ \\
\hline $\begin{array}{l}\text { S3- } \\
\text { Positioning } \\
\text { strategy }\end{array}$ & $\begin{array}{l}P 3,1 \text { - value; } \\
\text { P3,2 - solution to a problem; } \\
\text { P3,3 - competitive advantage (attribute); } \\
\text { P3,4 - association; } \\
\text { P3,5 - niche target audience. }\end{array}$ \\
\hline $\begin{array}{l}S 4-\text { Tools for } \\
\text { disseminating } \\
\text { communication } \\
\text { messages }\end{array}$ & $\begin{array}{l}P 4,1 \text { - mailing lists; } \\
\text { P4,2 - media; } \\
\text { P4,3 - banner advertisement; } \\
\text { P4,4 - news sites, reviews; } \\
\text { P4,5 - contextual advertising. }\end{array}$ \\
\hline $\begin{array}{l}\text { S5 - } \\
\text { Communication } \\
\text { message } \\
\text { elements }\end{array}$ & $\begin{array}{l}\text { P5,1 - header format: news; } \\
\text { P5,2 - header format: question; } \\
\text { P5,3 - header format: recommendation; } \\
\text { P5,4 - header format: solution } \\
\quad \text { to a problem; } \\
\text { P5,5 - header format: niche target } \\
\quad \text { audience. }\end{array}$ \\
\hline $\begin{array}{l}\text { S6- } \\
\text { Communication } \\
\text { message } \\
\text { patterns }\end{array}$ & $\begin{array}{l}\text { This layer contains combinations } \\
\text { of objects of the previous layers and } \\
\text { defines a path to the communication } \\
\text { message patterns. }\end{array}$ \\
\hline
\end{tabular}

model for selecting variants of communication message patterns is carried out in the following way: a basic model is constructed based on the knowledge and experience of the analyst expert in the field of marketing - many concept objects are selected and assigned to certain
Table 3. layers; the logic of constructing associative relationships between objects of different layers is determined. This version of the model allows a marketing specialist in a small IT company to interactively organize their work to continuously select one object from each layer of the production semantic network (Figure 2). Subsequently, as the knowledge base grows, it may become possible to generate automatically variants of patterns according to the request made by a marketing specialist.

Any changes (clarifications) of product rules based on the reaction of the target audience to the generated advertising texts should be implemented based on the experts' analysis of the conversion rate as the number of representatives of the target audience who carried out the desired action (visited the website that contains information about the software, downloaded the trial of the software, made an online purchase of the software, etc.) out of the total number of users who had contact with the communication message, expressed in percentages [18].

\section{An example of generating the content of a communication message}

As an example, let's consider a small IT company that has a completed unique software package - "Generator of working programs" which helps professors to create work programs and funds of evaluation tools that comply with the order № 1367 of the Ministry of Education and Science of the Russian Federation of December 19, 2013. In the context of a limited budget, the IT company management needs

Associative relations between objects of the "Types of consumer behavior" and "Positioning strategy" layers

Table 4.

\begin{tabular}{c|c|c|c|c|c}
\hline \multirow{2}{*}{$\begin{array}{c}\text { Types } \\
\text { of consumer } \\
\text { behavior }(\mathcal{S} 2)\end{array}$} & $\begin{array}{c}\text { Value } \\
(\mathbf{P 3}, 1)\end{array}$ & $\begin{array}{c}\text { Solution to a } \\
\text { problem }(\boldsymbol{P 3}, 2)\end{array}$ & $\begin{array}{c}\text { Competitive } \\
\text { advantage }(\boldsymbol{P 3}, 3)\end{array}$ & $\begin{array}{c}\text { Association } \\
(\mathbf{P 3}, 4)\end{array}$ & $\begin{array}{c}\text { Niche target } \\
\text { audience }(\boldsymbol{P 3}, 5)\end{array}$ \\
\hline Innovators $(P 2,1)$ & - & + & + & - & - \\
\hline
\end{tabular}


to develop a set of marketing measures to promote the software package to the target market segments (to determine the content of the communication message with a focus on preferences of consumers).

To solve this task, during the first stage (Figure 2), the IT company employees selected the head (of the university's management department) who, on the one hand, is responsible for compliance with the educational legislation and, on the other, has the authority to manage the financial resources of the university - as the representative of the target audience from the objects of the "Consumer target audience" layer (Table 3).

The second stage involves determining the type of consumer behavior of the decisionmaker. To do this, the current situation of the software package on the market is analyzed in an interactive way: since the product is only entering the market, it is recommended make an advertising message that targets "innovators".

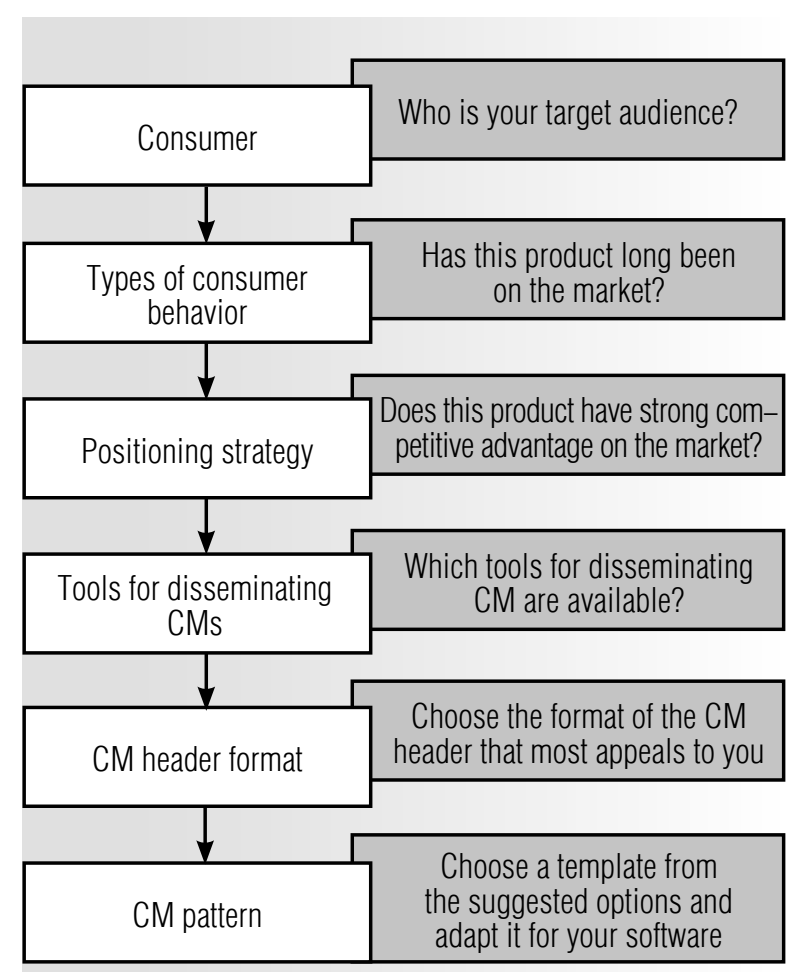

Fig. 2. Excerpt from a dialogue to select variants of design patterns for communication messages
The third stage involves choosing a positioning strategy that can be used to promote the software package. Taking into account the example described in Table 4, it was decided to use the "Solution to a problem" strategy. Based on the provisions of differentiated marketing and with the aim of fully communicating the unique consumer properties of the software package to the executive manager, the "mailing list" (by email) was chosen as the tool for disseminating a communication message. Given the clear problems that university professors face when creating work programs and funds of evaluation tools, "question" was chosen as the header format (Table 2).

Thus, the non-cyclic chain of the semantic network for creating a communication message pattern looks like this: $<P 1,1-$ company's chief executive officers; $P 2,1$ - innovators; $P 3,2-$ solution to a problem; $P 4,1$ - mailing lists; $P 5,1-$ header format: question $>$.

As a result of using the data in Tables 1 and 2, the following variant of the communication message pattern is proposed (the parentheses in the key lexical construction are omitted):

Headline: Do you have a problem with $<$ formulation of the consumer's problem $>$ ?

Beginning: <Software name> will ensure that your organization complies with [legislation, standards, requirements, regulations, expectations]!

Information block: This (cutting-edge, unique, new, innovative) <type of software> will reduce costs of your organization and allow $<3-4$ software key functions $>$. <Software name $>$ from $<$ developer's company name $>$ will become a universal solution to <formulation of the consumer's problem $>$.

Reference information: (Download, install) a free trial of $<$ software name $>$ to $<$ software key function $>$ on $<$ site link $>$. The trial version is valid for $<$ period of validity $>$. You can consult an expert by calling $<$ contact phone number $><$ work schedule $>$.

After giving body to the linguistic constructions, the communication message content may have the following form: 
Do you have problems of compliance with the order № 1367 of the Ministry of Education and Science of the Russian Federation of December 19, 2013? The generator of working programs will ensure that your organization complies with the statutory documents of the Ministry of Education and Science of the Russian Federation; $42 \%$ of all failures of the university to comply with the statutory documents is due to careless drafting of work programs!

This unique generator of working programs will reduce costs of your organization and facilitate and accelerate the process of creating work programs and funds of evaluation tools by professors; automate the process of checking the work program at all stages of approval thereby significantly reducing the time of internal paperwork; track and keep records of the availability of working programs in the university in the context of individual faculties, professors, and disciplines.

The generator of working programs from Tomsk State University of Control Systems and Radioelectronics (TUSUR) will become a universal tool to tackle the monotonous manual labor of your faculty.

Install a free trial of the generator to automatically create work programs on https:// workprogram.tusur.ru/ The trial version is valid for 1 month. You can consult an expert by calling 8 (3822) 70-15-57 at any time.

\section{Conclusion}

The proposed approach as a set of methods based on the provisions of semiology, ideas of communication theories, conceptual modeling and production systems, methods of artificial intelligence and design patterns of communication messages within a field of expertise, is focused on solving an important task (from the authors' point of view) of organizing Internet advertising when marketing low-budget software projects.

The use of positive experience from advertising agencies in the field of online advertising in patterns should help, above all, small IT companies (startups, groups of like-minded developers) to develop text communication messages that contain the semantic units that are most likely to urge their readers to perform desired actions and so increasing advertising effectiveness, in the context of a limited budget.

The issues of economic efficiency, quality of advertising texts, as well as changes in patterns and product rules will be examined by the authors in the future as statistical estimates of advertising effectiveness build up. Conversion rates [18] are to be used as quantitative assessment of efficiency.

The presented semantic network of design patterns for communication messages and the multilayer production semantic network for selecting variants of patterns constitute the basis of the software complex to be developed. The software complex functionality aims, on the one hand, at automating the work of professional knowledge engineers to maintain classifiers of layers and objects, form a semantic network structure, maintain a database of communication message patterns, maintain a rules-based system for selecting patterns, support a query generation language model, build a knowledge base, and on the other hand at creating a UI for marketing specialists (employees of IT companies) for practical purposes of selecting communication message patterns according to the generated queries that characterize the promoted software and/or potential consumers.

\section{References}

1. Yekhlakov Yu.P., Baraksanov D.N. (2012) Osnovnye polozheniya po razrabotke programmy prodvizheniya programmnykh produktov $\mathrm{v}$ seti Internet [The main provisions on the development of the program of promotion of software products in the Internet]. Business Informatics, no. 4 (22), pp. 33-39 (in Russian).

2. Vasiliev R.B., Levochkina G.A. (2012) Otsenka stepeni zrelosti rossiyskogo rynka IT-uslug [Estimation of maturity of the Russian IT services market]. Business Informatics, no. 2 (20), pp. 56-64 (in Russian). 
3. Lewinson J., Hanley P. (2006). Partizanskiy marketing [Guerrilla marketing]. St. Petersburg: Piter (in Russian).

4. Mann I.B. (2009) Bez byudzheta. 57 effektivnykh priemov marketinga [Without a budget. 57 effective marketing techniques]. Moscow: MIF (in Russian).

5. Romat E.V. (2008) Reklama [Advertising]. St. Petersburg, Piter (in Russian).

6. Yelina E.A. (2016) Semiotika reklamy [Semiotics of advertising]. Moscow: Dashkov and Co. (in Russian).

7. Mokshantsev R.I. (2000) Psikhologiya reklamy [Psychology of advertising]. Moscow: INFRA-M; Novosibirsk: Novosibirskoe soglashenie (in Russian).

8. Pirogova Yu.K., Parshin P.B. Reklamnyy tekst: Semiotika i lingvistika [Advertising text: Semiotics and linguistics]. Moscow: Grebennikov Publishing House (in Russian).

9. Alexander C., Ishikawa S., Silverstein M. (1977) A pattern language: Towns, buildings, construction. N.Y.: Oxford University Press.

10. van der Merwe R. (2012) Design patterns: When breaking the rules is OK. Available at: https://www. smashingmagazine.com/2012/06/design-patterns-when-breaking-rules-ok/ (accessed 26 June 2017).

11. Kudryavtsev D.V. (2010) Sistemy upravleniya znaniyami i primenenie ontologiy [Knowledge management systems and application of ontologies]. St. Petersburg: Polytechnic University (in Russian).

12. Gavrilova T.A., Khoroshevskiy V.F. (2000) Bazy znaniy intellektual'nykh sistem [Knowledge bases of intelligent systems]. St. Petersburg, Piter (in Russian).

13. Yekhlakov Yu.P., Baraksanov D.N. (2016) Struktura i soderzhanie kommunikatsionnogo soobshcheniya pri organizatsii Internet-reklamy programmnykh produktov [Structure and content of the communication message in the organization of Internet advertising of software products]. Internet Marketing, no. 3 (93), pp. 146-156 (in Russian).

14. Pronina V.A., Shipilina L.B. (2009) Ispol'zovanie otnosheniy mezhdu atributami dlya postroeniya ontologii predmetnoy oblasti [Application of relations between attributes for constructing a domain ontology]. Problemy Upravleniya, no. 1, pp. 27-32 (in Russian).

15. Temnikova E.A., Aslamova V.S., Berestneva O.G. (2015) Ontologicheskoe modelirovanie predmetnoy oblasti uchrezhdeniya dopolnitel'nogo professional'nogo obrazovaniya [Ontological modeling of the subject area of the institution of additional professional education]. Ontology of Designing, no. 4 (18), pp. 369-386 (in Russian).

16. Yekhlakov Yu.P. (2009) Vyvod prikladnogo programmnogo obespecheniya na rynok korporativnykh prodazh: vzglyad razrabotchika [Output of application software to the corporate sales market: developer's view]. Marketing in Russia and Abroad, no. 4 (72), pp. 45-50 (in Russian).

17. Mikhalyova E.P., Chinilina K.A. (2013) Model' diffuzii potrebitel'skikh innovatsiy na osnove postroeniya kumulyativnoy krivoy [Model of diffusion of consumer innovations based on the construction of a cumulative curve]. Creative Economics, no. 11 (83), pp. 46-53 (in Russian).

18. Memosales.ru (2017) Metody otsenki effektivnosti reklamy [Methods for evaluating the effectiveness of advertising]. Available at: http://memosales.ru/reklama/ocenka-effektivnosti-kampanii (accessed 15 September 2017) (in Russian).

19. Mitrofanova O.A., Panicheva P.V., Lyashevskaya O.N. (2013) Vizualizatsiya dannykh dlya kataloga russkikh leksicheskikh konstruktsiy (na materiale NKRYa) [Visualization of data for the catalog o $\mathrm{f}$ Russian lexical constructions (based on the material of the NKRN)]. Computer Linguistics and Intellectual Technologies, no. 12 (19), pp. 465-477 (in Russian).

20. Powerbranding,ru (2017) Upravlenie tovarom na raznykh stadiyakh ZhTsT [Managing the goods at different stages of the product life cycle]. Available at: http://powerbranding.ru/marketing-strategy/ razvitiye-tovara/ (accessed 15 September 2017) (in Russian).

21. Powerbranding,ru (2017) Unikal'nye sposoby pozitsionirovaniya [Unique methods of positioning]. Available at: http://powerbranding.ru/pozicionirovanie/main-types/ (accessed 15 September 2017) (in Russian). 


\title{
About quasi-solutions of traveling wave type in models for organizing cargo transportation ${ }^{1}$
}

\author{
Nerses K. Khachatryan \\ Senior Researcher, Laboratory of Dynamic Models of Economy and Optimization \\ Central Economics and Mathematics Institute, Russian Academy of Sciences; \\ Associate Professor, Department of Business Analytics \\ National Research University Higher School of Economics \\ Address: 47, Nakhimovsky Prospect, Moscow, 117418, Russian Federation \\ E-mail:nerses@cemi.rssi.ru; nkhachatryan@hse.ru

\section{Andranik S. Akopov} \\ Professor, Department of Business Analytics \\ National Research University Higher School of Economics; \\ Leading Researcher, Laboratory of Dynamic Models of Economy and Optimization \\ Central Economics and Mathematics Institute, Russian Academy of Sciences \\ Address: 20, Myasnitskaya Street, Moscow, 101000, Russian Federation \\ E-mail:aakopov@hse.ru
}

\section{Fedor A. Belousov}

Researcher, Laboratory of Dynamic Models of Economy and Optimization Central Economics and Mathematics Institute, Russian Academy of Sciences; Associate Professor, Department of Business Analytics

National Research University Higher School of Economics

Address: 47, Nakhimovsky Prospect, Moscow, 117418, Russian Federation

E-mail:sky_tt@list.ru; fbelousov@hse.ru

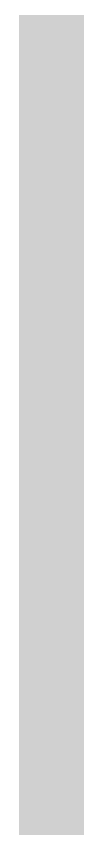

\begin{abstract}
This article is devoted to the construction and research of a model for organizing cargo transportation between two node stations connected by a railway line which contains a certain number of intermediate stations. The organization of freight traffic is facilitated by a number of technologies. These technologies determine the rules for taking on cargo at the initial node station, the rules of interaction between neighboring stations, as well as the rule of distribution of cargo to the final node stations. The process of cargo transportation is accompanied by the set rule of control consisting in measuring the volumes of goods transported at neighboring stations with a single time lag. For such a model, one must determine possible modes of cargo transportation and describe their properties. Traffic flow is described by a finite-difference analog of the nonlinear parabolic equation. The control system is set by nonlocal restrictions, which distinguishes the solutions of traveling wave type. The class of such solutions is extremely narrow. This results in the need for the "correct" extension of a class of solutions of the traveling wave type to a class of quasi-solutions of the traveling wave type. One type of expansion presupposes assumptions of discontinuous solutions of the traveling wave type; the second type allows for violations in a small control system. An essential lack of discontinuous solutions is their limitlessness. In this work, we investigate quasisolutions obtained with the help of a second type of extension. The distinctive feature of such quasisolutions is the assumption of feasibility of not local restrictions with the set error. The question of the limitation of such quasi-solutions is investigated. Using computer model implementation
\end{abstract}

\footnotetext{
${ }^{1}$ This work was partially supported by the Russian Foundation for Basic Research (project No. 16-01-00110)
} 
we investigate the dependence of the error in the performance of nonlocal restrictions on model parameters, which are the characteristics of the technologies used to carry out the cargo flow.

Key words: mathematical modeling of cargo transportation process, rule of control, differential equations, non-local restrictions, quasi-solutions, numerical realization.

Citation: Khachatryan N.K., Akopov A.S., Belousov F.A. (2018) About quasi-solutions of traveling wave type in models for organizing cargo transportation. Business Informatics, no. 1 (43), pp. 61-70.

DOI: 10.17323/1998-0663.2018.1.61.70.

\section{Introduction}

$\mathrm{O}$ ne of the key industries of any state is transport. One can distinguish among the main objectives of transport the following two: planning of transportation and organization of the process of transportation. For such an extensive territory as Russia, the second task becomes especially relevant. The set of research is devoted to the problem of organizing cargo transportation, which in particular, is considered in [1-7]. In [8-10] the model, an investigation is made of the organization of cargo transportation on the extended right of way with a large number of intermediate stations through which freight traffic passes. It is supposed that between two neighboring stations there is an interexchange railway track where part of cargo can temporarily be stored in special storage areas. We consider the capacity of such storage areas to be unlimited. The movement of cargo happens in one direction. The organization of freight traffic is carried out by means of two technologies. The first technology sets the rules for the interaction of neighboring stations, and the second - the rules for the interaction of stations with neighboring storage areas. One of the tasks of the second technology is to ensure uninterrupted cargo flow. A detailed description of these technologies is given in [8].

For cargo transportation, a simple control system is used. The amounts of processed freight for any planned interval of time at all stations should match a certain log of time, the same for all stations. Several variants of the model are considered. One of the variants of the model describes cargo transportation between two node stations and is given by the following system of differential equations with nonlocal linear restrictions [8]:

$$
\begin{gathered}
\dot{z}_{0}(t)=\psi_{1}(t)-\alpha z_{0}+\alpha z_{1}+\varphi_{0}\left(z_{0}\right), \quad t \in[0,+\infty) \\
\dot{z}_{i}(t)=\alpha z_{i-1}-2 \alpha z_{i}+\alpha z_{i+1}+\varphi\left(z_{i}\right) \\
i=1,2, \ldots, m, \quad t \in[0,+\infty) \\
\dot{z}_{m+1}(t)=\alpha z_{m}-\alpha z_{m+1}-\psi_{2}(t)+\varphi\left(z_{m+1}\right) \\
t \in[0,+\infty) \\
z_{i}(t)=z_{i+1}(t+\tau), i=0,1,2, \ldots, m, \quad t \in[0,+\infty)
\end{gathered}
$$

where $z_{i}(t)$ - the number of involved nodes at the $i$-th station at time $t, i=0,1, \ldots, m+1$.

Functions $\psi_{1}() \geq$.0 and $\psi_{2}() \geq$.0 determine, respectively, the intensity of handover of cargo on the initial node station and the intensity of the distribution of cargo from the final node station. Functions $\varphi_{0}($.$) and \varphi($.$) determine,$ respectively, speed of change of the number of involved processing nodes at the initial station and the number of involved processing nodes at other stations within the second technology. A description of the properties of the functions $\varphi_{0}($.$) and \varphi($.$) , and also their graphs is given in$ [8]. Here we note that these functions, as well as the functions $\psi_{1}($.$) and \psi_{2}($.$) are continuous.$

We will designate $c_{0}=-\dot{\varphi}_{0}(\Delta)$ and $c=-\dot{\varphi}(\Delta)$, where $\Delta$ is the number of involved processing nodes; when exceeded part of the cargo is sent to the storage area. Parameters $c_{0}$ and $c$ determine, respectively, the intensity of sending 
freight from the initial and intermediate stations to storage areas. Nonlocal linear restrictions (4) define a control system over the process of cargo transportation, and the parameter $\tau$ is its characteristic.

As noted in [8], the class of solutions of system (1) - (4) is extremely narrow. Therefore, its extension to the class of "quasi-solutions" was considered. The distinctive feature of the latter is the existence of gaps in a countable number of points. In [10] the existence and uniqueness theorem for quasi-solution is proved. The results of a numerical investigation of the system (1) - (4) are presented in [8]. The main task of the study was to study the dynamics of its quasi-solutions, as well as their dependence on some model parameters characterizing the control rule $(\tau)$, the technologies for transportation of cargo $(\alpha)$ and intensity of shipping cargo on a node station (function $\psi_{1}($.$) ). According to the$ results of numerical research, the quasi-solution systems (1) - (4) are majorized by exponential functions, whose growth decreases with increasing $\alpha$ and $\tau$. The parameter $\alpha$ values are limited due to the limited technological capabilities of the stations, and for large values $\tau$ the control system loses its relevance. Therefore, after a relatively short period of time, the number of involved nodes in the stations will become substantially larger than $\Delta$, which will entail failures in the organization of transportation. Thus, from a practical point of view, the limitlessness of quasi-solutions of system (1) - (4) is a lack of the model. We recall that quasi-solutions defined above, in contrast to solutions, contain gaps at points that are multiples of the characteristic of the control system. We call them quasisolutions of the first type.

Next, we consider another possible way of extending the class of solutions of the traveling wave type to a class of solutions of the "quasitravelling" wave type, namely, while weakening the nonlocal restrictions (4) (assuming that these restrictions are satisfied with some error).
Definition 1. The family of absolutely continuous functions $\left\{z_{i}(.)\right\}_{0}^{m+1}$, defined on $[0,+\infty)$, is called $\varepsilon$-quasi-solution of the traveling wave type of second type with characteristic $\tau>0$ for the system (1)-(4), if almost all $t \in[0,+\infty)$ functions $z_{i}($.$) satisfy the sys-$ tem of equations (1) - (3) and the condition $\left|z_{i}(t)-z_{i+1}(t+\tau)\right|<\varepsilon, i=0,1,2, \ldots, m, \quad t \in[0,+\infty) \quad$ is satisfied.

\section{On limited solutions of system (1) - (3)}

Before proceeding to the investigation of quasi-solutions of the system (1) - (4) of the second type, we study the set of all solutions of the system of equations (1) - (3). Obviously, for any initial conditions this system has a unique solution. Let us prove that for a certain choice of functions $\psi_{1}($.$) and \psi_{2}($.$) the solutions$ of the system of equations (1) - (3) are limited.

Theorem 1. Let the functions $\psi_{1}($.$) and \psi_{2}($.) be limited on a half-line $[0,+\infty)$. Then the solutions of the system of differential equations (1) - (3) are limited.

Proof. We will consider the first to be a component of the solution of a system of the differential equations (1) - (3), i.e. function $z_{0}($.$) . This function is either limited, or unlim-$ ited. We will assume that it is unlimited from the above. Then there is a sequence $\left\{t_{n}\right\} \rightarrow+\infty$ such that

$$
\lim _{n \rightarrow \infty} z_{0}\left(t_{n}\right)=+\infty \text { and } \lim _{n \rightarrow \infty} \dot{z}_{0}\left(t_{n}\right)>0 .
$$

Then it follows from equation (5), and in particular from the definition of the function $\varphi_{0}($.$) that$

$$
\lim _{n \rightarrow \infty} z_{1}\left(t_{n}\right)=+\infty \text { and } \lim _{n \rightarrow \infty} \dot{z}_{1}\left(t_{n}\right)>0,
$$

and also inequality

$$
\lim _{n \rightarrow \infty}\left[z_{1}\left(t_{n}\right)-z_{0}\left(t_{n}\right)\right]>0
$$

is carried out. 
From inequality (6) and the first equation of system of the differential equations (2) it also follows that

$$
\lim _{n \rightarrow \infty} z_{2}\left(t_{n}\right)=+\infty \text { and } \lim _{n \rightarrow \infty} \dot{z}_{2}\left(t_{n}\right)>0,
$$

and inequality

$$
\lim _{n \rightarrow \infty}\left[z_{2}\left(t_{n}\right)-z_{1}\left(t_{n}\right)\right]>0
$$

is carried out.

Acting by induction, we will find that

$$
\lim _{n \rightarrow \infty} z_{m+1}\left(t_{n}\right)=+\infty \text { and } \lim _{n \rightarrow \infty} \dot{z}_{m+1}\left(t_{n}\right)>0,
$$

and inequality

$$
\lim _{n \rightarrow \infty}\left[z_{m+1}\left(t_{n}\right)-z_{m}\left(t_{n}\right)\right]>0
$$

is carried out.

It follows from (7) - (8) that the left-hand side of equation (3) is positive, and the righthand side is negative. This contradiction is connected with the assumption of limitlessness of function $z_{0}($.$) from above. Thus, func-$ tion $z_{0}($.$) cannot be unlimited from the above.$ Similarly, it is possible to show that it cannot be unlimited from the below. So, function $z_{0}($.$) is$ limited.

Let us prove that the remaining components of the solution of the system of differential equations (1) - (3) will also be limited. We start with the function $z_{1}($.$) . We will assume that this$ function is unlimited from the above. Then there exists a sequence $\left\{t_{n}^{\prime}\right\} \rightarrow+\infty$ such that

$$
\lim _{n \rightarrow \infty} z_{1}\left(t_{n}^{\prime}\right)=+\infty \text { and } \lim _{n \rightarrow \infty} \dot{z}_{1}\left(t_{n}^{\prime}\right)>0 .
$$

Further, repeating the reasoning which is carried out at the proof of limitation of function $z_{0}($.$) , it is possible to show that take it$ takes the place of a ratio (7) and (8) where the sequence $\left\{t_{n}\right\}$ will be replaced with the sequence $\left\{t_{n}^{\prime}\right\}$. Therefore, for the chosen sequence $\left\{t_{n}^{\prime}\right\}$ the left part of the differential equation (3) will be positive, and right - negative. This contradiction is connected with the assumption of limit- lessness of function $z_{1}($.$) from the above. Thus,$ function $z_{1}($.$) also cannot be unlimited from$ the above. Similarly, it is possible to show that it cannot be unlimited from below. By an induction method, from the system of the differential equations (2) it is possible to show the limitation of functions $z_{i}(),. i=2,3, \ldots, m+1$.

So, according to the theorem 1 , at the limitation of functions $\psi_{1}($.$) and \psi_{2}($.$) , which is quite$ natural from the economic point of view, the solutions of the system of differential equations (1) - (3) are limited. For a more detailed investigation of the solutions, the system (1) - (3) was realized numerically with the help of the Runge-Kutta method of the fourth order. Before proceeding to a description of the numerical solution of this system, it is necessary to determine the functions $\varphi(),. \psi_{1}(t), \psi_{2}(t)$. Function $\varphi($.$) on a segment [0, \Delta]$ is given by a parabola $y=-a x^{2}+b x$, where $a>0, y(\Delta)=0$. Thus, the coefficients of the parabola are related by $b=a \Delta$. Obviously, the larger $a$, the greater the ordinate of the vertex of the indicated parabola, and, consequently, the intensity of reception of cargoes by the second technology. As functions $\psi_{1}\left(\right.$.) and $\psi_{2}($.) we will use two classes of functions:

a) constant function $\psi_{1}(t)=\psi_{2}(t)=d$;

b) periodic function $\psi_{1}(t)=\psi_{2}(t)=d+\gamma \cos (\omega t), d \geq \gamma$.

\section{Quasi-solutions of system (1) - (4) of the second type with constant functions $\psi_{1}($.$) and \psi_{2}($.}

We will consider the system of the differential equations (1) - (3) in which $\psi_{1}(t)=\psi_{2}(t)=d, d>0$. This means that on the initial node station freight traffic is carried out with constant intensity $d$ and with the same intensity as is distributed from the final node station. We will investigate the dependence of the solutions of the system (1) - (3) on the parameters of the model $\alpha, a, c_{0}, c, d$. Note that all these parameters are positive. According 
to results of numerical experiments, since at some time point, solutions of system (1) - (3) reach constant values for all values of parameters $\alpha, a, c_{0}, c, d$ this system, i.e. exists $\bar{t}>0$, it follows that conditions

$$
\begin{gathered}
z_{0}(t)=d_{0}, z_{1}(t)=d_{1}, \ldots, z_{m}(t)=d_{m}, \\
z_{m+1}(t)=d_{m+1}, t \in[\bar{t},+\infty),
\end{gathered}
$$

are satisfied, and numbers $d_{i}, i=0,1, \ldots, m, m+1$ satisfy the condition:

$$
d_{0}>d_{1}>\ldots>d_{m}>d_{m+1} .
$$

For example, one of solutions of system (1) - (3) is given in Figure 1.

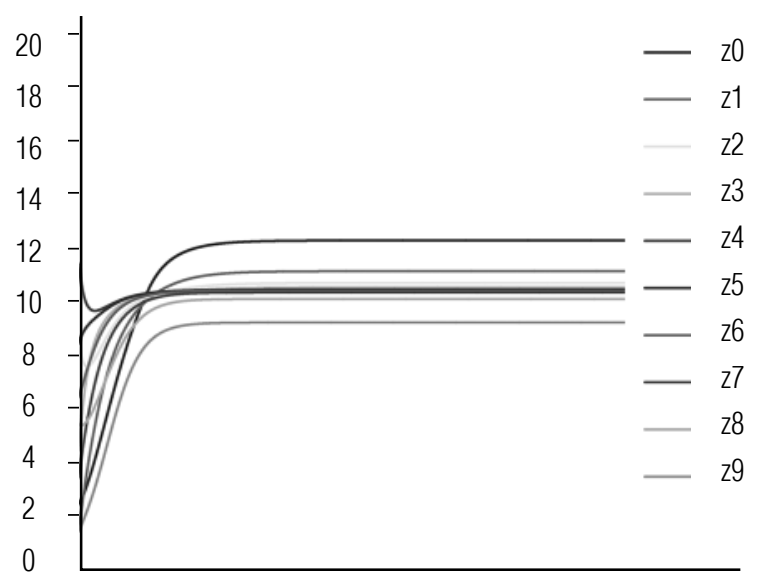

Fig. 1. The schedule of the solution of system (1) - (3) with constant functions $\psi_{1}($.$) and \psi_{2}($.

This solution is received at $\Delta=10$ and the following values of parameters: $a=0.2, c_{0}=c=1, d=3$.

We denote by $\bar{d}_{i}=d_{i}-\Delta, i=0,1, \ldots, m, m+1$. Thus, the numbers $\bar{d}_{i}$ determine the deviation of solutions from the value $\Delta$, that determines the capacity of the stations. In Figure 2 we give the histogram of the numbers $\bar{d}_{i}$ obtained from the solutions of the system (1) - (3), the graph for which is shown in Figure 1.

As can be seen from Figure 2, the first and last components of the solution of the system (1) - (3) have the greatest deviations from the

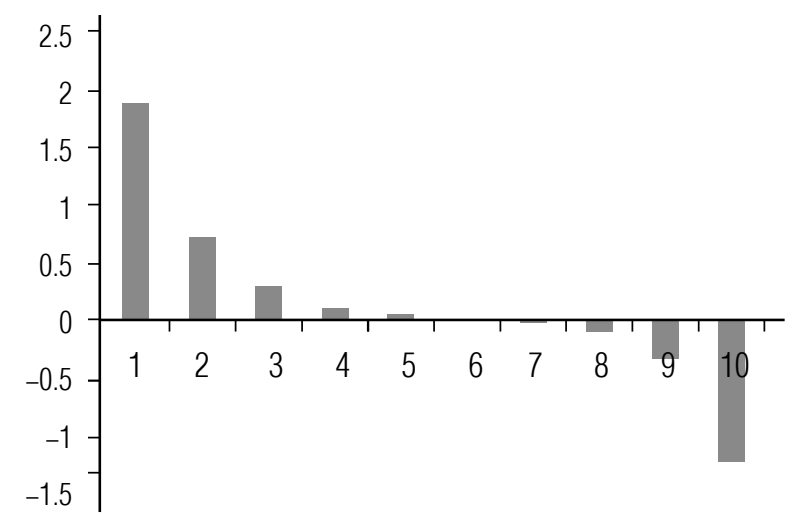

Fig. 2. The histogram of deviations of the solutions of system (1) - (3) from the value $\Delta$ (base case)

value $\Delta$. As we approach the central components of the solution, these deviations decrease, and both positive and negative deviations are present. We will give substantial interpretation of the histogram 2. For this purpose we will note that if the number of the involved nodes at the station is equal to $\Delta$, then it means that at this station the volume of infrastructure opportunities which allows us to organize uninterrupted freight traffic is completely used. A positive deviation from the value $\Delta$ indicates that the station connects additional capacities and at the same time there may be disruptions in the organization of cargo transportation, and negative - about the possibility of additional loading. Thus, the central stations make optimal use of infrastructure capabilities. The initial node station and the stations located near it are most loaded, and the final node station and the stations located near it do not fully utilize the infrastructure capabilities.

Let us investigate the dependence $\bar{d}_{i}$ on the parameters of the model. Let's start with the parameter $\alpha$. Recall that it defines the normative rules for the interaction of neighboring stations. We will increase the parameter $\alpha$ at constant values of other parameters. According to the results of experiments, the following regularity holds: the absolute value of the maximum deviation of the solution of system (1) - (3) 


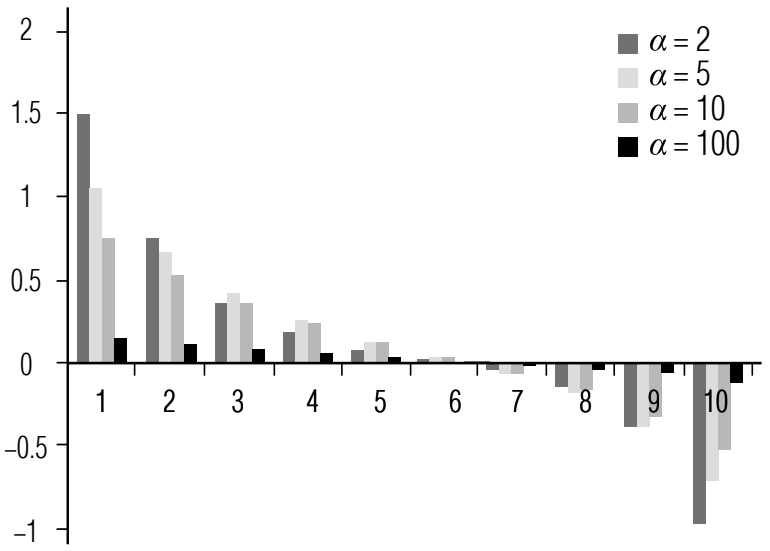

Fig. 3. The histogram of deviations of the solutions of the system (1) - (3) from the value $\Delta$ at change of parameter $\alpha$

from the value $\Delta$, i.e. $\max _{i=0,1, \ldots, m+1}\left|\bar{d}_{i}\right|$ decreases with increasing parameter $\alpha$, but for the central components of the solution these deviations can increase. This trend can be seen in Figure 3. It shows the histogram of deviations $\bar{d}_{i}$ for the parameter $\alpha$, equal to $2,5,10$ and 100 , and the following fixed values of the remaining parameters: $a=0.2, c_{0}=c=1, d=3$. Consequently, for arbitrarily small $\varepsilon>0$, there are values of the parameter $\bar{\alpha}$ such that for all $a \geq \bar{\alpha}$ (and for constant values of the other parameters) inequality

$$
\max _{i=0,1, \ldots, m, m+1}\left|\bar{d}_{i}\right| \leq \varepsilon
$$

will be carried out.

We will pass to a research of deviations $\bar{d}_{i}$ from the parameter $a$, which defines the intensity of receipt of goods by the second technology setting the rule of interaction of the station with neighboring storage areas. We will increase the value of this parameter at invariable values of other parameters. We recall that this leads to an increase in the intensity of receipt of goods on the second technology. As experiments show, this leads to a reduction of absolute values of negative deviations $\bar{d}_{i}$. At the same time, positive deviations $\bar{d}_{i}$ don't change. This tendency can be seen in Figure 4. It is the histogram of deviations $\bar{d}_{i}$ at the values of parameter $a$, equal to

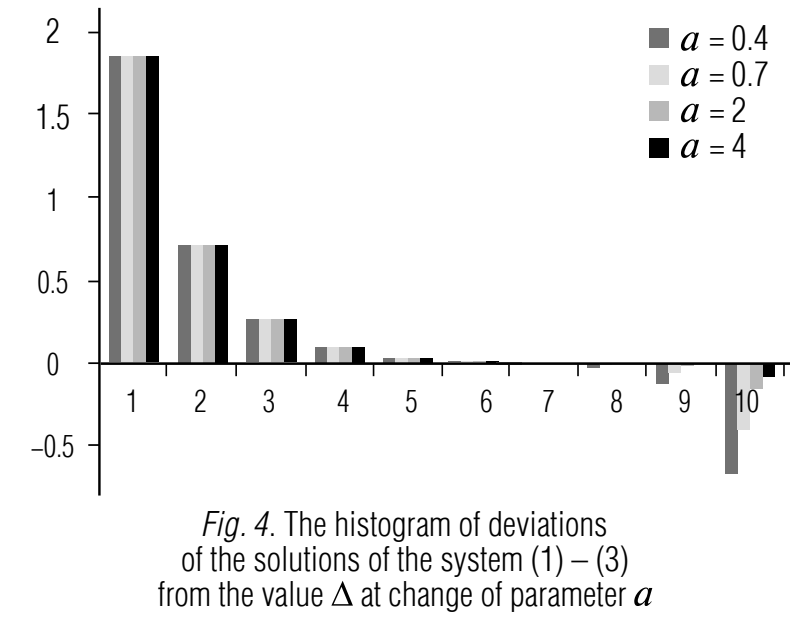

$0.4,0.7,2$ and 4 , and the following fixed values of other parameters: $\alpha=1, c_{0}=c=1, d=3$. We will note what, at such values of parameter $a$ and $\Delta=10$ the ordinate of vertex of a parabola accepts, respectively, the values 10 , 17.5, 50 and 100 .

We note that the parameter $a$ is present at all of the equation of system (1) - (3) except the first. Therefore, increasing parameter $a$, we increase the intensity of receipt of goods on the second technology at all stations, except for the initial one. It turns out that with the same effect, namely reduction of absolute values of negative deviations $\bar{d}_{i}$, it is possible to reach, changing parameter $a$ only in the last equation of system (1) - (3), i.e. increasing the intensity of receipt of goods on the second technology only at the final node station.

Let's proceed to a research of deviations $\bar{d}_{i}$ from the parameter $c_{0}$, that determines the intensity of departure cargoes from the initial node station to the storage area. We will increase the value of this parameter at constant values of other parameters. Recall that this leads to an increase in the intensity of departure goods from the initial node to the storage area. As experiments show, this leads to a decrease in positive deviations $\bar{d}_{i}$. In this case, negative deviations $\bar{d}_{i}$ do not change. This trend can be seen in Figure 5.

On the figure the histogram of deviations $\bar{d}_{i}$ at 


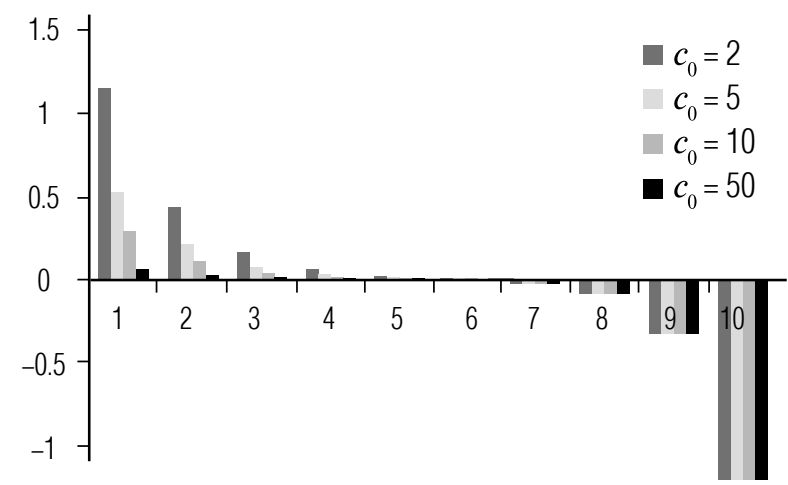

Fig. 5. The histogram of deviations of the solutions of the system (1) - (3) from the value $\Delta$ at change of parameter $c_{0}$

the values of parameter $c_{0}$, equal to $2,5,10$ and 50 and the following fixed values of the remaining parameters $\alpha=1, a=0.2, c=1, d=3$.

Thus, an increase in parameter $a$ in the last equation of system (1) - (3) and parameter $c_{0}$ leads to a reduction of an absolute value of the maximum deviation of the solution of system $(1)-(3) \max _{i=0,1, \ldots, m, m+1}\left|\bar{d}_{i}\right|$ from value $\Delta$. This in turn means, that for an arbitrarily small $\varepsilon>0$, there are values of the parameters $\bar{a}$ and $\bar{c}_{0}$, such that for all $a>\bar{a}, c_{0}>\bar{c}_{0}$ (and with constant values of the other parameters) inequality (9) will be satisfied.

Finally, we turn to the study of deviations $d_{i}$ from parameter $d$, representing the intensity of the delivery of cargo to the initial node station and the intensity of the distribution of cargo

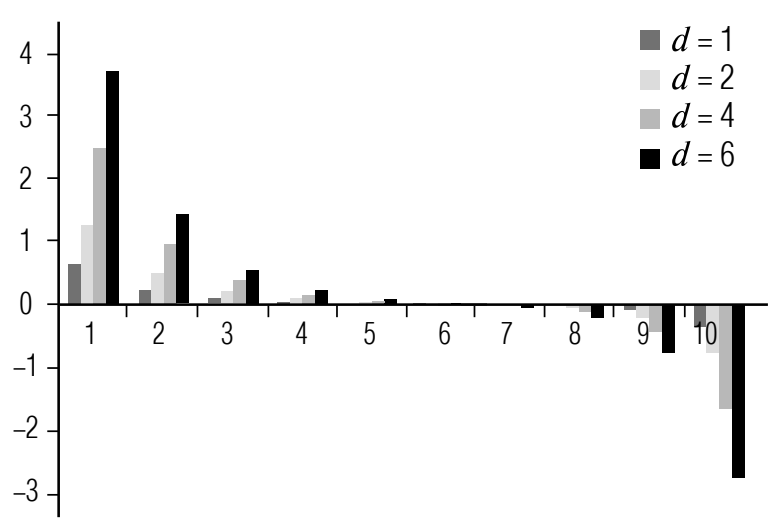

Fig. 6. The histogram of deviations of the solutions of the system (1) - (3) from the value $\Delta$ at change of parameter $d$ from the final node station. We will increase the value of this parameter at constant values of other parameters. As shown by experiments, this leads to an increase in the absolute values of the deviations $d_{i}$. This trend can be seen in Figure 6. On the figure, the histogram of deviations $\bar{d}_{i}$ at the values of parameter $d$, equal to 1 , 2, 4 and 6 and the following fixed values of the remaining parameters $\alpha=1, a=0.2, c_{0}=c=1$.

It should be noted that with decreasing parameter $d$ absolute values of deviations $d_{i}$ decrease to zero for $d=0$. In this case the solution of the system (1) - (3) converges to the stationary solution

$$
z_{0}(t)=z_{1}(t)=\ldots=z_{m}(t)=z_{m+1}(t) \equiv \Delta .
$$

This situation is shown in Figure 7.

We proceed to analyze the results obtained above with the help of numerical experiments. According to their results for as small as $\varepsilon>0$ by means of control parameters $\alpha, a, c_{0}$ it is possible to reach feasibility of inequality (9). A main objective of the conducted research is receiving $\varepsilon$-quasi-solutions of the traveling wave type with the characteristic $\tau>0$ for system (1) - (4), i.e. the organization of controlled freight traffic by means of the technologies defined above. It is easy to see that the solutions of system (1) - (3) satisfying condition (9) are $\varepsilon$-quasi-solutions of the traveling

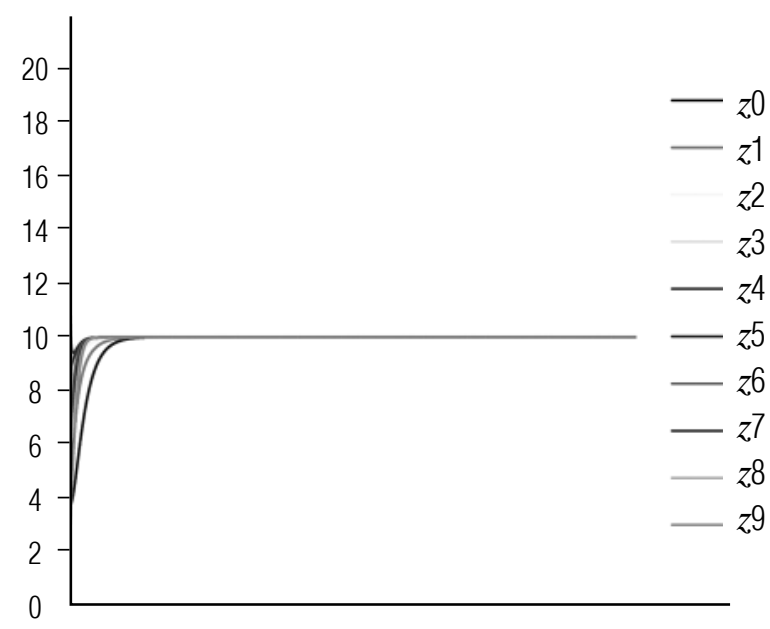

Fig. 7. The schedule of the solution of system (1) - (3) with $d=0$ 
wave type with an arbitrary characteristic $\tau>0$ for system (1) - (4).

Thus, we have revealed two methods of obtaining $\varepsilon$-quasi-solutions of the traveling wave type with an arbitrary characteristic $\tau>0$ for system (1) - (4). The first method is associated with the increase of the parameter $\alpha$, and the second with increasing parameters $a$ and $c_{0}$. Moreover, it is sufficient to increase the parameter $a$ only in the last equation of the system (1) - (3). Obviously, these two methods can also be combined with each other. From a practical point of view, the first method is associated with improving the infrastructure at all stations, and the second - with improving the infrastructure only at node stations, so that the latter is easier to use.

\section{Quasi-solutions of system (1) - (4) of the second type with periodic functions $\psi_{1}($.$) and \psi_{2}($.}

Let us consider a system of differential equations $(1)-(3)$, in which the functions $\psi_{1}($.$) and$ $\psi_{2}($.$) describing, respectively, the intensity of$ the supply of cargo to the initial node station and the intensity of the distribution of cargo from the final node station are periodic, i.e.

$$
\psi_{1}(t)=\psi_{2}(t)=d+\gamma \cos (\omega t), d \geq \gamma .
$$

According to the results of numerical experiments, starting from some time point $\bar{t}>0$, the solutions of the system (1) - (3) begin to oscillate in a certain neighborhood of the value $\Delta$, and the solution components satisfy the condition

$$
z_{0}(t)>z_{1}(t)>\ldots .>z_{m}(t)>z_{m+1}(t) \text { for any } t \in[\bar{t},+\infty) .
$$

Moreover, there exists a natural number $0<\bar{m}<m+1$ such that

$$
\begin{gathered}
z_{i}(t)>\Delta, \text { for } 0 \leq i \leq \bar{m}, t \in[\bar{t},+\infty), \\
z_{i}(t)<\Delta, \text { for } \bar{m}<i \leq m+1, t \in[\bar{t},+\infty) .
\end{gathered}
$$

For example, Figure 8 shows one of the solutions of system (1) - (3).

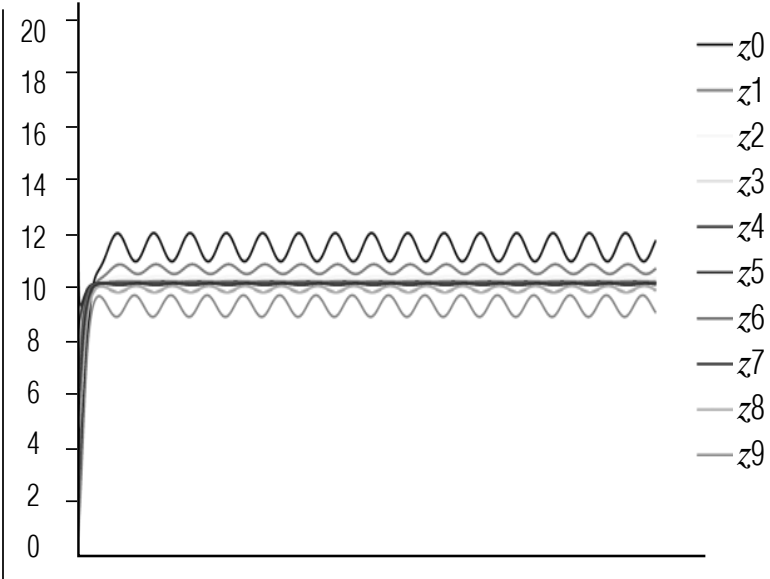

Fig. 8. The schedule of the solution of system (1) - (3) with periodic functions $\psi_{1}($.$) and \psi_{2}($.

This solution was obtained at $\Delta=10$ and the following values of the parameters

$$
\alpha=1, a=0.2, c_{0}=c=1, d=2, \gamma=1, \omega=1 .
$$

We denote by

$$
\bar{d}_{i}=\left\{\begin{array}{l}
\max _{t \in[\bar{t},+\infty)}\left(z_{i}(t)-\Delta\right), \text { if } 0 \leq i \leq \bar{m} \\
\min _{t \in[\bar{t},+\infty)}\left(z_{i}(t)-\Delta\right), \text { if } \quad \bar{m}<i \leq m+1 .
\end{array}\right.
$$

Thus, the number $\bar{d}_{i}$ determines the maximum deviation of the $i$-th component of the solution of the system (1) - (3) from the value $\Delta$, determining the capacity of the stations. It is obvious that the numbers $\bar{d}_{i}$ satisfy condition

$$
\begin{gathered}
\bar{d}_{0}>\bar{d}_{1}>\ldots>\bar{d}_{m}>\bar{d}_{m+1} ; \\
\bar{d}_{i}>0,0 \leq i \leq \bar{m} ; \bar{d}_{i}<0, \bar{m}<i \leq m+1 .
\end{gathered}
$$

Let us investigate the dependence $\bar{d}_{i}$ on the parameters of the model. Numerical experiments have shown that the dependence $\bar{d}_{i}$ on parameters $\alpha, a, c_{0}, c, d$ the same as in the case of constant functions $\psi_{1}($.$) and \psi_{2}($.$) . In par-$ ticular, by means of an appropriate choice of parameters $\alpha, a, c_{0}$ it is possible to make the absolute values of the deviations arbitrarily small. Thus, as in the case of constant functions $\psi_{1}($.$) and \psi_{2}($.$) , controlling these parame-$ ters, which determine the infrastructure capabilities of the stations, it is possible to organize a controlled freight flow. 


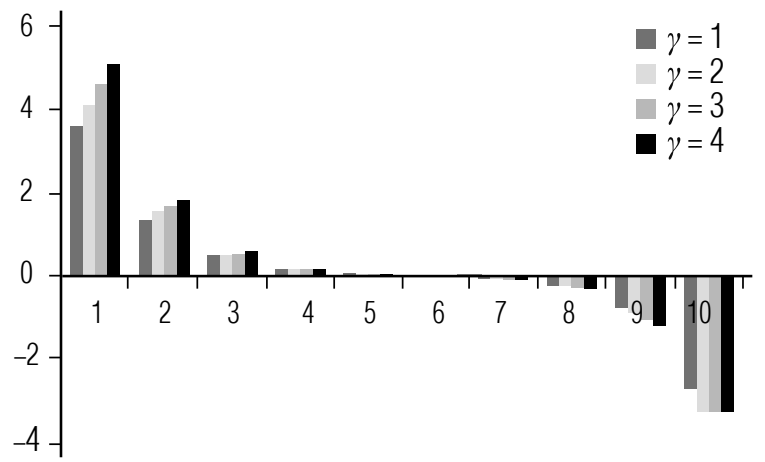

Fig. 9. The histogram of deviations of the solutions of the system (1) - (3) from the value $\Delta$ at change of parameter $\gamma$

It remains for us to investigate the dependence $\bar{d}_{i}$ on the parameters $\gamma$ and $\omega$. Unlike the parameters $\alpha, a, c_{0}$ only these parameters control does not allow us to make arbitrarily small absolute deviation values $\bar{d}_{i}$ and, accordingly, organize a controlled cargo flow. Nevertheless, we investigate the dependence $\bar{d}_{i}$ on $\gamma$ and $\omega$.

Let's start with the parameter $\gamma$. Note that this parameter determines the amplitude of the oscillations. We will increase the value of this parameter at constant values of other parameters. As experiments show, this leads to an increase in the absolute values of the deviations $\bar{d}_{i}$, i.e. dependence $\bar{d}_{i}$ from $\gamma$ is the same as on $d$. This trend can be seen in Figure 9.

The figure shows the histogram of deviations $\bar{d}_{i}$ at the values of parameter $\gamma$, equal to $1,2,3$ and 4 , and the following fixed values of other parameters $\alpha=1, a=0.2, c_{0}=c=1 \gamma=1$, $d=5, \omega=1$.
We will pass on to investigation of the dependence $\bar{d}_{i}$ on the parameter $\omega$. Since the period of functions $\psi_{1}($.$) and \psi_{2}($.$) is equal to$ $2 \pi / \omega$, then increasing the parameter $\omega$ leads to a decrease in the period of functions $\psi_{1}($.$) and$ $\psi_{2}($.$) . As shown by experiments, the depend-$ ence $\left|\bar{d}_{i}\right|$ on $\omega$ is a non-increasing function that takes values in a certain interval whose boundaries depend both on the index $i$, and on the remaining parameters of the model. Figure 10 shows a wide range of parameter variation $\omega-$ from 0.001 to 400 . The remaining parameters are fixed and take the following values: $\alpha=1, a=0.2, c_{0}=c=1 \gamma=1, d=2$. As can be seen from this figure, for example, the values $\bar{d}_{0}$ change in the interval lying in a segment $[1,2]$. It should be noted that for values $\omega$ close to zero functions $\psi_{1}($.$) and \psi_{2}($.$) are close$ to constants, therefore, the left boundary of the indicated intervals can be determined with the help of constant functions $\psi_{1}($.$) and \psi_{2}($.) (compare this histogram at $\omega=0.001$ with the histogram shown in Figure 2).

Finally, we analyze the results obtained in this section, i.e. in the case when the functions $\psi_{1}($.$) and \psi_{2}($.$) describing, respectively,$ the intensity of the supply of cargo to the initial node station and the intensity of the distribution of cargo from the final node station are periodic. As it turned out, these results do not qualitatively differ from the results obtained in the previous section, i.e. for the case when the functions $\psi_{1}($.$) and \psi_{2}($.$) are constants. For arbi-$

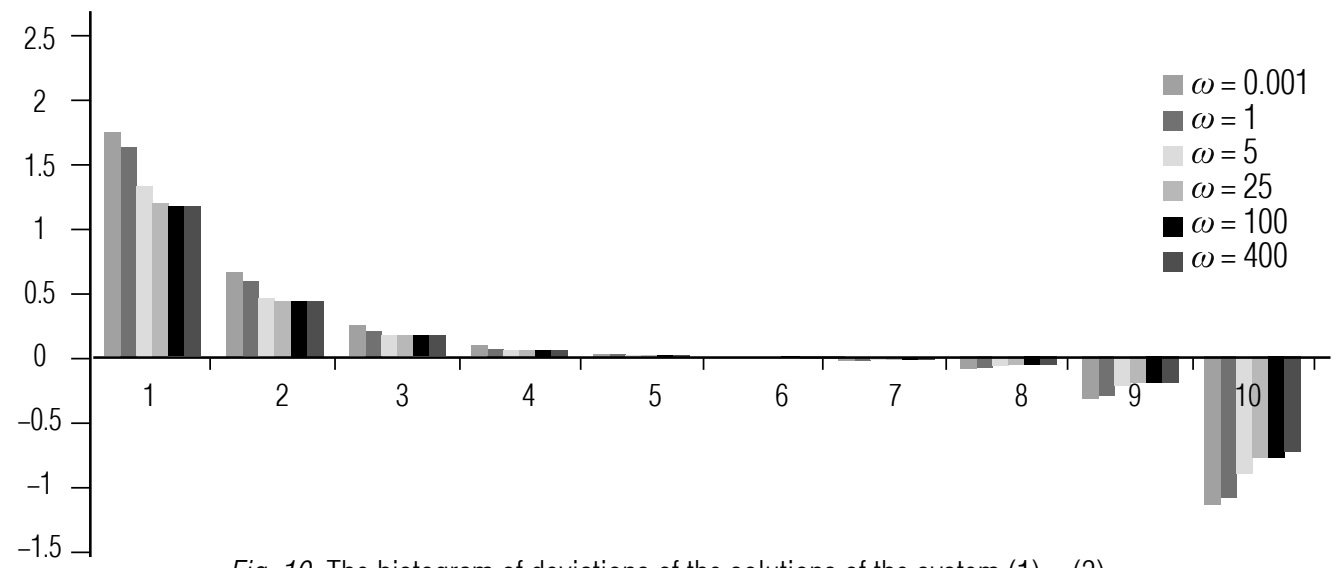

Fig. 10. The histogram of deviations of the solutions of the system (1) - (3) from the value $\Delta$ at change of parameter $\omega$ 
trarily small $\varepsilon>0$ we can obtain a $\varepsilon$-quasi-solution of the traveling wave type with the characteristic $\tau>0$ for system (1) - (3), i.e. organize a controlled flow of goods using the technologies described in the first paragraph. For this purpose, it is necessary to operate parameters $\alpha, a, c_{0}$, which is characteristic of the used technologies. The essence of this management comes down to improvement of the infrastructure of stations.

\section{Conclusion}

This article is devoted to the study of a model for organizing cargo transportation between two node stations carried out using a number of technologies with a set rule of control. Such a model is described by a finite-dimensional system of differential equations with non-local linear restrictions. The class of the solution satisfying nonlocal linear restrictions (solutions of the traveling wave type) is extremely narrow. This results in the need for the "correct" extension of class of solutions of the traveling wave type to a class of quasi-solutions of the traveling wave type. In [8-10] one of the methods of such an extension is given, thus making it possible to obtain quasi-solutions that differ from solutions by the presence of gaps in a countable number of points. The study of these quasisolutions has shown that they are unlimited. From a practical point of view, this is a serious flaw, since quasi-solutions describe the number of involved nodes in stations. In this connection, a different method for extending of class of solutions of the traveling wave type to a class of quasi-solutions of the traveling wave type is proposed. Quasi-solutions obtained with the help of this method differ from solutions in that they are allowed to satisfy nonlocal constraints with a given error. It is shown that such quasisolutions are limited.

Numerical experiments have shown that controlling the parameters of the model, one can obtain quasi-solutions for which nonlocal constraints are satisfied with arbitrarily small errors.

\section{References}

1. Galaburda V.G. (1983) Sovershenstvovanie tekhnologii perevozok i uvelichenie propusknoy sposobnosti zheleznykh dorog [Improvement of transportation techniques and increase in railroad traffic capacity]. Moscow: Moscow State University of Railway Engineering (in Russian).

2. Galaburda V.G. (1985) Optimal'noe planirovanie gruzopotokov [Optimal planning of cargo traffic]. Moscow: Transport (in Russian).

3. Kozovskii I.G. (1977) Ratsionalizatsiya perevozok gruzov na zheleznykh dorogakh [Improvement of railroad goods transportation]. Moscow: Transport (in Russian).

4. Levin D.Yu. (2010) Modelirovanie protsessov perevozki [Modeling of transportation processes]. World of Transport and Transportation, vol. 8, no. 5 (33), pp. 48-55 (in Russian).

5. Rubtsov A.O, Tarasov A.S. (2009) Modelirovanie zheleznodorozhnykh perevozok na territorii Rossii [Modeling of railway transport in the territory of Russia]. Proceedings of the Institute of System Analysis of Russian Academy of Sciences, no. 46, pp. 274-278 (in Russian).

6. de Jong G., Gunn H.F., Walker W. (2004) National and international freight transport models: an overview and ideas for further development. Transport Reviews, vol. 24, no. 1, pp. 103-124.

7. Yamada T., Russ B.F., Castro J., Taniguchi E. (2009) Designing multimodal freight transport networks: A heuristic approach and applications. Transportation Science, vol. 43, no. 2, pp. 129-143.

8. Khachatryan N.K., Akopov A.S. (2017) Model for organizing cargo transportation with an initial station of departure and a final station of cargo distribution. Business Informatics, no. 1 (39), pp. 25-35.

9. Beklaryan L.A., Khachatryan N.K. (2013) Ob odnom klasse dinamicheskikh modeley gruzoperevozok [On one class of dynamic transportation models]. Computational Mathematics and Mathematical Physics, vol. 53, no. 10, pp. 1649-1667 (in Russian).

10. Beklaryan L.A., Khachatryan N.K. (2006) Traveling wave type solutions in dynamic transport models. Functional Differential Equations, vol. 13, no. 2, pp. 125-155. 


\section{System for monitoring the quality of services provided by a public institution based on business processes}

\section{Larisa A. Bulysheva}

Professor, Department of Information Technology and Decision Sciences

Old Dominion University

Address: 23529, Norfolk, VA, USA

E-mail: lbulyshe@odu.edu

\section{Mikhail Y. Kataev}

Professor, Department of Automated Control Systems

Tomsk State University of Control Systems and Radioelectronics;

Professor, Yurga Technological Institute (Branch)

National Research Tomsk Polytechnic University

Address: 40, Lenin Avenue, Tomsk, 634050, Russian Federation

E-mail: kataev.m@sibmail.com

\section{Natalia V. Loseva}

Deputy Head of Department of Insurance for Temporary Incapacity for Work and in Connection with Maternity Social Insurance Fund of the Russian Federation, Tomsk Regional Branch

Address: 61, Belinsky Street, Tomsk, 634034, Russian Federation

E-mail: lonat@bk.ru

\section{Abstract}

Monitoring the quality of the services provided by public institutions is an important element in improving the effectiveness of the entire system of public services in the Russian Federation. As a rule, monitoring is associated with obtaining quantitative indicators of the level of satisfaction of citizens which characterize the quality of services provided. Monitoring results are the basis for modernizing the service management system. However, this approach allows us to evaluate only one side of the process by which a public institution renders services to the consumer of services (citizens). The other side of the issue is related to monitoring the processes of the institution itself. This direction also allows us to find approaches to improving the quality of service delivery, and to make the work of a state institution more efficient.

This article describes the methodology for monitoring the process of providing services in a public institution based on business processes. The description of the activity of the institution in terms of the implementation of services is presented in the form of a set of business processes. It is shown that the main element of business processes that can be measured is the time of their implementation. On this basis, a mathematical model for assessing the quality of public service delivery is constructed, including both qualitative assessments (obtained from experts and clients of the institution) and quantitative assessments of the quality of service delivery based on measuring the time of business processes. The quantitative aspect of the proposed methodology is directly related to the main direction declared by the Government of the Russian Federation - the development of digital economy. As an example, the article considers such a state institution as the Social Insurance Fund of the Russian Federation. 
Key words: monitoring, government service, business process, quality assessment methodology, stakeholders (clients), Social Insurance Fund of the Russian Federation.

Citation: Bulysheva L.A., Kataev M.Y., Loseva N.V. (2018) System for monitoring the quality of services provided by a public institution based on business processes. Business Informatics, no. 1 (43), pp. 71-78. DOI: 10.17323/1998-0663.2018.1.71.78.

\section{Introduction}

$\mathrm{F}$ or any public institution providing services, the relevance of monitoring in the field of public services [1] should be transparent and effective. Transparency for the client and the employee of the institution implies the existence of clear and uniform regulations which are based on state standards and laws. These regulations define clear rules for the process of obtaining and providing services, all of which eliminates the subjective approach and minimizes the level of corruption. On the other hand, the clarity of the service delivery process leads to an improvement in the efficiency of service delivery, reduction in time expended and reduction of related financial costs, without loss of quality. The clearness of the process of service delivery should also lead to an improvement of the validity of management decisions [2]. However, understanding responsibility and the regulatory framework does not always result in a positive result, since the implementation of the service delivery process is related to the qualifications and responsibilities of each specialist.

If there is a team of specialists, it is necessary to monitor the process of rendering services to clients. As a rule, such monitoring is carried out by specially created expert commissions at a given periodicity (for example, once every three years). The result of the work of such a commission should be a conclusion (mainly qualitative) leading to the improvement of the processes of rendering services in a public institution.
The introduction of monitoring results into service delivery processes is difficult to implement [3], since they are related to the personality of each employee. In this regard, the qualitative component of the assessment is, as a rule, somewhat subjective, and therefore there is the possibility of conflicting opinions and decisions. In this regard, we note that the achievement of quality and accessibility of services in public institutions in foreign and domestic literature are not sufficiently detailed. There are no indicators that would characterize the process of the employee's activities in a uniform manner, and which do not lead to an incorrect, contradictory interpretation.

\section{Statement of the problem}

The rapid development of modern society leads to the need to search for new approaches to management in the provision of services that would be based on parameters related to the type, dynamics and level of change [4]. Known approaches that have been developed for industrial and commercial enterprises [5] are not suitable for public institutions because of the underlying financial component of their activities. Nevertheless, for all types of enterprises and institutions, assessment of the state, analysis and adoption of effective management decisions is impossible without modern mathematical approaches to the management process organization, as well as using modern information technologies for data collection, processing and analysis. 
The necessity of applying mathematical and information methods [6, 7] and technological solutions will allow us to:

1) increase the number of management objects, due to the technological base of data collection and the possibility of using artificial intelligence systems;

2) expand the scope of the vision of business processes, which will increase the accuracy and timeliness of decision-making at all stages of the service delivery cycle;

3) to form not only operational, but also tactical and strategic managerial decisions, on the basis of an analysis of the current information on the process of rendering the service, at the levels of the particular employee, the unit and the institution as a whole.

One of the known approaches to assessing the state of various processes of activity developed in mathematical and programmatic terms is the technology of workflow [8]. This technology allows you to ensure the performance of production tasks in strict coordination among themselves, performers and customers on certain rules, based on an abstract representation of work processes. As a rule, the implementation of this approach is carried out in the form of a workflow system when the result of the processes is those or other documents. The disadvantage of such systems is a weak possibility to optimize the workflow system, which each time needs to be adjusted not only for the type of activity, but also for executors and customers. Therefore, we are developing an approach that makes it possible to add new elements in the chain of developed or existing workflow systems that expand the analytical capabilities of such systems.

These and other possible positive aspects of the application of modern methods in the field of making managerial decisions are impossible without accurate and timely data. This article presents a methodology for monitoring the quality of service delivery in a public institution which is based on the measurement of time parameters of business processes [9]. It should be noted that despite the ability to measure the temporal parameters of work processes, it is obvious that at present there are no methods in the regulatory documents describing the corresponding algorithms. Only temporary restrictions are known that are imposed on processes (for example, as stated in Decree of the Government of the Russian Federation from 22 December 2012 No. 1376 "On approval of the rules for the organization of multifunctional centers for the provision of state and municipal services", the time for rendering the service should not exceed 15 minutes).

The proposed methodology for monitoring the quality of service delivery in a government agency, on the one hand, will allow the management to see in real time the conditions of the institution at the tactical level, and each individual employee at the operational level. On the other hand, this information will make it possible to formulate management decisions in a precise and timely manner [10, 11], identify problems, obtain their quantitative description at a given level of regulatory constraints, determine possible solutions, and monitor and evaluate the results of the decision.

\section{Service in a state institution}

The service of an employee in a state institution is a heavily regulated business [12]. This circumstance causes the problem of personal skills realization in a time of rapidly changing environment. The employee must constantly adapt to various changes, improve skills, master new modern technologies to solve the problems of the institution. At the same time, the employee experiences influence from the management when forming orders, and from clients for whom services are rendered. In general, the client's opinion is crucial, and for this the quality and timeliness of providing the service is important $[13,14]$. 
In any state institution, there are certain temporary cycles within which the employee is permanently operating: 5 years, 3 years, a year, a half year, a quarter, a month, 10 days, a week and a day. This is a statutory set of deadlines connected to the performance of a certain work type required to provide services, as well as for the professional growth of employees. The legal basis for monitoring the quality of the provision of public services by the Social Insurance Fund is set out in:

\ Federal Law dated 27 July 2010 No. 210FZ "On the organization of the provision of state and municipal services";

$\downarrow$ Federal Law dated 2 May 2006 No. 59-FZ "On the procedure for considering applications from citizens of the Russian Federation";

\ Federal Law dated 29 December 2006 No. 255-FZ "On compulsory social insurance in case of temporary disability and in connection with maternity";

↔ Federal Law dated 24 July 1998 No. 125FZ "On compulsory social insurance against occupational accidents and occupational diseases";

$\downarrow$ Decree of the Government of the Russian Federation dated 16 May 2011 No. 373 "On the development and approval of administrative regulations for the performance of public functions and administrative regulations for the provision of public services."

Let us consider, for example, a governmental institution, such as the Social Insurance Fund (FSS) (http://fss.ru). Currently, the FSS has a functional form of managing the organization as a whole consisting of several categories of employees: specialist, lead specialist, chief specialist, etc. The distribution of the workload for employees providing public services is, as a rule, uniform, according to the number of policyholders on the list.

We will show that the existing form of distribution of the workload makes it possible to service all insured persons during the period of rendering the service "Acceptance of 4FSS calculation." For example, let us assume that in one of the departments of the FSS each of the specialists serves 1000 insurers (organizations). If we assume that the working hours of FSS employees are 8 hours a day, the time taken to render the service (in a formalized form, the business process) "Acceptance of 4 FSS calculation" is on average (for all quarters of the year) 16.25 work days. The FSS regulation specifies that the time for providing a public service is no more than 15 minutes per one policyholder (client). Having temporary data on the reception of a public service, it is possible to make calculations of the time necessary to carry out the business process "Accepting 4FSS calculation" (service provision) per specialist, on average, without considering the specialist category. The total working time is 7,800 minutes $(16.25$ working days $\times 8$ hours $\times$ 60 minutes). So, it takes 7.8 minutes in average to provide this kind of service for 1000 insurers (organizations), without considering potential time losses (consultations, instructions of the supervisor, rest, etc.).

All employees of state institutions are divided into professional categories, depending on employment time in the current position and the effectiveness of their work, which is expressed in the average time of the provision of public services. Let us consider the results of those differences.

Forthe "Specialist" category (workexperience from 0 to 1 year), the typical average time for providing a public service is approximately 10 minutes, which is 20.83 days for servicing 1000 insurers (10 minutes $\times 1000$ insurers / 8 hours / 60 minutes). This means that the "Specialist" is behind the normative working hours of the service "Acceptance of 4FSS calculation" for 4.58 days. The solution to this problem is simple: employee should either stay at work longer hours, or work on weekends, or improve skills and reduce the time for the given operation. 
For the category "Leading Specialist" (work experience from 1 to 5 years), the average time for providing this public service is approximately 7 minutes. Using the data given above, we calculate that the time for which this specialist is 14.58 days ( 7 minutes $\times$ 1000 insurers / 8 hours / 60 minutes). It can be seen from the calculation that the "Leading Specialist" manages to render the public service "Acceptance of 4FSS calculation" for the normatively allotted time (16.25 days), with a reserve of 1.67 days.

For the category of "Chief Specialist" (work experience of 5 years and above), the average time for providing this public service is approximately 5 minutes. The working time for this operation is 10.42 days ( 5 minutes $\times$ 1000 insurers / 8 hours / 60 minutes), which is 5.83 days less than the standard.

From these calculations we see that the average time spent by all categories of specialists of the FSS branch for the provision of the state service "Acceptance of calculation of 4 FSS" per one insured is $(5$ minutes +7 minutes +10 minutes) $/ 3=7.33$ minutes, e.g. corresponds to the previously calculated average time for the provision of a public service per insurer ( 7.8 minutes).

Different periods of service of the insured by different categories of specialists lead to a mismatch between the loads between them, which affects the effectiveness of the provision of services. This is especially evident in case of influence of external or internal factors. For example, in the absence of one of the specialists, the average time will change (increase), which will lead to the formation of a queue, which means a change in the quality of the provision of public services. Note that the existing approach to managing the delivery of public services does not consider the temporary features of the business process by specialists of different categories and, accordingly, can not lead to the effective formation and adoption of managerial decisions in the social insurance system. This circumstance requires considering the time characteristics of the business process (monitoring) [15] to account for management activities.

\section{Description \\ of the monitoring methodology}

Any business process can be defined as a logically interrelated sequence of functions, the results of which lead to the creation of a product or service. To obtain the result, appropriate information and resource support is needed. Components of the business process can be evaluated on a quantitative level, which allows you to build a numerical model of the process of creating products or providing services. The business process model consists of the following parts:

1) a set of functions;

2) the sequence of execution of each function;

3) the possibility of control and management in the performance of each function;

4) performers and responsible personnel for each function;

5) information and resource support.

For the state institution, the functions and their time limits are regulated by laws and regulations of the government of the Russian Federation. Financial and resource components are determined by the state and are considered unchanged in the task of managing the institution. Performers (specialists) of functions of business processes have different experience, qualifications and motivation. All this determines the need for their constant certification for self-improvement and to improve the quality of service delivery.

The methodology for organizing the process of preparing and conducting monitoring based on business processes includes the following steps: 
1) the preparatory stage;

2) the stage of data collection;

3) the stage of processing, data analysis;

4) the formation of a report.

The preparatory stage is the formation of groups of employees who meet certain goals. For example, it includes assessing the effectiveness of their professional activities, which is important for awarding, raising or lowering the position, etc. The difficulty of solving this problem is that each employee has an established procedure of the order and time frame for the process of providing the service to the client. At present, temporary processes of rendering services are not evaluated in any way in a certification (administrative) survey.

The criteria for dividing specialists into categories can be as follows:

1) the amount of work performed for a certain period of time;

2) responsibility in the performance of work (reprimands, delays, etc.);

3) willingness to work outside the working day;

4) advanced training;

5) contribution to public works of the institution (sports and social events, etc.).

The first criterion is quantitative and allows for an accurate estimate. The remaining criteria are qualitative, but they can lead to a quantitative assessment (an example is the rating system).

Suppose that as a result of the expert evaluation, the following indicators were obtained:

$$
P s(k)=\sum_{e=1}^{E} \sum_{v=1}^{V} P(e, v, k),
$$

where $P(e, v, k)$ - the expert evaluations submitted by the $e$-th expert $(e=1, \ldots, E)$ on the $v$-th indicator $(k=1, \ldots, V)$ for the $k$-th specialist $(k=1, \ldots, K)$.
The average time for the provision of the same service in a public institution can be estimated from the expression:

$$
T(k, t)=\frac{1}{M N} \cdot \sum_{i=1}^{M} \sum_{j=1}^{N} t(i, j, k),
$$

where $t(i, j, k)$ - the time when the state service is provided by the $k$-th specialist, for $i$-th customer $(i=1, \ldots, M)$, while $j$ functions $(j=1, \ldots, N)$ are required to provide the service.

Under the influence of external and internal factors on the state institution, deviations from the regulatory values arise, which can be represented by the expression:

$$
\Delta T(k, t)=T(k, t)-T r,
$$

where $T(k)$ - the real time of service delivery;

$T r$ - regulatory time determined by law (no more than 15 minutes).

For each specialist in the period of his/ her work $T w$ for a certain period of time, the deviations (3) can be fixed as an average value:

$$
T s(k)=\frac{1}{T w} \cdot \sum_{t=1}^{T w} \Delta T(k, t),
$$

where $\Delta T(k, t)$ - the deviation of the time of provision of the governmental service by the $k$-th specialist at the $t$-th time moment of the period $T w(t=1, \ldots, T w)$.

Then the integral assessment of the specialist's activity obtained during the monitoring process or when assessing the suitability of the candidate for a vacant position in the process of testing him/her, can be represented by an expression that takes into account the individual contribution (weight factors $\alpha, \beta, \gamma$ ) of each component:

$$
C(k)=\alpha \cdot P s(k)+\beta \cdot F(T s(k))+\gamma \cdot W s(k),
$$

where $P S(k)$ - the results of the assessment of the activity of the $k$-th specialist (according to the five-point system) by experts; 
$T s(k)$ - the total deviation from the standard time during the working day for the $k$-th specialist;

$W_{s}(k)$ - assessment of the $k$-th specialist's activity (on a five-point system), obtained on customer feedback;

$(\alpha, \beta, \gamma)$ - weighting factors $(\alpha+\beta+\gamma=1)$;

$F-$ a function that takes timing data into a five-point rating system.

The estimation of the weight factors $(\alpha, \beta$, $\gamma)$ in (5) is a nontrivial problem and is not discussed in this paper. It can be assumed that the most significant contribution to the value of employee performance is given by the factor at $T s$, since it is calculated on a regular basis (for example, $\beta=0.5$ ). The second factor is the multiplier for $P_{S}(\alpha=0.3)$, since the expert commissions consider the activity of employees quite rarely, not more often than once a year. Then the weighting factor for $W s$ $\gamma=0.2$. It should be noted that the $W s$ assessment is largely subjective, since the opinion of not all clients is included, the psychological state, etc., may be affected. However, this assessment is determined by the state regulations as significant.

For the formation of a score for each employee (integral rating) for a certain period (for example, a month), one can use the $C(k)$ estimator system, based on expression (5). Then, with a monthly evaluation, at the end of each year there will be at least ten integral ratings that will give an unambiguous assessment of each employee's work (Table 1).

\section{Evaluation of employee performance}

Table 1.

\begin{tabular}{c|c}
\hline Attestation appraisal & Integral rating \\
\hline "Excellent" & $45-50$ \\
\hline "Good" & $40-45$ \\
\hline "Satisfactorily" & $35-40$ \\
\hline "Unsatisfactory" & $<35$ \\
\hline
\end{tabular}

\section{Conclusion}

A specific feature of the activity of a state institution is the continuous nature of the process of rendering services to clients and preparing report documents. Constant changes in the regulations of work carried out by superior organizations lead to the fact that all employees need to constantly improve their activities and adjust plans. In addition, the governmental institution lives under certain regulations, within which it is necessary to carry out both regular work and temporary assignments. The form of evaluation of each employee's activity is periodic certification.

This article suggests a technique for monitoring the activities of employees in the process of providing services which are based on business processes. The methodology includes two components - qualitative and quantitative. This allows us to identify the specifics of the work performed by each specialist during a certain time period (including shortcomings in the organization of work), as well as assess the success of employees holding certain positions.

\section{References}

1. Park J., Mackay S. (2003) Practical data acquisition for instrumentation and control systems. Elsevier.

2. Burkov V.N., Korgin N.A., Novikov D.A. (2009) Vvedenie v teoriyu upravleniya organizatsionnymi sistemami [Introduction to the theory of management of organizational systems]. Moscow: Librikom (in Russian).

3. Novikov D.A. (2007) Upravlenie proektami: organizatsionnye mekhanizmy [Project management: organizational mechanisms]. Moscow: PMSOFT (in Russian).

4. Dmitriev O.N. (2002) Sistemnyy analiz v upravlenii [System analysis in management]. Moscow: Gnome and D (in Russian). 
5. Grigoryev L.Y., Gorelik S.D., Kudryavtsev D.V. (2010) Menedzhment po notam. Tekhnologiya postroeniya effektivnykh kompaniy [Management by notes. Technology for building effective companies]. Moscow: Alpina Business Books (in Russian).

6. Peregudov F.I., Tarasenko F.P. (1997) Osnovy sistemnogo analiza [Fundamentals of system analysis]. Tomsk: Ed. Scientific and Technical Literature (in Russian).

7. Krichevsky M.L. (2005) Intellektual'nye metody v menedzhmente [Intellectual methods in management]. St. Petersburg: Piter (in Russian).

8. Jablonski S., Bussler C. (1996) Workflow management: Modeling, concepts, architecture and implementation. Boston: International Thomson Computer Press.

9. Kataev M.Y., Ifutin Y.B., Emelyanenko A.A., Emelyanenko V.A., Borodin A.V. (2008) Protsessnoorientirovannyy podkhod $\mathrm{k}$ upravleniyu predpriyatiem [Process-oriented approach to enterprise management]. Bulletin of the Tomsk Polytechnic University, vol. 313, no. 6, pp. $20-23$ (in Russian).

10. Rumyantseva Z.P. (2001) Obshchee upravlenie organizatsiey: teoriya i praktika [General management of the organization: theory and practice]. Moscow: INFRA-M (in Russian).

11. Gorshkova L.A. (2000) Analiz sistemy upravleniya organizatsiey [Analysis of the organization's management system]. N.Novgorod: University of Nizhny Novgorod (in Russian).

12. Alexandrova A.P. (2002) Organizatsiya administrativnogo monitoringa sotsial'nykh programm na regional'nom i mestnom urovnyakh [Organization of administrative monitoring of social programs at the regional and local levels]. Moscow: Institute of Urban Economics Fund (in Russian).

13. Bushmeleva G.V. (2004) Monitoring v sisteme upravleniya predpriyatiem [Monitoring in the enterprise management system]. Ekaterinburg, Izhevsk (in Russian).

14. Rogozin D.M., Shmerlina I.A. (2014) Otsenka effektivnosti gosudarstvennykh i munitsipal'nykh uslug: Sotsial'naya kritika i professional'naya ekspertiza [Evaluation of the effectiveness of state and municipal services: Social criticism and professional expertise]. Moscow: Delo (in Russian).

15. Kataev M.Y., Loseva N.V. (2016) Uchet prostranstva vremennykh sobytiy pri okazanii uslug $\mathrm{v}$ gosudarstvennom uchrezhdenii na osnove biznes-protsessov [Accounting for the space of time events in the provision of services in a public institution based on business processes]. Electronic Means and Control Systems, no. 1-2, pp. 186-188 (in Russian). 


\section{International Workshop on the Internet of Things and Smart Services (ITSS 2018)}

Vienna, Austria, 11-14 July 2018

$\mathrm{W}$

Thile industries and corporations have acknowledged the importance of Web 2.0 and started integrating Web 2.0 in their business processes, they have made only limited contributions to the burgeoning knowledge in Web 3.0. Over the last decade, various technologies have moved to the qualitatively new phase of development. Mobile wireless communications, new data collection, new data retrieval and new data processing techniques have been introduced together with a cloud approach to storing data. All of that with the Internet of Everything paradigm and customer-centric approach formed a new concept of the Smart Services. Smart Commerce is one of the definitions of Web 3.0, bringing new approaches to e-business. Smart Services concept means that soon we might have fully globalized services that would allow business to transform according to a new step of globalization considering customer-centric approach and digital economy based on data.

ITSS 2018 is an international workshop on advances in theory, applications and different approaches to using Internet of Things and Smart Services. This workshop is about business transformation due to digital economy implementation and about new types of services and innovative business models stemming from the high impact of IoT and data-based services as the next step in globalization including new strategy and recommendations on Collaborative Economy in 2016 by the European Commission. The workshop will also include discussions on relevant topics of Big
Data and Big Data Analytics (related to information understanding and new business models).

The aim of the workshop is to encourage activities in the field of Collaborative Economy (based on Smart Services and the Internet of Things) and to bring together worldwide researchers with an interest in digital economy as well. Unlike the conventional conferences, this workshop will mainly discuss and explore theoretical and practical problems raised by the participants. Especially, we provide enough discussion parses for understanding the importance of sustainability and the relationships between the Computer science and Management science.

\section{Program committee:}

$\downarrow$ Dr. Svetlana V. Maltseva, Head of the School of Business Informatics, National Research UniversityHigher School of Economics, Moscow, Russia;

$\downarrow$ Dr. Mikhail M. Komarov, Deputy head of the School of Business Informatics for theinternational relations, National Research University Higher School of Economics, Moscow, Russia;

$\downarrow$ Dr. Jiri Hosek, Associate Professor at the Faculty of Electrical Engineering and Communication,Brno University of Technology, Czech Republic;

$\downarrow$ Dr. Yevgeni Koucheryavy, Full Professor at the Department of Communications Engineering at theTampere University of Technology (TUT), Finland. 


\section{AUTHORS GUIDELINES}

Articles should be topical and original, should outline tasks (issues), describe key results of the author's research and appropriate conclusions.

Manuscripts are submitted via e-mail: bijournal@hse.ru.

\section{MANUSCRIPT REQUIREMENTS}

TEXT FILES should be submitted in electronic form, as a MS Word document (version 2003 or higher).

LENGTH. Articles should be between 20 and 25 thousand characters (incl. spaces).

FONT, SPACING, MARGINS. The text should be in Times New Roman 12 pt, 1.5 spaced, fit to the width, margins: left $25 \mathrm{~mm}$, all other - $15 \mathrm{~mm}$.

TITLE of the article should be submitted in native language and English.

AUTHORS' DETAILS are presented in native language and English. The details include:

$\downarrow$ Full name of each author

- Position, rank, academic degree of each author

- Affiliation of each author, at the time the research was completed

\ Full postal address of each affiliation (incl. postcode / ZIP)

$\checkmark$ E-mail address of each author.

ABSTRACT are presented in native language and English.

- The abstract should be between 200 and 300 words.

$\downarrow$ The abstract should be informative (no general words), original, relevant (reflects your paper's key content and research findings); structured (follows the logics of results' presentation in the paper)

\ The recommended structure: purpose (mandatory), design / methodology / approach (mandatory), findings (mandatory), research limitations / implications (if applicable), practical implications (if applicable), originality / value (mandatory).

- It is appropriate to describe the research methods/ methodology if they are original or of interest for this particular research. For papers concerned with experimental work the data sources and data procession technique should be described.

↔ The results should be described as preciselyand informatively as possible. Include your key theoretical and experimental results, factual information, revealed interconnections and patterns. Give special priority in the abstract to new results and long-term impact data, important discoveries and verified findings that contradict previous theories as well as data that you think have practical value.

$\downarrow$ Conclusions may be associated with recommendations, estimates, suggestions, hypotheses described in the paper.

- Information contained in the title should not be duplicated in the abstract. Authors should try to avoid unnecessary introductory phrases (e.g. "the author of the paper considers...»).

- Authors should use the language typical of research and technical documents to compile your abstract and avoid complex grammatical constructions.

$\downarrow$ The text of the abstract should include key words of the paper.

KEYWORDS are presented in native language and English. The number of key words / words combinations are from 6 to 10 (separated by semicolons).

FORMULAE should be prepared using Math Type or MS Equation tool.

FIGURES should be of high quality, black and white, legible and numbered consecutively with Arabic numerals. All figures (charts, diagrams, etc.) should be submitted in electronic form (photo images - in TIF, PSD or JPEG formats, minimum resolution $300 \mathrm{dpi}$ ). Appropriate references in the text are required.

REFERENCES should be presented in Harvard style and carefully checked for completeness, accuracy and consistency.

The publication is free of charge. 